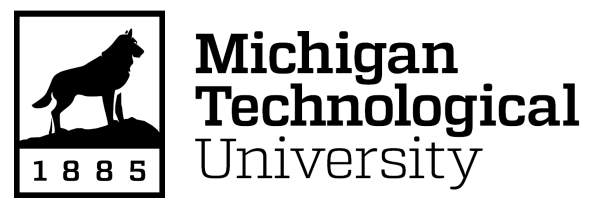

Michigan Technological University Digital Commons @ Michigan Tech

\title{
THE IMPLICATIONS OF SCIENCE AND TECHNOLOGY FOR CHINESE WOMEN: A CULTURAL STUDY OF THE CHINESE ERA OF REFORMS
}

Wenjing Liu

Michigan Technological University, Iwenjing@mtu.edu

Copyright 2019 Wenjing Liu

\section{Recommended Citation}

Liu, Wenjing, "THE IMPLICATIONS OF SCIENCE AND TECHNOLOGY FOR CHINESE WOMEN: A CULTURAL STUDY OF THE CHINESE ERA OF REFORMS", Open Access Dissertation, Michigan Technological University, 2019.

https://doi.org/10.37099/mtu.dc.etdr/966

Follow this and additional works at: https://digitalcommons.mtu.edu/etdr

Part of the Chinese Studies Commons, Communication Technology and New Media Commons, Critical and Cultural Studies Commons, Gender, Race, Sexuality, and Ethnicity in Communication Commons, and the Women's Studies Commons 
THE IMPLICATIONS OF SCIENCE AND TECHNOLOGY FOR CHINESE WOMEN:

A CULTURAL STUDY OF THE CHINESE ERA OF REFORMS

\author{
By \\ Wenjing Liu \\ A DISSERTATION \\ Submitted in partial fulfillment of the requirements for the degree of \\ DOCTOR OF PHILOSOPHY \\ In Rhetoric, Theory, and Culture
}

MICHIGAN TECHNOLOGICAL UNIVERSITY

2019

(C) 2019 Wenjing Liu 
This dissertation has been approved in partial fulfillment of the requirements for the Degree of DOCTOR OF PHILOSOPHY in Rhetoric, Theory, and Culture.

Department of Humanities

Dissertation Advisor: Jennifer Daryl Slack

Committee Member: Patricia J. Sotirin

Committee Member: Ketty Thomas

Committee Member: Sarah A. Green

Department Chair: Patricia J. Sotirin 


\section{Table of Contents}

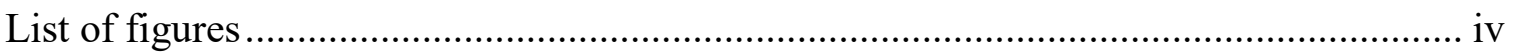

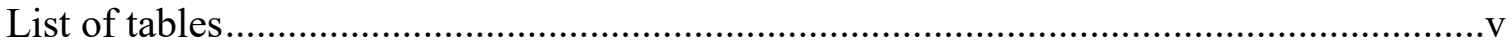

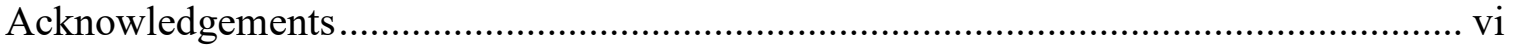

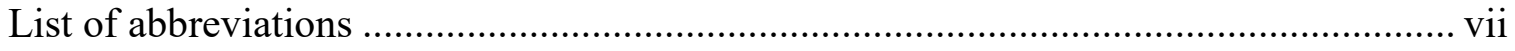

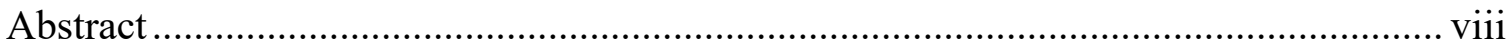

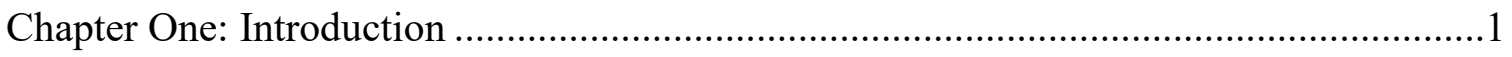

Chapter Two: Science and Technology in the Era of Reforms .........................................21

Chapter Three: Chinese Women's Roles in the Era of Reforms ……………………......78

Chapter Four: Putting It All Together: The Implications of Science and Technology for Women's Roles in the Era of Reforms ...................................................................142

Chapter Five: Conclusion ....................................................................................209

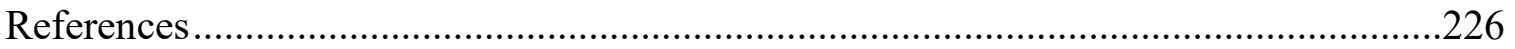

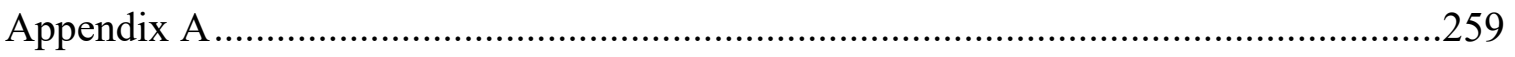

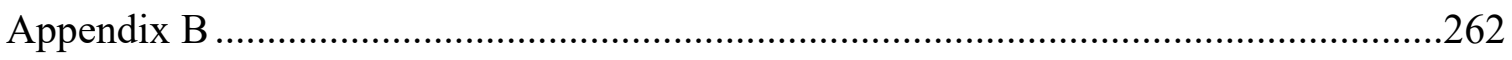

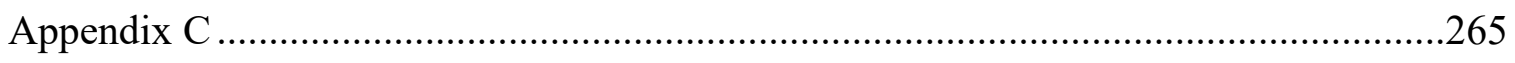

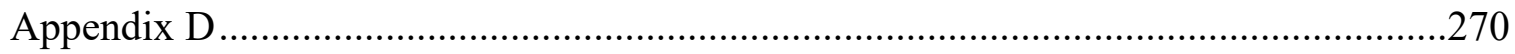

Appendix E Copyright documentation …………………........................................22 


\section{List of figures}

Figure 2. 1 Bagua In A Coin ..........................................................................................23

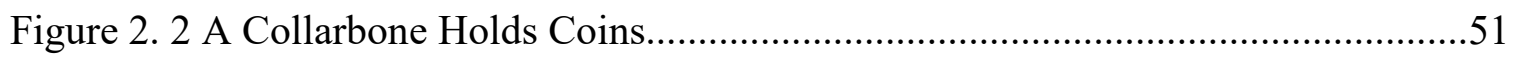

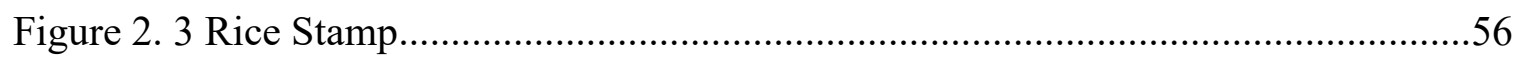

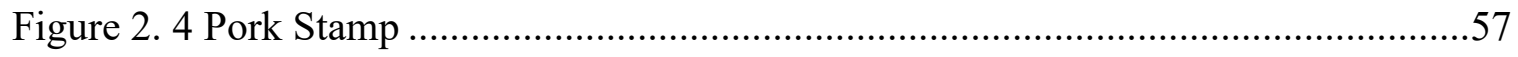

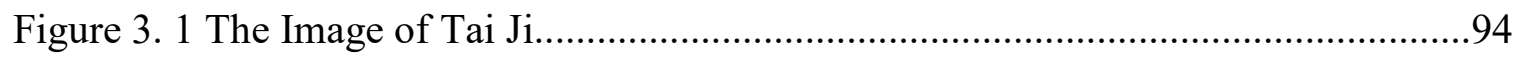

Figure 3. 2 Screen Capture of Online Articles On Xinhua Net ....................................109

Figure 3. 3 Stamp Of The Year Monkey (2016)......................................................118

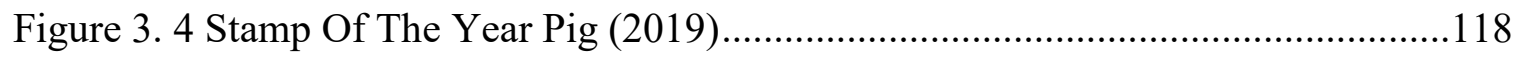

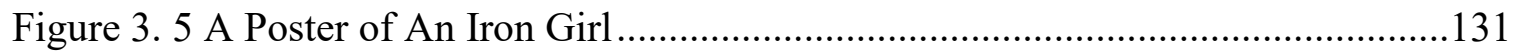

Figure 4. 1 Screen Capture 1 Of The Commercial "Because Love Won't Wait." ...........155

Figure 4. 2 Screen Capture 2 Of The Commercial "Because Love Won't Wait." ...........156

Figure 4. 3 Screen Capture 3 Of The Commercial "Because Love Won't Wait." ...........156

Figure 4. 4 Screen Capture 4 Of The Commercial "Because Love Won't Wait." ...........156

Figure 4. 5 Screen Capture 5 Of The Commerical "Because Love Won't Wait." ............157

Figure 4. 6 Screen Capture Of The Message From Zhenai Wang..................................159

Figure 4. 7 An Advertisement To Promote The Children's Fever Reducer Mei Lin.......190 


\section{List of tables}

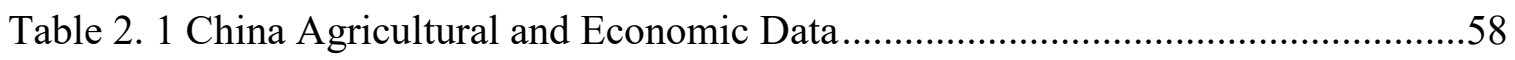




\section{Acknowledgements}

I would like to express my sincere gratitude to many people, who not only have supported and helped me in writing this dissertation, but also in the years that I have pursued a Ph. D. at Michigan Technological University.

First, I am very grateful to Dr. Jennifer Daryl Slack who has mentored me to become a better researcher. It is very lucky for me to have her as my advisor. I am also thankful to Dr. Patty Sotirin who supports me and helps me to overcome many difficulties. Thanks also to Dr. Kette Thomas and Dr. Sarah A. Green for your critical feedback and suggestions.

I also wish to thank the following people who made contributions to this project. To Emma Lozon, my writing coach, for spending many hours to work with me to edit my dissertation. To Charles Fugate and Aaron Hoover, for your feedback for my writing. I am also thankful to all my friends at Michigan Tech for your support, help, and friendship.

Finally, I wish to thank my family, for always having faith in me and accompanying me to face challenges and difficulties. 


\title{
List of abbreviations
}

\author{
Chinese Communist Party (CCP) \\ People's Republic of China (PRC) \\ The Reform and Opening-Up Policy (ROUP) \\ Great Firewall of China (GFW) \\ The British Broadcasting Corporation (BBC) \\ United Nations Educational, Scientific and Cultural Organization (UNESCO) \\ United States Department of Agriculture (USDA) \\ In Vitro Fertilization (IVF)
}




\section{Abstract}

This dissertation addresses the gendered implications of science and technology in the era of reforms. It argues that in this era, which began in 1978 and continues today, science and technology are highly romanticized as nearly omnipotent. This results in its being embedded not only into ordinary Chinese people's lives, hoping to bring them positive changes, but also into the Chinese government's political practices, hoping to achieve its political purposes through science and technology. It also points out that in the era of reforms, Chinese women's lived experiences are full of tensions, struggles, and conflicts, as evidenced by the expectations for them to become virtuous wives, caring mothers, and, at the same time, successful professionals. The veneration of science and technology in Chinese culture and the Chinese government's strict control over science and technology further complicate Chinese women's experiences.

To illustrate these points, I mainly use the analytical methods "articulation" and "mapping" from cultural studies to explore the impacts of Chinese myth, Confucianism and Daoism, Chinese language, Chinese political practices, and media and popular discourses to explain the status of science and technology and the living situation of Chinese women in the era of reforms. I analyze the cases of the development and use of science and technology: to promote marriage and family, for population control and family design, to promote the discourse of the super mother, and to help women gain independence and fight against sexual violence. I focus on the gendered implications of some specific scientific and technological artifacts, including dating websites, in vitro fertilization (IVF), breast pumps, social media, and many others. 
This dissertation contributes to understanding Chinese women and science and technology in contemporary China. It reveals that although Chinese women's living situations have improved significantly, many of them are still trapped and subordinated. Science and technology, which are always articulated with other elements, especially the Chinese government's politics, the traditional patriarchal culture, and many Chinese women's demands for gender equality, aggravate many women's suffering while also offering some of them extra job opportunities and access to virtual spaces to engage in social activism. 


\section{Chapter One: Introduction}

China is undergoing enormous changes in the twenty-first century. Its economic performance is impressive: products made in China circulate around the world, and China's GDP per capita is skyrocketing. In 2017 China's merchandise export reached 2,263,371 million USD and the GDP per capita reached 8,525 USD (United Nations Conference on Trade and Development, 2019). However, despite China's remarkable economic performance in recent years, the economic gap between the poor and the rich has become increasingly pronounced as claimed by Benjamin, Brandt, Giles, and Wang (2008). The Gini coefficient in China was 0.465 in 2016 (Statista, 2019). ${ }^{1}$ In contrast, in 1990, the Gini coefficient was 0.357 and in 2005 it was 0.449 (Wu, 2010, p.93).

Moreover, because China's economy has relied heavily on industrialization, its environment is under threat. Roumasset, Burnett, and Wang (2008) write that "One-third of China's total land is prone to desertification, including 262 million hectares of pastoral and oasis land in the Xinjiang, Inner Mongolia, Tibet, Gansu, and Qinghai Province"(p. 251). The industrialization not only results in the desertification of land, but also heavy environmental pollution in China. For example, $\mathrm{Hu}$ (2016) reports:

Discharge [into the Yangtze River] has been steadily increasing over the past decade: already surpassing 30 billion tonnes in 2006 and growing to 33.9 billion tonnes in 2014, according to the Yangtze River Water Resources Commission.

\footnotetext{
${ }^{1}$ The Gini income coefficient that is used to measure income distribution across a population can take any value between $0-1$.The closer the Gini coefficient is to 1 , the more unequal a country is.
} 
Also worth noting is that in $2014,80.8 \%$ of total waste water was discharged into the mainstream of the Yangtze; the major tributaries; and the Tai, Poyang \& Dongting Lakes—all parts of the Yangtze River's water system.

In order to deal with water pollution, the Chinese government has formulated a series of regulatory policies. For instance, China's revised Water Pollution Prevention and Control Law has been in effect since January 1, 2018. This law imposes several strict requirements, such as:

Those who build sewage outlets in protected drinking water source areas will face a maximum fine of one million yuan. [...] The law instructs government to build sewage treatment and garbage disposal facilities in rural areas, and that standards be set on fertilizer and pesticide use. (as cited in Meng, 2017)

Facing not only water pollution but also air pollution, which has led the capital city Beijing to be known as a smog city, the Chinese government issued the Air Pollution Prevention and Control Action Plan in September 2013. In this plan, which regulates emissions including those produced by coal burning, industry production, and vehicle exhaust, the Chinese government has made several promises such as:

By 2017, the urban concentration of $\mathrm{PM}_{10}$ must decrease by $10 \%$ compared with 2012, and as a result the annual number of days with fairly good air quality should gradually increase. $^{2}$

\footnotetext{
2 " $\mathrm{PM}_{10}$ is particulate matter 10 micrometers or less in diameter, $\mathrm{PM}_{2.5}$ is particulate matter 2.5 micrometers or less in diameter. $\mathrm{PM}_{2.5}$ is generally described as fine particles. By way of comparison, a human hair is about 100 micrometers, so roughly 40 fine particles could be placed on its width" (Australian Government Department of the Environment and Energy, n.d.).
} 
Concentrations of $\mathrm{PM}_{2.5}$ in the heavily polluted Beijing-Tianjin-Hebei, Yangtze

River Delta, and Pearl River Delta regions must fall by around 25\%, 20\%, and $15 \%$, respectively (as cited in Library of Congress, 2019).

On April 22, 2016, China signed the Paris Climate Agreement. In this way, the Chinese government demonstrates to the world its determination to tackle environmental issues.

Socially, China's literacy rate has improved. Due to China's free nine-year compulsory educational system spanning from primary school to middle school, which has been implemented since 1986, an increasing number of Chinese people are literate. Thus, in 1982, 65.505\% of Chinese adults (a person aged 15 or above) were literate; in contrast, in 2010, 95.124\% of Chinese adults were literate (The World Bank, n.d.). While it is positive that illiteracy, which had challenged the Chinese society for thousands of years, is no longer an issue, new issues have emerged - for example, food safety. In 2008, the Chinese Milk Scandal broke out. It was revealed that several large and famous Chinese milk companies (e.g. Sanlu/三鹿 and Yili/伊利) used the toxic chemical melamine, which can crystallize easily and result in kidney stones, in their products including powdered infant formula. In addition to the issue of food safety, an exploitative sex industry flourishes in contemporary Chinese society. From the mid-1950s to the early 1980 s, the sex industry almost vanished because of the Chinese government's policy that shut down brothels and nightclubs, taught sex workers other living skills, and retained sex workers to work in other industries. While in China the sex industry currently is still illegal on the surface, it has become an important industry, even one of the leading industries in some Chinese cities such as Dong Guan (东莞), due in part to the local 
government's corruption and individuals seizing opportunities to make profit. Osburg (2016) points out that nowadays Chinese society "has been marked by the rise of hierarchical, patron-client form of sexuality, especially among elite" (p. 108).

Politically, the Chinese government has an elevated status in the world. Until July 2018, more than 20 countries allowed Chinese citizens to enter without applying for visas. In contrast, before 2010, there were fewer than 10 visa-free countries for Chinese passport holders. Moreover, the Chinese government tries to connect with the rest of the world through exerting its soft power and in the forms of investment, trade, and exchange. ${ }^{3}$ By December 2017, the Chinese government had set up 525 Confucius institutes and 1,113 Confucius classrooms globally (Confucius Institute Headquarters, n.d.). These Confucius institutes and classrooms are responsible for teaching foreigners Chinese language and culture. Moreover, the Chinese government has carried out the Belt and Road Initiative since 2015. The Belt and Road Initiative aims to build a unified international market with China at the center. It includes several strategies such as making investments and creating infrastructure in Asian, European, and African countries. In general, the relations between China and other countries have been improved, but regional conflicts remain an issue. For instance, due to the disagreements concerning the South China Sea and Taiwan, military and political skirmishes persist between China and some countries.

\footnotetext{
${ }^{3}$ Soft Power: This term is contrary to hard power. Exercising hard power means a country uses its military power such as gunfire to exert its influence over other countries. In contrast, exercising soft power means a country tries to persuade other countries to respect it and follow its leadership without military coercion. Usually, a country works to craft a positive image of itself internationally and propagandize the superiority of its culture.
} 
These economic, environmental, social, and political changes in China are largely attributed to the Reform and Opening-Up Policy (Gai Ge Kai Fang Zheng Ce/改革开放 政策/ROUP), which was initiated by Deng Xiaoping, the paramount leader of the People's Republic of China (PRC) from 1978 to $1989 .{ }^{4}$ Deng Xiaoping announced this policy in the third plenum of the eleventh Central Committee of the Communist Party of China held from the $18^{\text {th }}$ of December 1978 to the $22^{\text {nd }}$.

In general, ROUP aims to carry out reforms in China and to open China to the rest of the world. ROUP replaces the Chinese Communist Party's previous emphases on egalitarianism and class struggle, instead encouraging competition and entrepreneurship. Accordingly, money is supposed to be distributed based on the amount and quality of work done, individuals can start their own business, and farmers can use their farmland to meet their own needs. ROUP also requires the Chinese government to shift its focus from class struggle to boosting the economy, developing science and technology, and cooperating with other countries. China's Communist Party summarizes the desired effects of implementing ROUP as: liberate and develop productive forces, enhance comprehensive national power, emancipate the mind and seek truth for facts, build a socialist country with Chinese characteristics, and so forth ("Reform and Opening-Up," n.d.).

Since 1978, China has entered the era of reforms. From Deng Xiaoping's leadership through successive leaders Jiang Zeming, Hu Jintao, and Xi Jinping, ROUP

\footnotetext{
${ }^{4}$ In this dissertation, I use the abbreviation of "ROUP" to refer to China's Reform and Opening-Up Policy.
} 
has remained one of the constitutional policies. The Chinese government consistently maintains that China's project of reforming and opening-up is an ongoing one. For example, on October 24, 2018, China's current chairman Xi Jinping visited Shenzhen, which was chosen by China's central government as a pioneering economic zone in 1980 . After attending an exhibition that celebrated how Shenzhen changed from a fishing village to an international city in the past decades, $\mathrm{Xi}$ (2018) said "China will never stop the project of reforming and opening-up. This is the promise we make to the world" (para. 1). Thus, the era of reforms began in the year of 1978 and continues to this day. ${ }^{5}$

The year 2018 marked the 40th anniversary of the implementation of ROUP. This occasion offered a time to step back and to think about what had been going on so far. This work of reflection was crucial because:

Understanding China's reforms is important first and foremost for getting the historical record right, and this record is still shifting despite the many volumes that have already been developed to this topic. Understanding China's past reforms and, with them, the basis for China's success is also important for China's future reforms; understanding the path travelled, the circumstances under which historical decisions were made and what their effects were on the course of China's economy will inform decision makers on where to go next. Third, reflections on China's reforms are increasingly important for the rest of the world.

\footnotetext{
${ }^{5}$ Some scholars (e.g. Minzner 2015) argue that China is in the post-reform era, a stance with which I do not agree. I believe that although in recent years, China's process of reform and opening-up has been slowed in some aspects (e.g. politics and the opening of the domestic market to foreign investors) compared with the past decades, China still is on track with making domestic changes and building connections with the rest of the world. Moreover, in China, the predominant discourse that is both forwarded by the government and believed by most Chinese people is that China is still in the era of reforms.
} 
Because of China's economic success, more and more countries see China as an example to emulate, a model of development that could help them move from rags to riches within a generation. (Hofman, 2018, p. 53)

There are a number of options for researchers if they want to understand what has been going on in the era of reforms. For instance, researchers can study the economic or environmental situation in China. In fact, these two aspects are the two most researched topics by scholars interested in the era of reforms (see the works of Chow 2004; Heston \& Sicular 2008; Pekins 2018; Roumasset et al., 2008; Pan 2018). However, this dissertation aims to study the implications of science and technology in the era of reforms. ${ }^{6}$ In fact, in this period, the Chinese government has initiated a number of scientific and technological projects and spent billions of dollars on developing science and technology, which have significantly contributed to China's impressive scientific and technological achievements and the perceived high status of science and technology in China in the era of reforms. For example, in March 1986, the Chinese government announced the National High-Tech Research and Development (R\&D) Program that is also known as the 863 Program. This program aimed to support research projects in various scientific and technological fields (e.g. biology, information and electronic

\footnotetext{
${ }^{6}$ Here, I want to clarify my uses of three terms "science," "technology," and "science and technology." In the Chinese language, the three corresponding terms are Kexue/科学 (science), Jishu /技术 (technology), and Keji/科技 (science and technology). Semantically, Kexue refers to knowledge that helps people to understand the natural/material/physical world theoretically (for example, the fields of mathematics, physics, and chemistry are regarded as fields of Kexue), Jishu refers to skills or expertise that can be applied to solve practical problems (for example, the fields of engineering are regarded as fields of Jishu), and Keji refers to both theoretical knowledge and practical skills. However, it is a common practice in China that people use the term of Keji even though they actually merely refer to Kexue or Jishu. Accordingly, in this dissertation, I follow the Chinese tradition of using the term "science and technology" to align with the existing scholarship in China even though in some situations using a single term of "science" or "technology" would probably be more appropriate.
} 
engineering, and automation). From 1986 to 2005, the 863 Program cost the Chinese government 33 billion Yuan (approximately 4.8 billion USD), and more than 150,000 million scientists and engineers participated in the 863 Program ("863 Program," n.d.). Accordingly, in the era of reforms, Chinese people have made some extraordinary scientific and technological achievements. For instance, on August 16, 2016, China launched Micius, which is the world's first quantum communication satellite. On July 29, 2017, China successfully produced gas from flammable ice for the first time. The perceived high status of science and technology in contemporary China is indicated in the popular saying, "A nation will prosper only when its science and technology thrive; a country will be full of hope and have a promising future only when its science and technology are advanced (Ke Ji Xing Ze Min Zu Xing, Ke Ji Qiang Ze Guo Jia Qiang/科 技兴则民族兴，科技强则国家强).”

The magnitude of the scientific and technological changes and their prestige in the era of reforms imply an interesting area of inquiry. However, "the implications of science and technology in the era of reforms" is still a broad research question. It is impossible for me to address the entirety of science and technology in a dissertation. So, I add another parameter to bring my topic into focus: to explore the implications of science and technology for gender relations, in particular for Chinese women in the era of reforms. ${ }^{7}$

\footnotetext{
${ }^{7}$ Here, I want to clarify my use of the terms of "woman"/“women" and "female"/"females." When I use the term “woman” or "women," I refer to the word of Funü(妇女) in Chinese language. In China, Funü refers to adult females. Accordingly, in this dissertation, "woman"/ "women" refers to adult females, while "female"/"females" is used without reference to age.
} 
This decision is made based on the following reasons. First, the population of Chinese women is substantial. In 2017, there were 678,710,000 females (National Bureau of Statistics of China, 2018). This number was greater than the total population of the U.S., Canada, Australia, and New Zealand combined. Thus, as a Chinese female researcher, it is both my interest and my responsibility to know what this large population of people are experiencing, to understand their happiness and sorrow, to share their stories with both Chinese and non-Chinese audiences, and to figure out ways to improve their living situations. Second, the discussion concerning Chinese women's lived experiences in the era of reforms is heated and includes many contradictory arguments. Some people argue that Chinese women have satisfactory livelihoods in the era of reforms. For example, on November 12, 2018, China's Women's News released an article in which a set of statistics and diagrams was used to prove that Chinese women's living situations have been bettered. ${ }^{8}$ This article pointed out that in $2017,52.5 \%$ of Chinese students who had received higher education were women; $48.6 \%$ of professionals in China were women; and 91.7\% of Chinese women had access to free pre-pregnancy physical examinations ("Report of The Outcome," 2018). However, some scholars argue that Chinese women's living situations are not satisfactory in the era of reforms. For example, Lin (2001) writes:

Reforms are failing women (along with workers and farmers), as evidenced by high unemployment, poor labour conditions, lack of protection for rural migrants,

\footnotetext{
${ }^{8}$ China's Women's News/中国妇女报, a newspaper sponsored by the All-China Women's Federation, is the only governmental national newspaper in China that focuses on Chinese women.
} 
the commercialisation (and traditionalisation according to artificial 'Oriental taste') of femininity, and ultimately the erasure of the problem of gender equality. (p. 1284)

I want to engage in this discussion, to unpack contradictions, and to contribute my point of view through focusing on the gendered influences of science and technology. In fact, as I argue in Chapter Two, in the era of reforms, new practices of science and technology have become indispensable in Chinese people's lives. Thus, if we want to understand Chinese women's living situations in the era of reforms, we need to take the elements of science and technology into consideration.

I want to make one further specification: in this dissertation I explore the implications of science and technology for Chinese women as wives, mothers, and professionals in the era of reforms. This research question is built based on my argument in Chapter Three, in which I argue that in the era of reforms, being wives and mothers remains crucial for Chinese women, meanwhile an increasing number of them are encouraged to join the workplace. Further, Chapter Four points out that the literature that maps the implications of science and technology for Chinese women's marriages, families, and careers in the era of reforms is scant and lacks complexity. Thus, my dissertation addresses this gap in the research. To sum up, in this dissertation, I answer the question of how science and technology influence Chinese women, especially their marriages, families, and careers in the era of reforms.

In order to answer my research question, I draw from the field of cultural studies. Cultural studies builds on and out of what is sometimes referred to as British cultural 
studies. In addition to the impact of Stuart Hall, the field of cultural studies has been developed by scholars from various disciplines, such as Marxist scholars (e.g. Antonio Gramsci), scholars in communication and media (e.g. Lawrence Grossberg), and scholars in gender studies and critical race theory (e.g. Angela McRobbie). Due to these various influences, cultural studies is "an interdisplinary, transdisciplinary, and sometimes counter-disciplinary field" (Nelson \&Treichler \& Grossberg, 1992, p. 4).

To risk the danger of over-simplification, the intellectual heritage of cultural studies can be characterized as having the following four aspects. First, cultural studies entails a particular view of what constitutes a culture and how to study it. Hoggart (1969) defines culture as "the whole way of life of a society, its beliefs, attitudes and temper as expressed in all kinds of structures, rituals and gestures, as well as in the traditionallydefined form of art" (p. 3). Williams (1958) points out that "culture is ordinary" (p. 91). These statements make the abstract concept of "culture" accessible: culture is something everyone lives. It is politics, rituals, religious faiths, ideologies, people's routine practices, affect, and so forth. Furthermore, because culture is ordinary, it can be perceived not only from elite artifacts (e.g. literature and highbrow art) but also from more "ordinary" artifacts (e.g. magazine articles and popular music). Thus, it is important for researchers to pay attention to the everyday "ordinary" artifacts. Accordingly, in this dissertation, concerning materials of analysis, I study different kinds of artifacts, which include but are not limited to government documents, popular sayings, news reports, folklore, magazine articles, TV series, songs, films, commercials, photos, paintings, stamps, and anonymous posts in open-access internet forums and discussion boards. 
Second, cultural studies emphasizes the analysis of struggles of power for the purpose of understanding how change happens. When Grossberg (2010) defines the project of cultural studies, he writes:

Cultural studies is concerned with describing and intervening in the ways cultural practices are produced within, inserted into, and operate in the everyday life of human beings and social formations, so as to reproduce, struggle against, and perhaps transform the existing structures of power. (p. 8)

In fact, one of the crucial purposes of conducting research in cultural studies is to investigate how culture operates to disempower and empower people. Because cultural studies is deeply concerned for marginalized and oppressed people, a primary task of researchers in this field is to discuss how power shapes the current landscape of the culture that privileges certain people, ideas, and practices at the expense of others. Then, researchers are expected to figure out ways to intervene into relations of power to change societies for better. In short, cultural studies is "politically driven, that is committed to producing knowledge that help people understand that the world is changeable and that offer some direction for how to change it" (Grossberg, 1997, p. 264).

Third, cultural studies is informed by a feminist orientation. For example, Angela McRobbie expressed her strong dissatisfaction with the absence of gender in analysis in early cultural studies. In 1980, she wrote "[in current works in cultural studies,] women and the whole question of sexual division have been marginalized" (p. 111). In 1992, Hall wrote that the feminist orientation is important for cultural studies and listed five significant contributions it has made: 
First, the opening of the question of the personal as political, and its consequences for changing the object of study in cultural studies, was completely revolutionary in a theoretical and practical way. Second, the radical expansion of the notion of power, which had hitherto been very much developed within the framework of the notion of the public, the public domain, with the effect that we could not use the term power-so key to the earlier problematic of hegemony-in the same way. Third, the centrality of gender and sexuality to the understanding of power itself. Fourth, the opening of many of the questions that we thought we had abolished around the dangerous area of the subjectivity and the subject, which lodged those questions at the centre of cultural studies as a theoretical practice. Fifth, 'the reopening' of the closed frontier between social theory and the theory of consciouspsychoanalysis. (p. 269)

Feminism profoundly informs my criticism. As a feminist researcher, I commit to making Chinese women's living situation visible, which I believe is an important first step to fight against sexism. Moreover, I embrace and value my situatedness as a Chinese woman. Haraway, a scholar in gender studies and cultural studies, puts forward the concept of "situated knowledge," which argues that although there are some "core" qualities, objectivity is mediated and our situatedness matters for understanding the world. By drawing from my situatedness, I not only resonate with many other Chinese women's experiences in the era of reforms but also engage in the work of self-reflection, which is promoted by cultural studies. Additionally, in this dissertation, I carefully consider ways to improve Chinese women's living situations. As a field whose commitment is to 
achieve social justice, feminism is not about privileging women at the cost of oppressing men; instead it is about changing our current societies into more fair and just places where everyone is able to have more access to self-fulfillment. Thus, one of my intentions in writing this dissertation is to reveal ways that Chinese women have empowered themselves and think about their future directions.

Fourth, cultural studies provides researchers analytical methods to study a culture. Cultural studies requires researchers to ask the question "What's going on?" (Grossberg, 2010). Drawing from Deleuze and Guattari, cultural studies promotes the method of mapping. Deleuze and Guattari (1987) explain mapping by contrasting it with the method of tracing. They write:

What distinguished the map from the tracing is that it is entirely oriented toward an experimentation in contact with the real. The map...fosters connection between fields...The map is open and connectable in all of its dimensions; it is detachable, reversible, susceptible to constant modification. It can be torn, reversed, adapted to any kind of mounting, reworked by an individual, group, or social formation ...A map has multiple entryways, as opposed to the tracing, which always comes back "to the same." (p. 12)

Thus, in cultural studies, good researchers are good "mappers" who work hard to record different elements, to figure out relations among elements, and to detect how relations are changing. They draw the connections that constitute the map and do the work of articulation. 
Articulation "is perhaps one of the most generative concepts in contemporary cultural studies" (Slack, 1996, p. 112). Although the word "articulation" can refer to the act of enunciation, in cultural studies, it is used to describe the process of linking (articulating), delinking (disarticulating), and relinking (rearticulating) different elements.

The concept of "articulation" can be traced back to Stuart Hall's use of Gramsci's work to resolve the confrontation between the culturalist paradigm and the structuralist paradigm of cultural studies. At the risk of over-simplification, the culturalist paradigm claims that culture is interwoven in all social practices such as common forms of human activity, and there is a "harmonious and well-structured social totality in which everything fits together" (Grossberg, 1997, p. 214). In contrast, the structuralist paradigm argues that people are bearers of structures, and unity "is constructed through the differences between, rather than the homology of, practices" (Hall, 1980, p. 68). Hall (1983) draws from both paradigms and provides "Marxism without guarantees"- a theory that argues ideological categories not only are generated based on "their own laws of development" but also are "generated out of given materials" (p. 45). Due to this relative openness, scholars should understand “'determinacy' in terms of setting of limits, the establishment of parameters, the defining of the space of operations, the concrete conditions of existence, [and] the 'givenness' of social practices" (Hall, 1983, p. 45).

I use the concept of "articulation" as an analytical method to explore "the process by which otherwise unrelated phenomena - practices, beliefs, texts, social groups, etc.come to be linked together in a meaningful and seemingly natural way" (Rodman, 1996, p.24). Thus, to understand an issue, I analyze its articulation in relation to a range of 
different elements. Rodman's analysis of the posthumous "life" of Elvis Presley is a good example of using "articulation" as an analytical method. In order to understand Elvis's posthumous ubiquity, Rodman discusses how race, sexuality, class, and the American dream are articulated to constitute the power and significance of a posthumous Elvis. Moreover, the concept of "articulation" claims that because connections are contingent, "not only does the cause have effects, but the effects themselves affect the cause, and both are themselves determined by a host of other relations" (Grossberg, 1992, p. 56). This point is important in terms of resisting simple determinist thinking. Since there is no determinant cause and effect, cultural theorists need to understand cultural phenomena relationally and to notice the dynamics and struggles that are crucial in the process of political and cultural changes.

The concept of "articulation" argues that connections are "not necessary, determined, absolute and essential for all time," but this doesn't imply that there is no "unity or stability" (Hall, 1986, p. 141). In fact, because "some connections are more difficult to disarticulate/rearticulate than others," articulations vary in their tenacity (Slack, 1993, p. 27). The phrase "lines of tendential force" refers to articulations that are more resistant to change. For example, many women are discriminated against in the workplace. The connection between gender and the lack of trust for women's credibility is a line of tendential force. Although this connection is not necessary, it is a common practice that women's salary is less than men's and it is harder for women to get promoted even when the quality of their work is on par with men's. This means that gender-based discrimination in the workplace is relatively "stable." However, despite its 
"stable" status at this point, articulation is an ongoing process of change without a definite termination. This means maybe one day, women can be treated fairly given that political systems, people's minds, and sexist cultures are open to change.

Last but not the least, the concept of "articulation" provides a productive way for researchers to conceptualize history. The concept implies that in order to understand the present moment, we must understand its history. Because, as Williams (2011) puts it:

In the analysis of contemporary culture, the existing state of [the] selective tradition is of vital importance, for it is often true that some changes in this tradition—establishing new lines with the past, breaking or redrawing existing lines - is a radical kind of contemporary change. (p. 74)

Thus, it is through history that we can better understand the present. It is through the present that we can better predict the future trajectory of development. When we look at history, we look for "what's old;" when we look at the present, we look for "what's new" and for "what has been rearticulated;" and when we look for trajectories of change, we consider the question of what can be disarticulated and what is possible to be articulated and re-articulated.

My analytical materials include various cultural artifacts while the methods of "mapping" and "articulation" are my two primary research methods, and feminism is my critical perspective. Through focusing on the element "gender" and mapping what Chinese women are experiencing in the era of reforms, I answer the question of "What's going on?" Through using the method of "articulation," I look for "what's old," "what's new," and "what's rearticulated" in order to understand struggles of power that influence 
genders asymmetrically. Then I put forward ways of articulating, disarticulating, and rearticulating these relationships for the purpose of contributing to the project of “end[ing] sexism, sexist exploitation, and oppression” (hooks, 2015, p. xii).

This dissertation includes five chapters. Chapter One, "Introduction," provides an overview of what's going on in the era of reforms. I argued that the changes in era of reforms pose an interesting area to explore with regard to the gendered implications of science and technology in contemporary China. To explore this area, I outlined a theoretical orientation to cultural studies that guides me to choose analytical materials to study a culture, that emphasizes a feminist perspective, and that provides the research methods of "articulation" and "mapping."

Chapter Two, "Science and Technology in the Era of Reforms" argues that in order to understand science and technology in the era of reforms, we must consider the articulation of Chinese myth, Confucianism and Daoism, the intellectual heritage of the Westernization Movement and the New Culture Movement, the Chinese tradition of numeracy, the discrepancy between the needs of the large Chinese population and the country's inadequate capacity for production with a particular focus on food supply, and the policies of China's Communist Party. This chapter concludes that in the era of reforms, science and technology are romanticized as solutions to all social, economic, and political problems, which results in many Chinese people's fascinations with science and technology, the inhumane costs of developing them, and their embeddedness into Chinese political practices. 
Chapter Three, “Chinese Women in the Era of Reforms," focuses on women's roles in contemporary China. It argues that in the era of reforms, Chinese women are still expected to become wives and mothers. I explore the articulation of four lines of tendential force: Chinese myth, Chinese language, Confucianism and Daoism, and the Chinese government's political practices, which significantly contribute to this expectation. However, at the same time, due to the forces of the discourse of the New Woman that promotes the image of an independent and knowledgeable woman and the Chinese government's political practices of encouraging and preparing women to join the workplace that have begun to exert increasingly important impacts, many Chinese women have become professionals. Tensions have formed between women's traditional roles as wives and mothers and their contemporary roles as professionals, resulting in significant changes to their lived experiences. For example, women are expected to become super mothers: confident and knowledgeable mothers who have highly successful careers and at the same time can take good care of their children.

Chapter Four, "Put It All Together: The Impacts of Science and Technology for Women's Prescribed Roles the Era of Reforms" is developed based on my Chapter One, Two, and Three. This chapter begins with my analysis that reveals the insufficiency of literature that addresses the implications of science and technology for Chinese women. Then, this chapter points out Chinese women's lived experiences, which are already characterized by tensions, are complicated by the perceived nearly omnipotent power of, the prevalent applications of, and the embeddedness in the Chinese government's political practices of science and technology. I used four examples to demonstrate this 
claim: the development and use of science and technology to promote marriage and family, the development and use of science and technology for population control and family design, the development and use of science and technology to promote the discourse of the super mother, and the development and use of science and technology for women to gain independence and to resist sexist violence.

Chapter Five, "Conclusion," summarizes the implications of science and technology for Chinese women in the era of reforms. This chapter narrates cultural stories of science and technology and Chinese women in the era of reforms. This chapter also lays out the theoretical significances of this dissertation to the fields of cultural studies and women's studies, as well as its practical significances for understanding contemporary China and fortifying the fight against sexism. At the end of this chapter, I address the limitation of my dissertation and explain my future directions for expanding this dissertation and developing other research projects. 


\section{Chapter Two: Science and Technology in the Era of Reforms}

To understand the implications of science and technology for women, especially their marriages and families in the era of reforms, this chapter lays the groundwork for understanding the significance of science and technology in China. It considers the articulation of the key elements of Chinese myth, Confucianism and Daoism, the Westernization Movement and the New Culture Movement, the Chinese tradition of numeracy, the discrepancy between the needs of the large Chinese population and the country's inadequate capacity for production with a particular focus on food supply and housing, and China's Communist Party's policies. Through discussing these mythical, historical, philosophical, religious, cultural, humanitarian, and political forces, this chapter reveals that in the era of reforms, many Chinese people believe that science and technology are powerful, even nearly omnipotent, and can enable positive societal and cultural changes. Thus, science and technology are highly valued and even venerated. Due to the perceived high status of science and technology in the era of reforms, they are developed even at the cost of sacrificing human interests and have become indispensable to the Chinese government's political practices. 


\section{Myth}

Myth has exerted profound impacts on Chinese culture. Thus, in order to understand science and technology in the era of reforms, it is crucial to explore the role of Chinese myth, which has a long tradition of valuing science and technology.

Most Chinese mythical figures have specialized scientific and technical skills. Nü Wa (女娲), Fu Xi (伏羲), Shen Nong (神农), and Sui Ren Shi(燧人氏) are four figures who are believed to have significantly contributed to Chinese civilization and people's lives with their skills. ${ }^{9}$

The goddess Nü Wa, who has a female upper body and a snake tail, is respected as the mother of human beings, as described in the story "Nü Wa Created Man." After the birth of the world, there were no humans. Nü Wa wanted life and beauty in the world, so she made people from clay. Another story "Nü Wa Patched the Sky" describes how she fixed a big hole in the sky that led to the death of people by extraterrestrial fire and meteorites. She accomplished this by melting rocks of five colors into magma to patch the hole, and by catching a giant tortoise and using its four legs as pillars to hold up the sky. These two stories reflect the three most important technical skills Nü Wa has: to produce human beings, to master the technology of melting, and to be a good architect. In Chinese myth, Nü Wa is the most significant creator-and engineer- who used her scientific and technical power to create, save, and help humans.

\footnotetext{
${ }^{9}$ To know more about Chinese mythical stories, please consider reading these books: 1) Birrell, A.(1993). Chinese Mythology. Baltimore: Johns Hopkins. 2) Christie, A.(1968). Chinese Mythology. Feltham: Hamlyn Publishing. 3) Werner, E.T.C. (1922). Myths and Legends of China. New York: George G. Harrap \& Co. Ltd. 4) Yang, L.; An, D.; \&Turner, J., A. (2005). Handbook of Chinese Mythology. New York, NY: Oxford University Press.
} 
The god Fu Xi is the forefather of Chinese civilization in Chinese myth due to his several great achievements. Fu Xi invented bagua/八卦一an influential epistemology.

Below is a photo of a bagua:

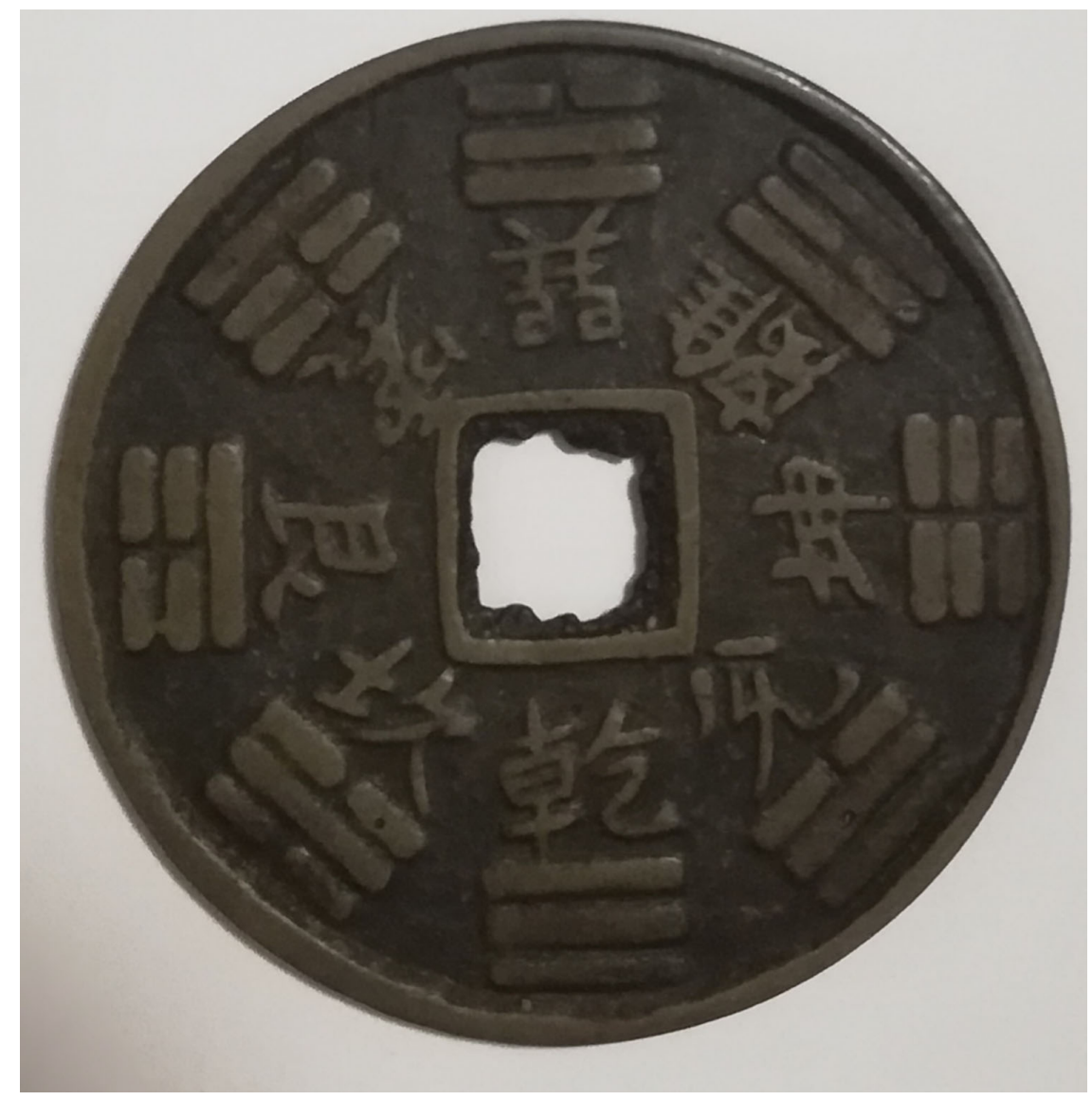

Figure 2. 1Bagua In A Coin. This photo was taken by the author.

Bagua includes eight characters. The character “乾” refers to sky, “坤” refers to ground, “巽” refers to wind, “震” refers to thunder, “坎” refers to water that cannot be controlled such as floods and rainstorms, “离/離” refers to fire, “艮” refers to mountain, and “兑” refers to the water that can be used and controlled by human beings. Bagua includes two images. “- -” refers to yin/阴, which can be roughly 
understood as femininity and “一” refers to yang/阳, which can be understood as masculinity. Fu Xi argued that these two images and six characters can be combined in many ways and the combinations can represent and interpret everything in the world. Fu $\mathrm{Xi}$ also invented the practices of hunting and fishing, thereby giving people more regular access to protein. Moreover, he created the Cangjie system of writing Chinese characters, thereby the culture shifted from primarily oral to written communication. In this way, people could learn knowledge in a more systematic way and pass down information over generations.

The god Shen Nong is the father of medicine and agriculture. The famous story "Shen Nong threshes the hundred grasses" tells how he tasted hundreds of grasses in order to explore their different characteristics, such as taste, toxicity, and medicinal properties. He shared this knowledge and instructed people in the use of plant-based medicine, thereby greatly extending the lives of Chinese people. Shen Nong's knowledge became the basis of Chinese medicine. He is also credited with the invention of agricultural tools such as the plow and the hoe and with teaching the practice of agriculture.

The god Sui Ren Shi is the father of fire. In Chinese myth, he was described as a man who was different from his peers. While others were afraid of fire, he was willing to be around it. He found out that fire brings warmth, which benefits wellbeing and can be used to cook food, which makes food more digestible and delicious. Hence, he advocated for using fire tactically. Sui Ren Shi also created the practice of sparking fire by friction, 
which he taught to other people. Because of Sui Ren Shi's contribution, he is well respected and his hometown is recognized as the birthplace of fire culture in China.

In Chinese myth, many goddesses and gods were originally ordinary people.

However, due to their scientific and technical contributions, they were deified, such as $\mathrm{Da}$ Yu (大禹) who had the skills of hydraulic engineering, You Chao Shi (有巢氏) who specialized at building houses, and Lu Ban (鲁班) who was elevated as the father of carpenters in China. Chinese people built temples to memorialize and mythologize these figures. This demonstrates ancient Chinese people's veneration of science and technology and their deep respect for scientists and engineers. Further, in Chinese myth, the development of Chinese civilization is aligned with the development of science and technology. For example, Fu Xi supports the system of Chinese written language, Shen Nong promotes the development of Chinese medicine, and Sui Ren Shi elevates Chinese people's mastery and use of tools. Chinese myth reflects the close relation between the development of civilization and the development of science and technology. As these mythical stories reveal, in Chinese culture there is a deeply rooted belief that science and technology can bring people power, benefits, conveniences, and happiness.

\section{Confucianism and Daoism}

Besides myth, to understand science and technology in Chinese culture, it is necessary to consider the impacts of Confucianism and Daoism. These two important Chinese ideological and religious forces have contributed to the high status of science and technology in the era of reforms in significant ways. 
Confucianism emerged in the Warring States Period between the years of 475 and 221 BC. ${ }^{10}{ }^{11}$ Confucius (551-479 BC) and his disciples were the forefathers of this school of thought. Before the Han Dynasty (206 BC-220 AD), Confucianism as well as other schools of thought, such as legalism and Mohism, thrived and developed because different emperors had different preferences. For example, Qin Shi Huang (259 BC—210BC), the first emperor of a unified China, prioritized legalism and applied it to govern the country.

In the early Han Dynasty, because of the scholar Zhongshu Dong's recommendation, Emperor Wu of Han (156 BC-87 BC) rejected the other schools of thought in favor of adopting Confucianism exclusively. This historical event is known as “Ba Chu Bai Jia Du Zun Ru Shu/罢黜百家独尊儒术.” This policy enabled Emperor Wu of Han to constrain people's beliefs and maintain his governance. After Emperor Wu of Han, this policy passed down from emperor to emperor. While a few emperors were not of Han ethnicity (e.g. Genghis Khan) resulting in occasional challenges to the superior status of Confucianism, for the most part, emperors regarded Confucianism as the governing socio-cultural-political theory. In fact, Confucianism was regarded as the epitome of the intelligence of Han ethnicity, which is the ethnicity that the majority of

\footnotetext{
${ }^{10}$ I want to clarify my use of the English term “Confucianism.” Some scholars (e.g. Chen 1999, and Fen \& Chen 2015) argue that Confucianism is or is becoming a religion. In fact, from ancient to modern times, Chinese people adhering to Confucianism perform some ritual practices such as bowing in Confucius temples to pray for strong academic performance. However, the Chinese government doesn't include Confucianism when they work on the statistics on religions in China. Thus, although Confucianism has a strong religious dimension, it is not officially recognized as a religion in contemporary China. Accordingly, I view Confucianism as an intellectual and cultural tradition that was developed by Confucius scholars such as Confucius, Mencius, and Zhu Xi.

${ }^{11}$ To know more about Confucianism, please consider reading the following books: 1) Gardner, D. K. (2014). Confucianism: A Very Short Introduction. New York: Oxford University Press. 2) Lee, M. (2017). Confucianism: Its Roots and Global Significance. D. Jones (ed.). Honolulu: University of Hawaii Press. 3) Rainey, L., D. (2010). Confucius \& Confucianism: The Essential. West Sussex: Wiley-Blackwell. 3)
} 
Chinese people identify with and that has been at the center of power in China throughout most of history. In general, from the Emperor Wu of Han through the Qing Dynasty (1644-1912), Confucianism was the dominant ideology in Chinese society.

From the late Qing Dynasty to the early 1980s, the influence of Confucianism declined. In the early 1900s, Confucianism was seen "as the cause of all the failures of society and government....Confucianism was to blame for almost everything" (Rainey, 2010, p. 179). During the Cultural Revolution (1966-1976), Confucianism was viewed as the "four olds" (old culture, old thinking, old habits, and old customs), which should be destroyed. However, Confucianism was never completely obliterated, and since the late 1980s, it has experienced a resurgence in mainland China. Some scholars have advocated for preserving and reviving Confucianism, because they believe that "only by returning to a Confucian foundation can Chinese societies maintain a solid culture. 'Confucian values' are basic to [the] culture, attitude, and behavior of these societies" (Rainey, 2010, p.183). ${ }^{12}$ Even the Chinese government advocates reviving Confucianism. Yeung and Fung (2011) point out that the Chinese government's intention to develop soft power is profoundly shaped by Confucianism, which emphasizes the need for attracting people to adopt beliefs that the government promotes and provides persuasive strategies for fulfilling that need (pp. 109-134). Accordingly, since 2004, the Chinese government has begun to set up Confucius Institutes and classrooms internationally for the purposes of improving China's global image and soliciting foreign followers for the CCP.

\footnotetext{
${ }^{12}$ Chinese societies not only refers here to the society in mainland China, but also to the societies in which Chinese people constitute the majority group, such as the Singaporean society and the Hong Kong society.
} 
Confucianism emphasizes moral development, which primarily promotes the ideas of being virtuous, and subordinating oneself to the ruling class, and obeying authority. These two ideas can be detrimental to the development of science and technology, since in essence they do not cultivate the spirit of being critical and innovative. Confucianism also emphasizes education, arguing that "books offer the path to be rich and to attract beautiful women/Shu Zhong Zi You Yan Ru Yu, Shu Zhong Zi You Huang Jin Wu/书中自有颜如玉，书中自有黄金屋.”However, Confucianism focuses on education in the humanities solely, which resulted in the paucity of STEM education in ancient China.

First, Confucianism promotes cultivating morality and constructing moral systems in society. Confucian scholars argue that a person should develop the five constant virtues: ren /仁 (benevolence), yi/义 (righteousness), li/礼 (propriety), zhi /智 (wisdom), and $\operatorname{xin} /$ 信 (sincerity). Upon careful observation of these five characteristics, it is clear that ren, yi, li, and xin are primarily ethical and moral characteristics, which are not typically associated with innovation. Only zhi has connotations related to learning and exploring science and technology as a way to cultivate one's intellect. However, originally, Confucius only emphasized three characteristics: ren, yi, and li. It was Mencius who later added the characteristics of "zhi." As Confucianism was developed further, the five virtues were extended into fifteen: ren/仁 (benevolence), yi/义 (righteousness), li/礼 (propriety), zhi/智 (wisdom), xin/信 (sincerity), wen/温 (gentleness), liang/良 (modesty), gong/恭 (courtesy), jian/俭(temperance), rang/让 
(complaisance), zhong/忠 (loyalty), xiao/孝 (filiality), lian/廉(self-discipline), chi/耻 (conscientiousness), and yong/勇 (bravery). Thus, according to Confucianism, people with high moral standards are respected above those with high intelligence. Consequently, a person's primary task is to nourish his or her soul. In fact, for Mencius," human[s] who are different from animals in a few [aspects]...The [biggest] difference between [a] human and [an] animal is 'four-mind of human nature', that is, to sympathize, to feel shame and abhor, out of modesty and courtesy, and to tell from right and wrong, with the 'kindheartedness view' as the core concept”'(Wang, 2017). Based on Mencius's viewpoint, the way for people to become better is to cultivate virtues; and the more virtuous people are in a society, the better society will be. This viewpoint, which positions morality as the core distinction between humans and non-human animals, differs significantly from a predominant Western viewpoint, which maintains that either language or the ability to use tools marks the difference. This Western viewpoint emphasizes the importance of scientific knowledge and technological skills deemphasized by Confucianism. In fact as has been argued by Gale (2005), Confucianism is principally a moral philosophy and places the moral life above all other aspects of human activities. For Confucians the ultimate value of human activities depends solely on their contribution or lack of a contribution to the good moral life of humanity (ren). In other words, apart from its contribution to the good moral life, an activity does not possess any value. This moral view has been subjected to narrow interpretations and at times has devalued science and technology. (section: Applications to Science, Technology, and Ethics ) 
In this configuration of beliefs, there was no intrinsic motivation for people to become scientists or engineers in ancient China, since a person's virtuous reputation rather than skills - including scientific and technical skills - enables the person to be accepted and respected in the society. In fact, in ancient China, the social status of artisans was low, only slightly above that of thieves and prostitutes.

Confucianism strongly supports the division of classes and highlights the idea of people's subordination to the ruling class and obedience to the authority. Confucianism argues that a polite, ethical, and harmonious society is also a hierarchical one. It acknowledges and promotes the hierarchical order of heaven (Tian/天), earth (Di/地), emperor (Jun/君), parents (Qin/亲), and teachers (Shi/师). This means that a person should show his or her ultimate respect first to heaven, second to the earth, third to the emperor, fourth to parents, and fifth to teachers. Because of the abstractness of heaven and earth, the practices of respecting the other three were applied most prevalently. For example, in ancient China, a well-accepted practice was that if the emperor wanted a person to die, the person should commit suicide, which is directly captured by the Chinese phrase, “Jun Yao Chen Si, Chen Bu De Bu Si/君要臣死，臣不得不死.” In general, it was a citizen's responsibility to cater to his or her emperor, through abiding by the emperor's wishes. Besides being subservient to the emperor, Confucianism also promotes the hierarchical relationship between children and parents, which I will explain in detail in Chapter Three. Moreover, the emperor is more important than parents. Thus, when a conflict arises between serving the emperor and taking care of parents, a virtuous person should put the interests of the emperor first, as indicated by the sequence of the 
fifteen virtues in which loyalty precedes filiality. The relationship between students and teachers was rigidly hierarchical such that it was intolerable if a student disrespected his teachers in any way, for example, by questioning teachers, defying teachers' instructions, dressing inappropriately, and behaving poorly in front of teachers. Thereby, it was unacceptable for students to question their teachers' ideas and challenge their teachers' authority since they were expected to accept their teachers' instruction uncritically.

Consequently, in ancient China, since emperors emphasized cultivating their citizens' morality instead of developing science and technology, most ancient Chinese people were educated to follow emperors' instructions to work hard to satisfy emperors, and they did not emphasize STEM learning or crafting scientific and technical skills. Moreover, the relationship between students and teachers in ancient China deprived many people of opportunities to develop the spirit of critical thinking, bold conjecture, and an inclination to challenge existing theory, which are crucial for doing research in science and technology.

Moreover, although Confucianism emphasizes education, it merely emphasizes education in humanities. Confucianism argues that people should "pursue... high ideals [such as human relations, and human nature] ...[and] should not concern oneself with mere tools — concrete, practical, technical problems, and knowledge" (Kim, 2010, p. 210) . In other words, compared with scientific and technological knowledge, people should focus on scholarship in the humanities such as philosophy and literature.

In ancient China, education primarily was based on the nine Confucian books that were known as four books and five classics: Great Learning (Da Xue/大学), Doctrine of 
The Mean (Zhong Yong/中庸), The Analects of Confucianism (Lun Yu/论语), Mencius (Meng Zi/孟子), The Classic of Poetry (Shi Jing/诗经), The Book of Document (Shang Shu/尚书), The Book of Rites (Li Ji/礼记), The Book of Changes (Yi Jing/易经), and The Spring and Autumn Annals (Chun Qiu/春秋). Great Learning instructs people on how to improve themselves ethically and thus make society a better place. It is regarded as a selfhelp book through which people learn why and how to become a person of high morals. Doctrine of The Mean explains and promotes morality, arguing that it is the raw substance of the Dao. The Analects of Confucianism records conversations between Confucius and his students that best represent Confucius's thoughts on humanities such as social relations, while Mencius is a collection of anecdotes and conversations centered on Mencius concerning moral philosophy. Classic of Poetry is a collection of 305 poems that were composed between $11 \mathrm{BC}$ to $6 \mathrm{BC}$ that offers insight into the birth and development of literature in Chinese civilization. The Book of Document is a collection of rhetorical prose. It includes many speeches made by major figures in the eras from Yu the Great, to the Xia Dynasty, Shang Dynasty, and Zhou Dynasty. Book of Rites is a collection of texts concerning the social forms, administration, ceremonies, rites, etiquettes, and so forth. Due to the Confucian emphasis on $\mathrm{Li}$, which can be understood as good and polite rules of conduct, Book of Rite, whose Chinese name is $L i J i$, is a very important book. Book of Rites argues that we should believe in the absolute positive power of " $\mathrm{Li}$ " for people and a society and to this end aims to promote a restoration of traditional rites and practices that had been lost throughout history. Book of Changes, also known as The I Ching, is a book of philosophy. This book introduces hexagram (gua), 
which can be understood as an essential unit of change. This book argues that through studying the 64 different hexagrams, people can understand the process of change and predict the future. The Spring and Autumn Annals is a book of history. It focuses on the time period from the year from 722 to $481 \mathrm{BC}$ and offers a chronicle of the State of $\mathrm{Lu}$, the state in which Confucius and most of his students were born. It records many events that occurred in the State of Lu during each year such as marriages, deaths, and wars.

These nine books were the primary sources from which ancient Chinese people obtained their knowledge. However, none of these nine books are particularly related to science and technology. ${ }^{13}$ Furthermore, exams in ancient China were composed primarily based on the nine Confucian books. These exams typically included several types of questions such as asking students to interpret sentences and paragraphs from the nine books, to provide solutions for political problems using Confucian ideas, and to craft arguments by quoting and paraphrasing sentences from the nine books. To pass exams was significant for ancient Chinese students because it was only through passing exams and becoming a Jun Ren that one would be respected, recognized as a scholar, and win candidacy to work for the government. ${ }^{14}$ Thus, for most students in ancient China,

\footnotetext{
${ }^{13}$ Here I want to add a note of clarification. Although these nine books are not specialized books on science and technology, some of these books do include minor insights regarding science and technology. For example, in $\mathrm{Li} J$ “commentaries on the 'Yueling'月令 ( Monthly Ordinances)...contained discussions of specialized knowledge in the calendrical astronomy" (Kim, 2010, p.213). Moreover, in ancient China, there were other books that center on scientific and technological knowledge such as Astronomical Compilations from the Six Classics and Essential Techniques for Common People. However, these books were not as popular as the nine Confucian books and primarily served the purposes of personal interest and recreation.

${ }^{14}$ Jun Ren (举人): a rank achieved by people who successfully passed the triennial provincial exam in ancient China. It was a rank higher than the rank of XiuCai (秀才) achieved by people who successfully passed the entry-level exam, but lower than the rank of Jin Shi (进士) achieved by people who successfully passed the triennial court exam.
} 
studying science and technology was not necessary and would potentially distract them from preparing for exams. Due to the predominance of the nine Confucian books as the main source of knowledge and the exam system in ancient China, "the intellectual, and social, status of the specialized scientific and technical knowledge [was subordinated]" (Kim, 2010, p. 225).

Due to the embeddedness of Confucianism in Chinese culture in the past thousands of years, some of its ideas still matter profoundly in contemporary China. Two persistent ideas are people's subordination and obedience to the government and to authority, and the emphasis on education, which in the era of reforms are re-articulated with other elements such as the Chinese government's emphasis on science and technology, resulting in the rapid scientific and technological development.

In line with Confucian traditions, in contemporary China, for many Chinese people, the government is sacred. This high esteem for the government is reflected in the ferocious competition in China's national examination for admissions to civil service. For example, the Guangdong Meteorological Service planned to recruit 1 employee; however, 4040 people applied for this job opening when registering for the national exam (National Public Servant, 2018). Many Chinese people want to work for the government even though they might get higher salaries if they work for industry, because it is believed that working for the government means having "a golden bowl," which means that the job can offer a decent salary, but more importantly, social respect. Due to the high status of government in Chinese culture, many Chinese people are inclined to follow the government's policies without question. For example, as mentioned in the Chapter One, 
in the era of reforms, when the government has focused on developing science and technology, many Chinese people have devoted themselves to the fields of STEM. Moreover, Chinese children are educated to respect authority from a young age. In Chinese elementary schools, it is a common practice that a student should raise his or her left hand to wait until called on and approved by his or her teachers to answer a question, or even to go to the bathroom. If a student fails to conform to this practice, the student will be criticized as being impolite and unruly, which are grounds for punishment, even corporeal punishment. This education reinforces the Chinese people's subordination to their leaders and the government.

Moreover, education is still tremendously emphasized in contemporary China. For example, even the New York Times Magazine reported on the famous Chinese high school “Mao Tan Chang Zhong Xue/毛坦厂中学”, which was nicknamed as the biggest test-prep factory in Asia (Larmer, 2014). This school recruits more than 20,000 students annually and specializes at preparing students for the national college entrance examination through training students to almost machine-like in their accuracy and efficiency at answering exam questions. This school and other test-prep "factories" are popular in China because college education matters tremendously in Chinese society. This prioritization is evidenced by the fact that it is legitimate for parents to quit their jobs to take care of their children who are preparing for the exam and to compel drivers to stop honking on exam days to avoid distracting students from answering questions. This strong emphasis on education resulted in the rapid development of humanities in ancient China and of science and technology in contemporary China when the focus 
shifted from humanities education to STEM education, which I will explain in more detail later in this chapter.

Besides Confucianism, Daoism, also known as Taoism, also significantly affects the status of science and technology in the era of reforms. To better understand the impacts of Daoism, I must first explain the distinction between Daoism as a school of intellectual thought and as a religion. In fact, in Chinese, Daoism as a school of intellectual thought is written as “道家,” and Daoism as a religion is written as “道教.” However, the English conflation of these two phrases into the same word "Daoism" blurs significant differences including perspectives on science and technology.

Similar to Confucianism, Daoism, which was forwarded and developed by several thinkers such as Lao Tze and Chuang Tze, initially emerged as a school of intellectual thought. As a school of intellectual thought, the essence of its ideas "can be summarized into one phrase 'returning to nature"' (Fung, 1922, p. 241). Daoism argues that people should let things work out by themselves and in their own ways and, further, people should concentrate on their essentially good nature, should be satisfied with the current moment whether it is good or not, and should be able to find happiness through focusing on inner peace in their hearts. Accordingly, Daoism contends that "knowledge is of no use and can do only harm: 'Our life is limited, but knowledge is not limited. With what is limited to pursue what is not limited is a perilous thing" (Fung, 1922, p. 243). Moreover, Daoism as a school of thought views technology as a corrupting evil power that can lead 
to moral degradation, as indicated by the phrase “machine heart/ji Xin/机心." ${ }^{15}$ Although

this phrase still exists in contemporary China, it is seldom used.

In contemporary China, Daoism is recognized predominantly as a religion rather

than a school of intellectual thought. According to the website of China's National

Religious Affair Administration, the five most widely practiced religions in China are

Buddhism, Daoism, Islamism, Catholicism, and Protestantism ("National Religious").

Daoism as a religion emerged in the Han Dynasty and was developed based on its origin

as a school of intellectual thought. For instance, the most preeminent God in the Daoist

religion is Tai Shang Lao Jun/太上老君, who is the mythified Lao Tze一 the founder of

the Daoist school of intellectual thought. Tao Te Ching, which is one of the first and the

\footnotetext{
${ }^{15}$ This phrase comes from a story in Chuang Tze, which is one of the most important books in Daoism. The story is about:
}

Zigong traveled south to Chu, and on his way back through Jin, as he passed along the south bank of the Han, he saw an old man preparing his fields for planting. He had hollowed out an opening by which he entered the well and from which he emerged, lugging a pitcher, which he carried out to water the fields. Grunting and puffing, he used up a great deal of energy and produced very little result.

"There is a machine for this sort of thing," said Zigong. "In one day it can water a hundred fields, demanding very little effort and producing excellent results. Wouldn't you like one?"

The gardener raised his head and looked at Zigong. "How does it work?"

"It's a contraption made by shaping a piece of wood. The back end is heavy and the front end light and it raises the water as though it were pouring it out, so fast that it seems to boil right over! It's called a well sweep."

The gardener flushed with anger and then said with a laugh, "I've heard my teacher say, where there are machines, there are bound to be machine worries; where there are machine worries, there are bound to be machine hearts. With a machine heart in your breast, you've spoiled what was pure and simple; and without the pure and simple, the life of the spirit knows no rest. Where the life of the spirit knows no rest, the Way will cease to buoy you up. It's not that I don't know about your machine - I would be ashamed to use it!"

Tzu-kung blushed with chagrin, looked down, and made no reply.

(Zhangzi, 2013, pp.90-91) 
classic texts of Daoism as the school of intellectual thought, also became the classic book of the Daoist religion.

However, there are some significant differences between Daoism as a school of intellectual thought and as a religion. As I discussed previously, the Daoist school of intellectual thought emphasizes returning to nature and not intervening with the natural developments of things. However, Daoism as a religion focuses on pursuing and practicing immortality. This shift of focus in part is caused by the foundation of Confucianism as the only orthodox school of intellectual thought in ancient China. Thus, Daoism, in order to co-exist with Confucianism and attract followers, had to evolve continuously. Finding ways to avoid death and become immortal is a key focus of the Daoist religion to serve an essential need of many people, that is to be immortal and maintain their youth and health forever. In short, "[D]aoism as a philosophy teaches the doctrine of following nature, while $[\mathrm{D}] \mathrm{aoism}$ as a religion teaches the doctrine of working against nature" (Fung, 1948, p. 3).

This focus of the Daoist religion leads to an emphasis on developing science and technology. For example, the Daoist religion is famous for making alchemy, which significantly contributed to the emergence of gunpowder, one of the four greatest scientific and technological achievements in ancient China. Many Daoist priests who devoted themselves to making pills to avoid death were famous doctors, such as Sun Simiao/孙思激 who is the respected as “the God of Doctors" in China. His book Thousand Golden Prescriptions/Qian Jin Yao Fang/千金要方, which records his ideas on how to treat many diseases, is still used in contemporary China. Ma Danyang, another 
Daoist priest, is also recognized as an exceptional doctor because of his contribution to the science of acupuncture and moxibustion. ${ }^{16}$ Moreover, the Daoist religion also profoundly influenced astronomy in ancient China. Because the ultimate goal of practicing Daoism is to become a god, many Daoist priests, such as He Hong in the Wei Jin Southern and Northern Dynasties, studied astronomy in order to understand earth and the galaxy. Fung (1948) points out that "the [D]aoist religion has the spirit of science, which is the conquering of nature" (p.3).

Some scholars argue that Confucianism and Daoism had significantly hindered the development of science and technology. For example, Gong (2012) claims that Confucianism and Daoism together "have discouraged curiosity, commercialization and technology. They helped to produce a scientific void in Chinese society that persisted for millennia" (p. 411). However, this viewpoint overlooks some notable historical developments. In fact, as I analyzed previously, Confucianism and Daoism, especially the Daoist religion, contributed to some scientific and technological achievements in ancient China. More importantly, some of their commitments, such as the importance of receiving education and figuring out ways to be immortal, which are also active in contemporary China, have strongly affected impacted the status of science and technology in the era of reforms.

\footnotetext{
${ }^{16}$ Moxibustion is a traditional Chinese therapy, in which some herbs, the most typical one is dried mugwort, are burnt so that their heat and smell can be applied to some specific points of the body. It is believed that moxibustion can reduce pain and stimulate people's immune systems.
} 


\section{The Westernization Movement and the New Culture Movement}

The Westernization Movement and the New Culture Movement were two influential social, cultural, and political movements in modern China (1840-1949) that aimed to promote science and technology, and have profoundly impacted the status of science and technology in the era of reforms. The currents of the Westernization Movement emerged in the 1840s. In 1842, the year in which the First Opium War ended with China's complete defeat, the book of Illustrated Annals of Oversea Countries/Hai Guo Tu Zhi/ 海国图志 was published. This book was written by Wei Yuan (魏源), the prefect of Gaoyou District, who participated in the First Opium War in the frontlines, witnessing the power of Western technologies, especially weapons. He argued that Chinese people must open their eyes to see what is happening in the world. Illustrated Annals of Oversea Countries documents Western countries' science and technology, political systems, cultures, histories, religions, education, trades, geographies, and so forth. In the preface, Wei Yuan writes that the purpose of the book is to help Chinese people to learn from the West and puts forward the famous argument that Chinese people should learn from foreign countries in order to fight against and surpass them (Shi Yi Chang Ji Yi Zhi Yi/师夷长技以制夷).

Wei Yuan's book enforced the growing argument that China must learn from the West. Facing the situation that China was under pressure of further foreign aggression and internal social turmoil, some high ranking officials of the Qing government supported this argument and urged the government to accept Western ideas and practices, especially those related to developing science and technology. Zeng Guofan, Zuo 
Zongtang, and Li Hongzhang launched the Westernization Movement (Yang Wu Yun Dong/洋务运动), also known as the Self-Strengthen Movement, in 1861. The ultimate purpose of the movement was to use Western scientific and technological knowledge to maintain the rule of the Qing government. The slogan of this movement was "Chinese learning should be followed as the essence; Western learning is for use" (Zhong Xue Wei Ti, Xi Xue Wei Yong/中学为本西学为用). To face the danger of over-simplification, this means that Confucianism should still remain the dominant ideology, but advanced science and technology should be imported from the West to solve practical problems. This was a process of dis-articulation and articulation: the emphasis on valuing humanities exclusively was disarticulated from Confucianism while Western science and technology were articulated with Confucianism. The Qin government and many Chinese intellectuals believed that this new articulation could make the country prosperous.

In general, the Westernization Movement emphasized introducing and applying science and technology from the West to industrialize China. In practice, the Qing government focused on learning advanced scientific theories such as optics, bringing in new technological devices such as guns, and promoting education in STEM. The Qing government opened several big factories such the Tianjin Machine factory and Jiangnan Arsenal. The Qing government also sent Chinese students to learn in the West, primarily in the fields of STEM. On August 11, 1872, the first group of Chinese students to study abroad left Shanghai for the U.S. From 1872 to 1875 , the Qing government sent 120 Chinese students ranging in age from 10 to 16 to study in the U.S. Many of these students who studied in elite U.S. universities such Harvard and Yale became prominent scientists 
and engineers upon their return to China. For example, the father of China's railroad, Zhan Tianyou, known in the West as Jeme Tien Yow, was among these students. The Qing government also established schools specializing in STEM education. For instance, for the purpose of building a strong and modern navy, the Qing government set up the Foochow Shipbuilding College. McNeill, Li, and Wang (2010) explain the structure and the curriculum of the Foochow Shipping College:

Foochow Shipbuilding College started with two departments, or divisions. The first division, or Qian Xue Tang (literally “forward school”, 前学堂) trained students in the design and manufacture of battleships, while the second division, or Hou Xue Tang (literally “rear school”, 后学堂) trained students in navigation and ship maintenance. This second division was developed essentially for the training of naval officers.

Table 1. The course of the Qian Xue Tang

\begin{tabular}{|l|l|}
\hline Foreign language & $\begin{array}{l}\text { French (all the textbooks were in French), } \\
\text { English }\end{array}$ \\
\hline Basic sciences & $\begin{array}{l}\text { Arithmetic, trigonometry, analytic geometry, } \\
\text { calculus, physics and mechanics }\end{array}$ \\
\hline Major courses & $\begin{array}{l}\text { Engineering Cartography; the manufacture and } \\
\text { structure of steam engines; manufacturing of } \\
\text { ship hulls }\end{array}$ \\
\hline
\end{tabular}

(pp. 15. 635.8-15.635.9) 
As revealed by its curriculum, there was no other training in humanities besides the two language courses that were designed to help students to better understand science and technology for Western countries.

The Westernization Movement did not successfully prevent China from being invaded and the Qing government from being overthrown. In 1895, the Qing navy was defeated by the Japanese navy in the first Sino-Japanese War, which was viewed as a failure of the Westernization Movement. In 1912, the Qing government was overthrown and the Republic of China was founded. Despite its failure, the Westernization Movement was the first movement in China that introduced a large volume of scientific and technological knowledge from the West. Furthermore, I maintain, as an effect of the Westernization Movement, the belief that science and technology are powerful and capable of bringing positive changes, became widely acknowledged and influential in Chinese culture.

This faith in science and technology continued to grow in the Republic of China and contributed to the establishment of the New Culture Movement. On January 15, 1915, Chen Duxiu, one of the most influential scholars who received education in Japan - a country that was further ahead in terms of Westernization — and who in 1917 became the dean of Peking University - the best Chinese university in the fields of humanities, published "My Response to the Criticism" in the journal New Youth /Xin Qing Nian/新青年. This journal focused on criticizing traditional Chinese culture, especially Confucianism, and promoting Western ideas. Chen (1919) wrote: 
Westerners fight hard for Mr. Democracy and Mr. Science. However, [their efforts are worthwhile] because Mr. Democracy (De) and Mr. Science (Sai) saved Westerners from the darkness. In fact, only Mr. Democracy and Mr. Science can save Chinese politics, moral system, academics, and ideology from darkness and evil.

Chen's article was widely read and supported. “For Mr. Democracy/德先生 and Mr. Science/赛先生” became the slogan of the New Culture Movement.

The New Culture Movement (Xin Wen Hua Yun Dong/新文化运动) began around 1916, reached its height in 1919, and continued through the 1920s. This movement was anti-imperialist, cultural, and political. On May 4, 1919, because of the Republic of China's government's acceptance of the Treaty of Versailles, college students in Peking refused to attend schools and marched in the streets. ${ }^{17}$ Accordingly, the New Culture Movement is also known as the May Fourth Movement. In the following days, students from the rest of the China as well as Chinese people in different occupations and from different classes participated in the protest. For example, many workers refused to go to factories and many businesspersons refused to run their businesses.

In general, the New Culture Movement argued that China's current backward politics, culture, and social practices should be abolished. This movement advocated for restoring China's integrity, replacing the emphasis on learning Confucianism with

\footnotetext{
17 The Treaty of Versailles was the peace treaty which brought the World War Ito an end. During World War I, China helped the U.K. to fight against the Germans. However, this treaty awarded China's Shandong Province to Japan.
} 
learning Western science and technology, using vernacular Chinese (Bai Hua Wen/白话 文) to replace classical Chinese (Wen Yan Wen/文言文) in order to increase literacy, and creating a democratic political system. Compared with the Westernization Movement, which still viewed Chinese knowledge, such as Confucianism, as the essence of Chinese culture and society, the New Culture Movement was determined to completely disarticulate Confucianism from Chinese culture and infuse China with Western science and technology and its democratic political system.

As evidenced in the Westernization Movement and the New Culture Movement, three ideas have become articulated to the status of science and technology in Chinese culture. The first idea is that Western countries and Western cultures are more advanced and civilized than their Chinese counterparts. This idea has resulted in the prevalence of beliefs in Chinese society that only Western countries are able to master advanced scientific knowledge and develop innovative technological artifacts for decades. The second idea is that a key cause of China's backwardness is the underdevelopment of science and technology, which have the potential to bring positive social changes, resulting in the veneration of science and technology in Chinese culture. The third idea that has taken root is that the development of science and technology must first serve the Chinese government's political purposes, given the continuing articulation of Confucianism in promoting the superior status of the government over the people, as discussed previously. Recall, the driving force behind the Qing government's support of the Westernization Movement was to avoid being overthrown. Similarly, the Republic of 
China's plans for developing science and technology were highly political. Kirby (1989) writes:

Industrialization became a primary concern for the government of Chiang Kaishek, which depended on the modern sector of the economy for much of its income, and sought security through creation of a world-class armed force supported by state-of-the-art metallurgical, chemical, and munitions industries. (p. 25)

In this way, the emphasis of the government of Chiang Kaishek on metallurgical, chemical, and munitions industries can be largely attributed to the government's insecurity after witnessing the Japanese government's determination and ability to invade China. Although both the Westernization Movement and the New Culture Movement ended, their intellectual heritage, especially the value placed on developing science and technology, persists in contemporary China.

\section{The Chinese Cultural Tradition of Numeracy}

Besides myth, Confucianism and Daoism, the Westernization Movement and the New Culture Movement, the Chinese cultural tradition of numeracy also has significantly contributed to the high status of science and technology in Chinese culture. Numbers are important in Chinese culture. The Nine Chapters on the Mathematical Arts/九章算术， which was composed by several Chinese mathematicians from the 10th to 12 th century, is one of the most ancient but influential books in terms of studying numbers. This book, which used to serve as a textbook both in China and in some other countries, is 
recognized as evidence of ancient Chinese people's talent in quantitative studies. Moreover, “the nine-nine song/九九乘法口诀表,” which is a song about multiplication, has been passed down for almost two thousand years. Below is my translation of "the nine-nine song" based on its Chinese text:

- 一一得一 (one times one gets one)

- 一二得二 (one times two gets two) 二二得四 (two times two gets four)

- 一三得三 (one times three gets three) 二三得六 (two times three gets six)

三三得九 (three times three gets nine)

- 一四得四 (one times four gets four) 二四得八 (two times four gets eight) 三四十二 (three times four gets twelve) 四四十六 (four times four gets sixteen)

- 一五得五 (one times five gets five) 二五一十 (two times five gets ten) 三五十五 (three times five gets fifteen) 四五二十 (four times five gets twenty) 五五二十五 (five times five gets twenty-five)

- 一六得六 (one times six gets six) 二六十二 (two times six gets twelve) 三六十八 (three times six gets eighteen) 四六二十四 (four times six gets twenty-four) 五六三十 (five times six gets thirty) 六六三十六 (six times six gets thirty-six) 
- 一七得七 (one times seven gets seven) 二七十四 (two times seven gets

fourteen) 三七二十一 (three times seven gets twenty-one)

四七二十八 (four times seven gets twenty-eight)

五七三十五(five times seven gets thirty-five) 六七四十二 (six times seven

gets forty-two)

七七四十九 (seven times seven gets forty-nine)

- 一八得八 (one times eight gets eight) 二八十六 (two times eight gets sixteen) 三八二十四 (three times eight gets twenty-four) 四八三十二 (four times eight gets thirty-two) 五八四十 (five times eight gets forty)

六八四十八 (six times eight gets forty-eight)

七八五十六 (seven times eight gets fifty-six) 八八六十四 (eight times eight gets sixty-four)

- 一九得九 (one times nine gets nine) 二九十八 (two times nine gets eighteen) 三九二十七 (three times nine gets twenty-seven) 四九三十六 (four times nine get thirty-six) 五九四十五 (five times nine gets forty-five) 六九五十四 (six times nine gets fifty-four) (seven times nine gets sixty-three) 八九七十二 (eight times nine gets seventy-two) 九九八十一 (nine times nine gets eighty-one) 
This song remains one of the most popular nursery rhymes in contemporary China. Generations of Chinese children grow up listening to this song and many of them even have memorized it before they enter elementary school. In this way, Chinese people have begun to build a mathematical approach to understand numbers since they are young.

Building on this attachment, there is also a long tradition in China of interpreting numbers from a cultural perspective. Since ancient China, Chinese people have assigned special connotations to numbers. For example:

The number 0 refers to the beginning of all things. It is usually regarded as an auspicious number because of its round shape. However, since some Chinese people believe that 0 can refer to nothing, its valence becomes negative when it is the final digit of a number (for example 870 and 560). There are mixed and contradictory associations with the number 1. It can refer to the winners of the first place in a competition; but at the same time, it can refer to singlehood. The number 2 is usually regarded as a good number because it refers to companionship. There is a Chinese proverb "good things come in pairs/hao shi cheng shuang /好事成双.” For some Chinese people, the number 3, which sounds like "sheng/life or to live," is a good number. However, for some Chinese people with a different dialect, this number sounds like "san/ separation," which makes it an inauspicious number. The number 4 is viewed as a bad number because it sounds like "si/ death." The number 5 is associated with "not" or "lacking" because it sounds like "wu/ do not have." The number 6 is an auspicious number because it sounds similar to "liu/smooth/success," and "lu/happiness, and prosperity." There are mixed and contradictory associations with the number 7 . This number sounds like "qi/arise/rising 
up," thus some people believe that it is a good one. However, because July is the ghost month in the Chinese lunar calendar, some people think this number is inauspicious. ${ }^{18}$ The number 8 is another auspicious number because it sounds like "fa/being rich and prosperous." Thus, it is the number that many Chinese businesspersons favor most. The number 9 is often used in weddings because it sounds like "jiu/ lasting forever." Moreover, because in ancient China this number was also associated with the emperors, it is also regarded as a royal number.

From ancient to contemporary China, Chinese people continue to have preferences regarding some numbers. For example, almost all Chinese telecoms companies and DMVs mark phone and car numbers that include several auspicious numbers (such as 666888) as special ones and sell them for large sums of money.

Due to Chinese people's fascination with numbers, it is a common practice that people use numbers to represent and evaluate lived experiences. In 2015, there was a very popular competition in China. The competition was about the numbers of coins people could hold with their collarbones. Many Chinese people zealously participated: they put coins on their collarbones, took selfies, uploaded the selfies to social media, and competed with others concerning the number of coins. Below is a representative photo:

\footnotetext{
${ }^{18}$ In Chinese culture, it is believed that during the ghost month, ghosts can leave hell and wander around on earth.
} 


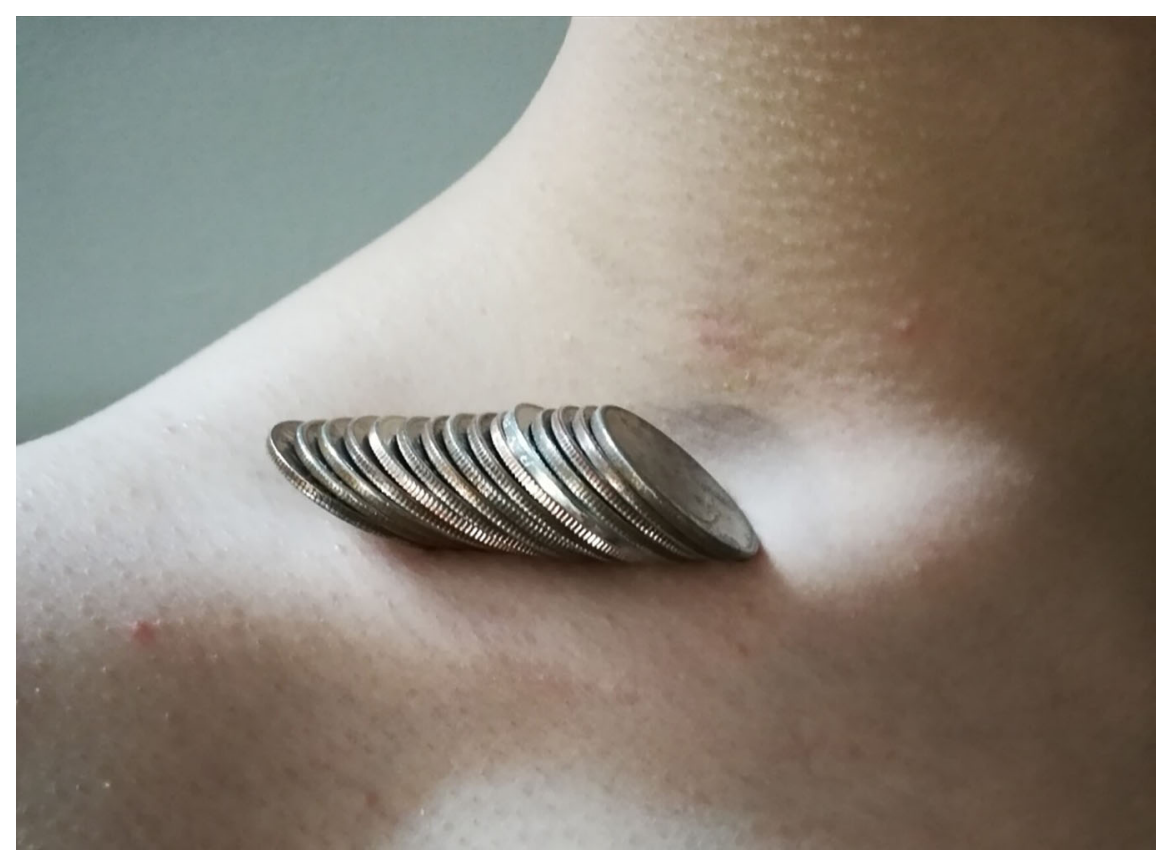

Figure 2. 2 A Collarbone Holds Coins. This photo was taken by the author.

Basically, people perceived having more coins as more valued and closer to the ideal. This competition not only reflected Chinese people's appreciation of a slender body but also their obsession with quantifying and evaluating merely based on numbers. It was astonishing that millions of Chinese people were willing to use numbers of coins to represent their bodies, to believe that more coins better represent the "ideal body," and to reduce the worth of their bodies to this metric.

In almost every aspect of Chinese people's lives, numbers are applied for the purposes of representation and evaluation. For example, the Chinese government uses GDP per capita to evaluate Chinese people's quality of life; the Chinese government believes that the higher the GDP per capita, the happier Chinese people are. In terms of evaluating intellectual performance, Chinese people look at grades, the ranking of universities, and the numbers of journal articles published. It is common that job 
openings in Chinese universities require their applicants to graduate from the top 250 or 300 universities based on QS World University Ranking system and to have published at least 3 journal articles that, combined, must exceed certain impact factors. In fact, when the 2018 Science and Engineering (S\&E) Indicators announced that China had overtaken the U.S. with the highest number of publications in S\&E, many Chinese people became extremely excited (National Science Foundation, 2018). Many media outlets subsequently released news reports that celebrated Chinese people's impressive intellectual performance. For example, on February 3, 2018, Sina, which is one of the most popular websites in China, published an article titled "The Rise of a Superpower: The Number of Chinese Articles in Science and Engineering Surpasses the Number of U.S. Articles in S\&E and Ranks the Highest Worldwide." Chinese people were proud of the number of journal articles they published even though some Chinese people are clear that many Chinese journal articles are of low quality and significance.

The popularity of a Chinese counselor Ayawawa also reflects many Chinese people's obsession with numbers and quantification. Ayawawa is famous for developing a theory, which centers on two terms MV and PU, to help women attract partners. MV stands for mating value and PU stands for paternity uncertainty. Ayawawa argues that an attractive woman should have a high MV, which means that she should be beautiful and young, and have a lower value of PU, which means that she should be submissive to avoid generating her partner's anxieties. In essence, Ayawawa's theory quantifies women and reduces them into some numbers. 
The tradition of numeracy in China significantly contributes to the flourishing of an epistemology that centers on quantification of human beings and their lived experiences. This epistemology prioritizes understanding and evaluation based on numbers at the expense of accounting for elements that elude numeric representation such as people's feelings. This epistemology potentially inspires the development of science and technology in China in accordance with Chinese people's inclination to understand the world "truthfully" based on "accurate" quantifications and representations. For example, the Sesame Credit/Zhi Ma Xin Yong/芝麻信用, which was developed by Ant Financial Service Group, is very popular in China. The Sesame Credit can score its customers from five perspectives: personal credit records, social behaviors, capabilities to fulfill contracts, identities (such as jobs), and connections. The higher the scores people get, the more benefits they can enjoy, such as renting cars and apartments without paying for deposits, because it is believed that high-scored persons are more trustworthy and probably are "better" citizens.

\section{The Discrepancy between the Needs of the Large Chinese Population and the Country's Inadequate Capacity for \\ Production}

The previous sections discussed myth, Confucianism and Daoism, the Westernization Movement and the New Culture Movement, and the Chinese tradition of numeracy. This section explores another important force that has profoundly impacted 
the status of science and technology in the era of reforms. This force-the discrepancy between the needs of the large population and the country's inadequate capacity for production —not only has captured my attention but also has been of interest to the Chinese government. The Sixth Plenary Session of the $11^{\text {th }}$ Central Committee of the Communist Party of China (1981) published the fundamental document "Resolution on Certain Questions in the History of Our Party since the Founding of the People's Republic of China." In this document, the Chinese government both reflected on and confessed the mistakes it had made during the Cultural Revolution and pointed out that "the principal contradiction our country has had to resolve is that between the growing material and cultural needs of the people and the backwardness of social production" (The Six Plenary Session, 1981). In fact, since ancient times, Chinese society has always struggled with the discrepancy between the needs of the large Chinese population and the country's inadequate capacity for production. To put it simply, a significant issue that Chinese society has faced is how to feed, cloth, house, and transport so many people. This discrepancy not only has led to widespread social turmoil in China, such as people's rebellions against governments and the overthrown of governances, but also has closely related to the development of science and technology. To explain this argument, I pay special attention to the issue of food supply and housing.

For Chinese people, their most basic need is to have a sufficient food supply. Although every culture cares about eating, Chinese culture uniquely emphasizes food because of the frequency and severity of famine. $\operatorname{Li}(1982)$ recorded severe national famines in modern and contemporary China: 
The North China famine of 1876 to 1879 , one of the great mortality crises in world history, was caused by a drought that extended over five provinces, affecting a population of over 100 million people and leaving an estimated 9.5 to 13 million dead. [...] Between 1928 and 1931, northern China was once again struck by a major drought that affected a population of 57 million, 12 million of them "gravely." (pp. 687-688)

Moreover, from 1959-1961, because of drought, floods, and the Great Leap Forward Movement, about 30 million Chinese people died from starvation (Smil, 1999, p. 1619). Besides the three national famines that Li discussed, other regional famines also happened. For example, another severe food crisis happened from 1920 to 1921 in north China, resulting in famine-related deaths for an estimated 5 million people (Fuller, n.d.). Many Chinese people have suffered during famines. For example, Branigan (2013) recorded Chinese people's experiences in the Great Chinese Famine, which happened from 1959 to1961:

People died in the family and they didn't bury the person because they could still collect their food rations; they kept the bodies in bed and covered them up and the corpses were eaten by mice. People ate corpses and fought for the bodies. In Gansu they killed outsiders; people told me strangers passed through and they killed and ate them. And they ate their own children. (para. 8)

Due to these severe famines, Chinese culture is infused with people's anxiety about food shortages. For example, a typical way for Chinese people to greet each other is to ask the question “Have you eaten?” (Ni Chi Le Ma/你吃了吗?). The famous Chinese saying 
“Food is everything/Min Yi Shi Wei Tian (民以食为天)" reflects Chinese people's prioritization of food.

To solve the issue of starvation, the Chinese government has put forward many policies, which have aimed to promote an equal distribution of the limited resources. For example, from the 1950 s to the 1980 s, the Chinese government implemented a national food distribution system. The government collected food and distributed it to individual Chinese people based on the size of their families. The government gave Chinese people food stamps (Liang Shi Piao/粮食票). Below are pictures of a rice stamp and a pork stamp:

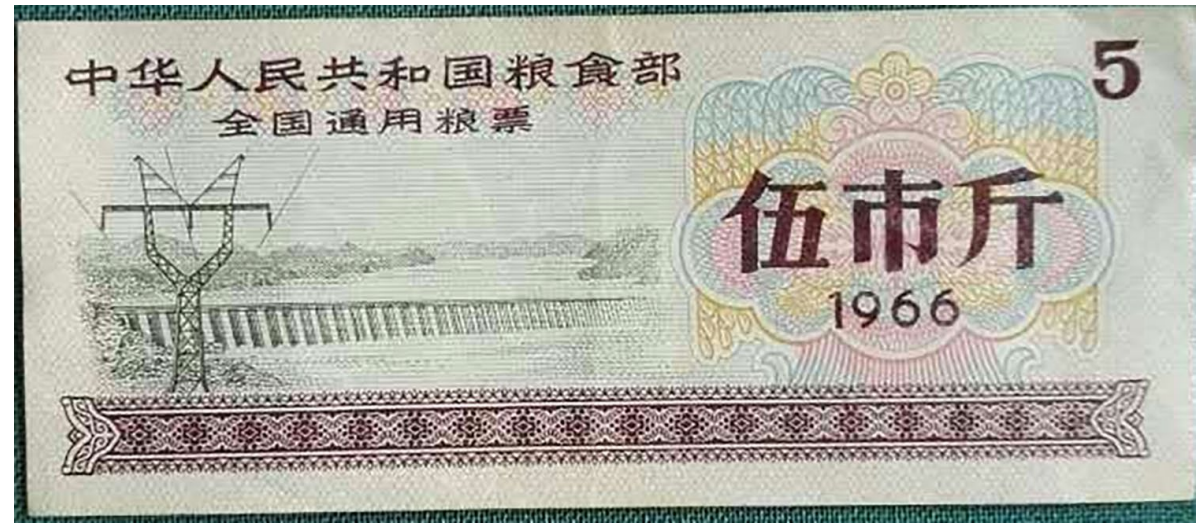

Figure 2. 3 Rice Stamp. This photo was taken by the author. 


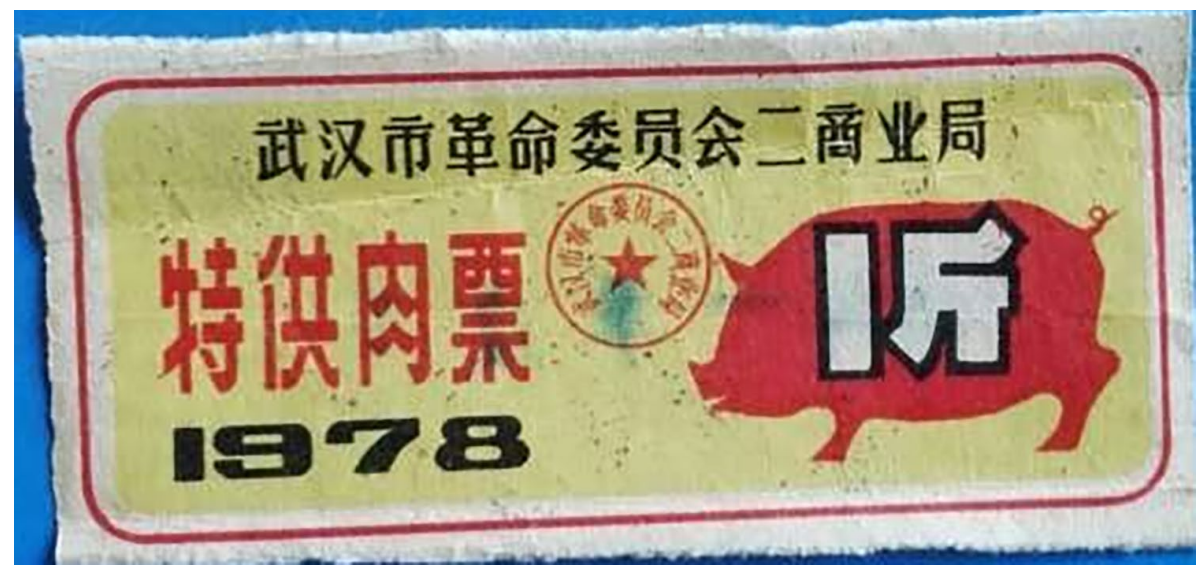

Figure 2. 4 Pork Stamp. This photo was taken by the author.

Although this national distribution system lessened the discrepancy between the sustenance needs of so many people and China's limited capacity of food production through saving some poor Chinese people from dying of starvation, it did not fundamentally resolve this discrepancy. In fact, in 2016, the arable land (per hectares per person) in China was 0.09 ; in contrast, in the U.S. the number was 0.47 and for Canada the number was 1.21 (The World Bank b, n.d.). Facing the unfavorable natural conditions for agriculture and the needs of a large population, it became necessary for Chinese society to develop agricultural science and technologies to improve food production by making full use of every hectare of arable land.

Yuan Longping, a Chinese agricultural scientist, has devoted his career to promoting super hybrid rice that "emphasize[s] the plant morphological improvement and utilize[s] the inter-subspecific heterosis [to increase the yield of rice]" (Ma \& Yuan, 2015 , p. 200). In fact, “by 2003, half of China's rice production area was planted with [Yuan's super hybrid rice] .... [By] 2007, China's total rice yield was 500 million tons" (The World Food Prize, 2008 ). This means that now China's capacity of rice production 
has improved significantly, which results in the reduction of the likelihood of nationwide famine and greatly alleviates Chinese people's fear of starvation. Besides the science and technology of super hybrid rice, farming, breeding, aquaculture, and other agricultural science and technologies also have been developed and are widely used. Accordingly, China has gradually been able to cultivate and harvest more crops, including 38 items such as rice, wheat, and vegetables:

\begin{tabular}{|l|l|}
\hline Year & Amount of Crops (in 1000 tons) \\
\hline 2010 & $33,263.00$ \\
\hline 2000 & $20,431.00$ \\
\hline 1990 & $4,319.00$ \\
\hline 1980 & $2,363.00$ \\
\hline 1970 & 798.00 \\
\hline 1960 & 296.00 \\
\hline
\end{tabular}

Table 2. 1 China Agricultural and Economic Data. Statistics were retrieved from "China Agricultural and Economic Date", USDA, https://data.ers.usda.gov/reports.aspx?ID=17884.

Consequently, China "met its Millennium Development Goal of halving the number of hungry people by 2015 and reduced the global hunger rate by two thirds" (World Food Programme, n.d.).

Besides food supply, the discrepancy between housing the large Chinese population and the country's inadequate productive capacity has also been a serious issue in Chinese society for a long time. Chinese people have always emphasized owning a living space, as evidenced in the Chinese character“家,” which means home. This 
character includes two parts: the upper part “ゆ” refers to shelter, and the lower part “豕” refers to pig. In ancient Chinese culture, it was believed that a home should have a shelter and a pig. However, with the change of Chinese society from an agrarian to a more modern society, many Chinese people no longer believe that a home must include pigs or poultry; however, to this day, most Chinese people still believe that without owning a housing unit, a home is not complete. ${ }^{19}$ There is a popular Chinese song "I want to have a home"/ Wo Xiang You Ge Jia/我想有个家. The lyrics of this song include, “I want to have a home. It doesn't need to be a fancy place...It doesn't need to be a big place.” This song reflects Chinese people's strong affection for their homes and their longing for owning living spaces.

However, because of the large population of Chinese people and the limited space that is suitable for building houses, many Chinese people lived in overcrowded spaces before the 1980s. In 1978, in urban China, the floor area of residential building per capita was $6.7 \mathrm{sq} \mathrm{m}$, and in rural China, it was $8.1 \mathrm{sq} \mathrm{m}$ ( CEIC, n.d.). In contrast, in the U.S., in 1973 the sq ft. per person reached 551 (approximately 51 sqm) ( Perry, 2016). These statistics clearly revealed the sharp contrast between the average Chinese person's living space and the average American's living space in the 1970s.

Facing the situation in which it is impossible for China to expand its geographical borders, the feasible solution to increasing Chinese people's living space is to construct

\footnotetext{
${ }^{19}$ I want to clarify the word "home" ( $\mathrm{Jia}$ ) in Chinese culture. "Home" is regarded as more than the combination of a man, a woman, and children. More significantly, "home" is regarded as the root of a people, a sense of belonging, and the place where people can release all their emotions at ease. Thus, even for people who do not want to get married, they might still want to have homes. Thus, for many single people, if they want to have homes, they choose to buy apartments or houses as well.
} 
tall buildings to make full use of vertical space available, which requires steel. China did not have a steelmaking factory until the opening of Han Yang Tie Chang/汉阳铁厂 in 1890. Given China's low capacity of steelmaking, from November 1957 to December 1958, the Chinese government promoted backyard furnacesand encouraged all Chinese people to participate in steelmaking, a movement that I will explain more later in this chapter. ${ }^{20}$ It was not, however, until the era of reforms that China mastered the science and technology of mass-producing high-quality steel and that the industry of steelmaking began to flourish. According to the World Steel Association (2019), in March 2019, “China's crude steel production... was 80.3 Mt....The US produced 7.8 Mt of crude steel....Japan produced 9.1 Mt of crude steel” (para 3). With the increasing amount of steel available, China has been able to build more skyscrapers, which has contributed to the dramatic increase of China's residential area per capita. In 2017, in urban China, floor area of residential building per capita reached $36 \mathrm{sq} \mathrm{m}$ and, in rural China, it reached 45 sq m, which was almost 6 times the floor area of residential building per capita in 1987 (CEIC, n.d.). Thus, although compared with some other countries such as the U.S., the living spaces for Chinese people are still relatively cramped, their living situations have improved significantly in the era of reforms. The improved availability of living space demonstrates how scientific and technological development has contributed to alleviating the discrepancy between the needs of China's large population and the country's

\footnotetext{
${ }^{20}$ According to Wikipedia, "backyard furnaces (土法炼钢) were small blast furnaces....People used every type of fuel they could to power these furnaces, from coal to the wood of coffins. Where iron ore was unavailable, they melted any steel objects they could get their hands on, including utensils, household objects like chairs and doors, bicycles, and even their own farming equipment, the intended end product being steel girders" ("Backyard Furnaces," n.d.).
} 
inadequate productive capacity. Moreover, this positive change enabled by science and technology reinforces the argument that science and technology are nearly omnipotent and that they should continue to play significant roles with regard to addressing the issue of housing in China.

Besides developing agricultural and architectural science and technologies, other kinds of science and technology have also developed rapidly, driven by Chinese people's needs to survive and live comfortably. For example, China has worked hard on developing and promoting high-speed train and railroad science and technology. This kind of science and technology is crucial since it can profoundly improve the country's capacity of production because it offers more mobility for workers and products in comparison with traditional trains. With the industrialization of some Chinese cities, these cities need more workers. In this context, high-speed train and railroad science and technology provide a comparatively affordable way to Chinese people, especially migrant workers, to leave their hometown and conveniently travel to work in different cities. Moreover, the nationwide high-speed train systems enable products to circulate around the country and even around the worldrapidly at a lower cost in comparison with air travel. ${ }^{21}$ According to The Economist (2017), “[China] ha[d] 20,000 km (12,500 miles) of high-speed rail lines, more than the rest of the world combined. It is planning to lay another 15,000 km by 2025" (para 2). These high-speed rail lines increased China's capacity for transportation and production, bettering many Chinese people's travel

\footnotetext{
${ }^{21}$ For example, China now has several high-speed railroads to some European countries. These railroads are used exclusively for product transportation.
} 
experiences and the efficiency of product transportation. Using science and technology, China has demonstrated its ability to provide for the material needs of its people and is poised to continue doing so.

To understand the status of science and technology in the era of reforms, we need to recognize that the discrepancy between the needs of a large population and China's inadequate capacity of production consistently drives the development of science and technology for the purpose of increasing its productive capacity. In fact, as promoted by the Westernization Movement and the New Culture Movement, which are the two movements that signified the beginning of modern China, the power of science and technology can bring positive changes and solve practical social problems. Because of this faith in science and technology, Chinese society has invested in their development, which has resulted in progress such as the diminished issue of food shortages and Chinese people's improved living spaces. In return, this progress has reinforced the faith in science and technology.

\section{China's Communist Party's Policies}

Apart from myth, Confucianism and Daoism, the Westernization Movement and the New Culture Movement, the Chinese tradition of numeracy, and the discrepancy between the needs of the large Chinese population and the country's inadequate capacity for production, China's Communist Party's policies also have significantly impacted the status of science and technology in the era of reforms. China's Communist Party was founded in 1921. Many of its forefathers (such as Mao Zedong and Li Dazhao) were 
students and intellectuals who had actively engaged in the New Culture Movement. Moreover, some forefathers of the CCP had the experience of studying abroad, notably, Zhou Enlai and Deng Xiaoping. Due to the backgrounds of the CCP's founders and the context of their political power, the CCP emphasizes developing science and technology. In fact, from the first chairman of the PRC Mao Zedong, to Deng Xiaoping, Jiang Zemin, Hu Jintao, and the current Chairman Xi Jinping, all of them have initiated important policies and projects related to science and technology. These policies and projects have driven the development of science and technology, which are viewed by the CCP as powerful tools to solve social, economic, and political problems.

Mao Zedong initiated two significant scientific and technological projects. The first was about mastering nuclear science and making nuclear power and satellites; the second was the national project of "mass science." In 1956, Mao pointed out that if China wanted to protect itself from Western invasions, it must have its own nuclear weapons. In October 1956, Mao approved the development of satellites and nuclear weapons, which resulted in the successful launch of China's first nuclear bomb on June 17, 1967 and its first satellite on April 24, 1970.

Concerning the project of "mass science," the Chinese government recruited common Chinese people to participate in scientific and technological explorations even though many of them had little or no STEM education. There were numerous programs of mass science. For example, from 1957 to 1958, there was a program of producing steel. As discussed previously, Chinese people were asked to collect and use iron products such as iron pots and screws to make steel, and while steel workers spent days and nights in 
the factories, other Chinese people were encouraged to produce steel in their backyards. This mass participation reflected how the Confucian emphasis on citizens' support, sacrifice, and subordination to the government without questioning its justification became articulated with Mao's government's desire to develop steel science and technology to influence Chinese people in significant ways. Fan (2017) explains the reasoning behind the project of mass science:

Maoist programs of mass science, such as earthquake prediction, barefoot doctors, and various attacks on "elite science," were based on the tenets of integrating experts and the masses and combin[ing] indigenous and Western science. The underlying political doctrine asserted the class character of science, exalted everyday knowledge, and projected a particular vision of scientific and political modernity. (p. 302)

Fan's argument reveals that Mao's national projects of mass science enabled the articulation of local Chinese science and technology with Western science and technology, and more importantly, reinforced the articulation of science and technology with politics.

These two projects under Mao's administration exerted significant impacts in the following ways. First, they reinforced the importance of science and technology, especially military science and technology, in spite of what might be considered other, negative measures of success. Thus, although developing nuclear weapons was expensive and time-consuming, the Chinese government continued to support the projects during the three years of national famine in China (1959-1961) when many Chinese people were 
starving to death. Scientists and engineers who worked for this project were even under protection during the Cultural Revolution, while many university professors were tortured. Second, the project of mass science plays an important role with regard to disarticulating science and technology from being seen as the purview of the West. As argued previously, the belief that science and technology belonged exclusively to the West was developed during the Westernization Movement and the New Culture Movement. Instead, Mao's project of mass science aimed to articulate science and technology with traditional Chinese culture. Mao believed that in traditional Chinese culture, there were useful scientific and technological ideas to exploit. In his view it was necessary to combine both indigenous and Western knowledge. For example, in the program of barefoot doctors, Mao emphasized that besides learning Western pharmacology, doctors should also draw from traditional Chinese lore on medicine. Third, Mao insisted that science and technology were "inherently political... neither neutral nor value-free" (Fan, 2017, p. 314). Mao's idea of mass science reflected his efforts to eradicate gaps between classes and create an egalitarian society in which everyone worked and everyone was served at the same time. However, as Elman (2008) points out, "Maoist science and its rhetoric of science's role in class struggle [served as] a smokescreen for power politics" (p. 518). This means that Mao believes that science and technology should always serve the government's political purposes.

In January1963, Zhou Enlai, the premier of Mao Zedong's government, introduced the plan of four modernizations/Si Ge Xian Dai Hua 四个现代化 at the Conference on Scientific and Technological Work held in Shanghai. Zhou argued that the 
government and the people should work diligently to realize the modernizations of agriculture, industry, national defense, and science and technology. This was an essential scientific and technological plan that exerted profound influence on the CCP's later policies even though this plan ended abruptly due to the breakout of the Cultural Revolution.

The Cultural Revolution (1966-1976) dismantled the institutional scientific infrastructure including scientific administration, scientific communities, and the educational system in China. Thus, during that decade of social, cultural, and political turmoil, the Chinese people and government were not capable of making important progress in science and technology. In 1977, with the death of Mao and the return of Deng Xiaoping to the power center of the CCP from the political wilderness, the Cultural Revolution ended and the CCP shifted its focus to develop the economy as well as science and technology.

Initially, Deng returned to Zhou's plan of four modernizations. In March 1979, Deng (1979) pointed out that "realizing the four modernizations is a many-sided complex and difficult undertaking” (p. 188). In December of the same year, Deng announced the reform and opening-up policy, which was his expansion of the plan of the four modernizations.

ROUP maintains the core focus of the plan of four modernizations on developing science and technology. Deng "identified technological change as the main mechanism for improving economic performance and maintaining economic growth" (Saich, 1989, p. 68). He made a famous statement about science and technology on September 5, 1988 in 
a meeting with the president of Czechoslovakia that "science and technology are the most important and fundamental productive forces (Ke Ji Shi Di Yi Sheng Chan Li/科技是第 一生产力).” Deng's statement, which implied that science and technology are the forces to create history, differed significantly from Mao's (1945) claim that "people, only people, are the force to create history" ("On Coalition Government"). For Deng, the value of science and technology exceeded that of human beings. Deng's arguments indicated the beginning of a new era in which science and technology are strongly articulated to the government's main focus on economic development. Science and technology, it is now believed, will bring the country a prosperous future.

From a young age, Deng was committed to promoting science and technology. In 1920, when Deng's father asked him what he expected to gain when he was leaving to study in France, Deng, a sixteen-year-old at that time, replied "to learn knowledge and truth from the West in order to save China." Deng's reply reflected his faith in the power of science and technology to bring China a promising future. Goldman and Simon (1989) summarized Deng's understanding of science and technology in this way:

Much of the rhetoric of the Deng Xiaoping regime, which came to power in late 1978, resonates with the May Fourth Movement's [which is also known as the New Culture Movement's] celebration of science and technology as the key to solving all China's problems. This disillusionment with the prevailing ideologythis time, Marxism-Leninism-Maoism—once more created an ideological vacuum that the leadership and intellectuals again sought to fill with the idealization of advanced science and technology. (p. 9) 
In short, Goldman and Simon argue that Deng romanticized science and technology and assumed that they could fill the gap and solve the issues left by disappointment with and inadequacy of Marxism-Leninism-Maoism.

Deng formulated several policies that fundamentally contributed to the development of science and technology in the era of reforms and initiated several large national scientific and technological projects. First, Deng resumed China's National College Entrance Exam/Gao Kao/高考 in 1977 after it had been stopped for almost 10 years. Moreover, Deng pointed out that besides considering the class of a student's family, which was the main criterion used previously, universities should take students' academic performances seriously in recruiting. Since then, intelligent and diligent students have had the chance to receive higher education, regardless of their class background. In fact, many members of the Chinese Academy of Sciences and the Chinese Academy of Engineering began their university years in 1977 and 1978, such as Zhou Shouwei, Bao Weimin, and Wang Xiaofan. Furthermore, Deng vigorously imported Western science and technology and promoted STEM education and research. For example, after the normalization of diplomatic relations between China and the U.S., Deng visited the U.S. for the first time in 1979 and signed "The U.S.-China Agreement on Cooperation in Science and Technology." In February 1984, Deng visited The Exhibition of Scientific and Technological Achievements held in Shanghai and pointed the significance of developing computer training programs in schools. In 1986, Deng initiated the 863 Program, which is one of the biggest scientific and technological projects that promoted research in STEM fields in contemporary China. In the same year, 
Deng also initiated the Spark Program/Xing Huo Ji Hua/星火计划, which aims to utilize science and technology to boost the development of rural China. In fact, it has been maintained that since 1978, the spring of science and technology has arrived in China.

After Deng Xiaoping, Jiang Zemin and Hu Jintao continued to develop science and technology, reinforcing the articulation of science and technology with the country's progress. For example, in 1995, Jiang Zemin announced the strategy of invigorating China through science and education (Ke Jiao Xing Guo/科教兴国). Jiang argued that scientific and technological developments were essential for China's success; thus the Chinese government should emphasize scientific and technological research and STEM education. This strategy reflected Jiang's efforts of articulating science and technology with the Confucian emphasis on education in order to cultivate talents in STEM that could serve the country. In 1997, Jiang argued that science and technology determined the future of China's economy. This argument brought science and technology "to the centre" and expected "them to play a significant role in economic construction of China" (Dolla, 2015, p. 43).

Hu Jintao, the chairman after Jiang Zemin, also emphasized science and technology. In 2006, Hu stated his plan for China's future to become an innovative country in 15 years. This meant that besides learning from the West, China was expected to create new scientific and technological achievements independently and to craft products that are competitive and carry Chinese intellectual property rights. In the same year, Hu's government published "The National Outlines for Medium and Long-Term Planning for Scientific and Technological Development (2006-2020).” This outline was a 
comprehensive plan for scientific and technological developments in China from 2006 to 2020. It called for launching independent innovative scientific and technological projects both in traditional fields such as chemistry and in cutting-edge fields such as mobile communication. Since 2003, which was the year that Hu became the chairman, the Chinese government had "spent 340.6 billion Yuan on science and technology over the past five years" and "China's total investment in research, experimentation and development rose from the 128.8 billion Yuan in 2002 to 366.4 billion Yuan in 2007” (Wen, 2008).

Xi Jinping, who succeeded Hu Jintao as Chairman of the PRC, has consistently asserted the importance of science and technology for China's future. Xi's government has inherited and expanded the Thousand Talents Plan (Qian Ren Ji Hua/千人计划), first initiated by Hu Jintao's government in 2008. This plan brings to China outstanding international scholars, researchers, and entrepreneurs in STEM by providing them competitive salaries, spacious apartments, and other benefits such as offering scholars' spouses decent jobs. This project demonstrates Xi's as well as Hu's commitments to developing science and technology. Accordingly, while the Chinese government has invested a considerable amount of money on experts in STEM, talented scholars in the humanities and arts are largely ignored, because it is believed that they cannot create social wealth. In this way, the humanities have become disarticulated from educational value, which was strongly emphasized in ancient China.

Facing the pressure of a trade war between China and the U.S., Xi is concerned that some scientific and technological fields in China rely too heavily on Western 
countries. Xinhua Net, a website sponsored by the Chinese government, summarized one of Xi Jinping's most important speeches about developing science and technology, especially in the event that China entered a trade war with the U.S., which was delivered in May 2018:

$\mathrm{Xi} \ldots$ said as China strives for prosperity and rejuvenation, it needs to devote great energy to promoting science and technology, and endeavor to be a major world center for science and innovation ...Xi called on the country's science and technology personnel to grasp the main trends, seize opportunities, face problems squarely, and rise to challenges....Xi said they should aim for the frontiers of science and technology, lead the direction of its development, shoulder the heavy responsibilities bestowed by history, and be vanguards in innovation in the new era...Xi said efforts must be made to ensure "high-quality science and technology" to underpin the development of a modernized economy.... 'The initiatives of innovation and development must be securely kept in our own hands,' Xi said. (Xinhua , 2018).

In fact, in 2015, Xi's government announced the program "Made in China 2025" (Zhong Guo Zhi Zao 2025/中国制造 2025). This program aims to change China's situation from being the world's factory of low-cost and low-quality products to an innovative one that designs and crafts valuable high-tech products and provides cutting-edge technical services and support. Fang and Walsh (2018) reported that the Chinese government would roughly invest $\$ 300$ billion US dollars (approximately 2024 billion Yuan) in this plan. 


\section{The Status of Science and Technology in the Era of Reforms}

Earlier in this chapter, I explored several forces that have profoundly impacted the status of science and technology in contemporary China. Chinese myth, which includes numerous gods and goddesses that are scientists and engineers, reveals that there is a deep tradition of valuing science and technology. Some aspects of Confucianism and Daoism stifled the development of science and technology, especially in ancient China. Other Confucian and Daoist aspects have contributed to scientific and technological development even in ancient China, such as the emergence of gunpowder. Still, other aspects have articulated with new elements in the era of reforms resulting in a transition from stifling to encouraging scientific and technological development, such as valuing education, which has tenaciously been articulated to what it means to be a good Chinese citizen but has now been disarticulated from the humanities in ancient China and rearticulated to STEM in contemporary China. The Westernization Movement and the New Culture Movement significantly promoted the idea that science and technology, which are associated with the West, are powerful and can bring Chinese people and the nation a promising future. In addition, the Chinese tradition of numeracy and the discrepancy between the needs of the large population and the country's inadequate capacity for production have profoundly driven the development of science and technology. Progress enabled by scientific and technological development in terms of providing more food and living space for Chinese people has reinforced Chinese people's faith in and need for science and technology. The CCP has formulated many policies to 
promote science and technology, even investing them as the remedies to all social problems.

Due to the articulation of these mythical, ideological, religious, intellectual, cultural, humanistic, and political influences, science and technology are romanticized in the era of reforms. As a result, many Chinese people are fascinated with science and technology, and they privilege scientific and technological developments regardless of the costs. Additionally, science and technology have become integral to the Chinese government's political practices.

On July 22, 2018, the New York Times published the article "Wild About Tech, China Even Loves Robot Waiters that Can't Serve.” In the article, Mozur (2018) discusses the phenomenon that increasing numbers of Chinese people embrace science and technology without any hesitation. Many Chinese people support new scientific and technological devices even when the new devices have no practical use. Moreover, Chinese people even fly abroad to purchase "more advanced" scientific and technological products, which are sometimes unnecessary. Chang (2015) observed that in "stores [in Japan], China's ravenous consumers cleared out shelves, buying electronic rice cookers, air purifiers, digital cameras, and, most notably, electronic toilet seats."

In fact, many Chinese children grow up with the saying "If you can study mathematics, physics, and chemistry well, you can face the world confidently" (Xue Hao Shu Li Hua, Zou Bian Tian Xia Dou Bu Pa/学好数理化走遍天下都不怕). Due to this education, many Chinese people view science and technology as the most powerful force that can definitely bring them happy lives, as described by a Chinese netizen: 
The way Chinese people treat science and technology is similar to the way American people treat Christianity. American people visit churches during the weekend piously. Chinese people view science and technology piously...Currently, in China, science and technology replace arts, aesthetics [, and humanities]. American people believe God is the creator of the world, and Chinese people believe science and technology are the creators of the world. ${ }^{22}$ Because of the value placed on science and technology, it has become commonplace to promote the development of science and technology regardless of the costs. A recent example concerns the births of two genetically edited babies. In November 2018, these twin girls were born in China. The Chinese scientist He Jiankui collaborated with several Western scientists to alter and modify the genes of these girls when they were still embryos. Dr. He claimed that after editing the genes of these babies, they were born healthy, proving that they are likely resistant to HIV even though their father is an HIV carrier, who in ordinary circumstances would have likely passed down the disease of AIDS to his children. Although Dr. He's research probably contributes to biological science and technology in significant ways, it has serious potential inhumane costs, including the potential long-term health repercussions for these babies and their descendants.

\footnotetext{
22默默无闻/Mo Mo Wu Wen left this comment in Baidu Tieba on 23 November 2018. Baidu Tieba is one of China's biggest and most active open-access social network with forum-like features. Baidu Tieba claims to be the biggest online community that is in Chinese. People can create posts, leave and reply to comments under pseudonyms. This comment is retrieved from: http://tieba.baidu.com/p/5958780368. I translated the comment from Chinese to English.
} 
A very interesting and increasingly relevant articulation of the elevation of science and technology to politics is the Chinese government's growing effects to harness, control, and constrain the power of science and technology since they offer potentially subversive opportunities for Chinese citizens to resist the government's control. Thus, the government surveils and constrains Chinese people's access to and use of science and technology, for example by implementing the Great Firewall of China. The Chinese government designed and applied the Great Firewall of China (GFW) to block and filter information flows. As a result, Chinese people cannot access certain websites such as Google, Youtube, Facebook, Twitter, and Instagram because the Chinese government is concerned that these websites include potentially politically sensitive information and wants to inhibit the flow of this information in China. ${ }^{23} \mathrm{By}$ implementing the GFW, which enables the Chinese government to censor the Internet, the government controls a main source of knowledge.

Besides the GFW, the Chinese government has implemented other national scientific and technological projects such as Tian Wang (天网), a system of surveillance. ${ }^{24}$ The Tian Wang system is "the world's biggest camera surveillance

\footnotetext{
${ }^{23}$ Legally, Chinese people cannot access these websites because based on the location of their IP addresses, their requests to visit these websites would be rejected by GFW. However, many Chinese people pay for VPN services that are provided by private companies. The service of VPN can change Chinese Internet users' IP addresses, thus they can visit these blocked websites. However, since January 2015, the Chinese government has worked on blocking VPNs. Since 2015, several of the most popular companies that provide VPN services such as Express VPN and Green VPN were prohibited by the Chinese government from providing their services in mainland China.

${ }^{24}$ The name of the system "Tian Wang" is taken from a Chinese proverb "The net of heaven has large meshes, but it lets nothing through" (Tian Wang Hui Hui, Shu Er Bu Lou). Originally, this proverb was used to imply that justice has long arms and that people should have faith in God. The Chinese government took the first two characters ("Tian Wang") of this proverb to name a nationwide system of surveillance to signify that the system can catch everything.
} 
network. Across the country, 170 million CCTV cameras are already in place and an estimated 400 million new ones [would] be installed [between 2017 and 2020]. Many of the cameras are fitted with artificial intelligence, including facial recognition technology" (Liu, 2017). This system can cover most public places in China since those CCTV cameras were installed in railway stations, airports, shopping malls, streets, schools, universities, restaurants, cinemas, stadiums, buses, trains, cabs, flights, markets, and so forth. Through using the Tian Wang System, the Chinese government can monitor Chinese people's everyday activities in a quick and effective way. Moreover, by connecting to a database, which includes the pictures and identifying information of people including foreigners in China, the Tian Wang system can not only quickly recognize the identity of a person captured by a CCTV camera, but can also review the person's behaviors in the past few weeks and even the information regarding that person's social network. This system is very powerful. In 2017, a BBC News correspondent John Sudworth tested the Tian Wang system by trying to stay hidden from CCTV cameras in Guiyang City, Guizhou Province China. However, in 7 minutes, he was captured by police because the Tian Wang System could even predict his possible pathways of escape based on the previous footage captured by CCTV cameras $(B B C$ News, 2017).

This chapter explores myth, Confucianism and Daoism, the Westernization Movement and the New Culture Movement, the tradition of numeracy, the discrepancy between the needs of Chinese people and the country's inadequate productive capacity, and the CCP's political practices, which are articulated and have exerted profound 
impacts on the status of science and technology. As this chapter has demonstrated, these forces contribute to the veneration of science and technology in the era of reforms in significant ways. The next chapter will address the other central issue of this dissertation, Chinese women and their living situations in the era of reforms. 


\section{Chapter Three: Chinese Women's Roles in the Era of Reforms}

Chapter Two considered the influences on science and technology in the era of reforms of Chinese myth, Confucianism and Daoism, the Westernization Movement and the New Culture Movement, the Chinese tradition of numeracy, the discrepancy between the needs of the large population and China's inadequate capacity of production, and the CCP's policies. These elements contribute to the belief that science and technology are powerful and can bring positive changes to Chinese society and people. The previous chapter concluded that science and technology are venerated, which results in many Chinese people's preoccupation with them, their development regardless of the costs, and their embeddedness into the CCP's political practices.

This chapter focuses on Chinese women in the era of reforms through mapping their roles. This chapter argues that the articulation of Chinese myth, Chinese language, Confucianism and Daoism, and the CCP's political practices disciplines Chinese women to be wives and mothers in the era of reforms. However, at the same time, the articulation of the discourse of The New Woman and the CCP's political practices to encourage and prepare women to join the workplace impacts women's roles in the era of reforms, resulting in an increasing number of Chinese women becoming professionals. Thus, in the era of reforms, two predominant roles that many Chinese women have are being a mother and a wife, and being a professional. The traditional role of being wives 
and mothers and the emerging new role of being professionals have created tensions and contradictions that have impacted women's living situations in significant ways.

As prelude to my discussion, I want to discuss an influential TV series, The First Half of My Life/Wo De Qian Ban Sheng/我的前半生(2017), in which the two leading characters—Luo Zijun/罗子君 and Tan Jing /唐晶— are women in contemporary China. This TV series is a noteworthy example because it showcases many tensions Chinese women have experienced in the era of reforms. It became so popular that a photo of the actresses Ma Yili and Yuan Quan, who played the roles of Luo Zijun and Tang Jing, was chosen in November 2017 as the cover page of Elle (China), one of the most influential high-fashion magazines in China. This TV series has also received many accolades such as The Magnolia Award in 2018.

The first half of Luo Zijun's life was spent as a rich housewife. However, in her 30s she was deserted by her husband after he decided to marry his mistress. After reflecting on the first half of her life and deciding to support herself independently, Zijun returned to the workplace with the help from her friend Tang Jing and Tang Jing's boyfriend He Han, with whom Zijun later felt in love. Tang Jing, unlike Luo Zijun, devoted herself to work. However, after being betrayed by her long-term boyfriend He Han and Zijun, Jing began to reflect on the first half of her life during which she rejected He Han's proposals and sacrificed her love for her career.

This TV series, which centers on Zijun and Jing's struggle to balance their careers and family lives, resonated with many Chinese women. In the era of reforms, the discourse that good women are independent is popular; however, at the same time, good 
women are still expected to be virtuous wives and caring mothers. What follows is a discussion of women's two predominant and often conflicting roles in the era of reforms_-being wives and mothers and being professionals.

\section{Chinese Women' Roles as Wives and Mothers}

Chinese women have always been expected to become wives and mothers. This expectation is deeply rooted in Chinese myth, Chinese language, Confucianism and Daoism, and Chinese political practices. The link between women and these sociocultural roles is a line of tendential force that resists disarticulation in the era of reforms even when many significant changes have happened in Chinese society, as discussed in Chapter One and Two.

\section{Myth}

Chinese women are always expected to get married and to have children. This expectation was solidified in the early stages of Chinese civilization, as reflected in mythical stories. Among Chinese mythical figures, we should pay special attention to four of the most famous goddesses: Nü Wa/女娲, Guan Yin/观音, Chang E/嫦娥, and Sao Ba Xing/扫把星. ${ }^{25}$

\footnotetext{
${ }^{25}$ To know more about Chinese mythical figures, please consider reading these books: 1) Birrell, A.(1993). Chinese Mythology. Baltimore: Johns Hopkins. 2) Christie, A.(1968). Chinese Mythology. Feltham: Hamlyn Publishing. 3) Werner, E.T.C. (1922). Myths and Legends of China. New York: George G. Harrap \& Co. Ltd. 4) Yang, L.; An, D.; \&Turner, J., A. (2005). Handbook of Chinese Mythology. New York, NY: Oxford University Press.
} 
Nü Wa, as discussed in Chapter Two, is a goddess with a human upper body and a snake tail and is respected as the mother of human beings in China. She made people by creating them from clay and is respected for her love for them. For example, in order to patch the big hole in the sky, she used rocks of five colors and four legs of a giant tortoise. When she was running out of materials, she sacrificed her body to patch the sky.

While ancient, Nü Wa remains an influential stereotype of Chinese women. Chinese women are expected to follow Nü Wa as an example of shouldering the responsibility of reproduction with love, taking good care of their children, and even sacrificing their lives for their children unhesitatingly. Nü Wa is one of the most significant figures in contemporary Chinese culture. For example, the popular Chinese TV drama series Chinese Paladin (仙剑奇侠传), which aired from 2005 to 2016, depicts the honorable lives of Nü Wa's descendants, all of whom were women and who were born with the obligation of taking care of people and later sacrificed themselves to fulfill this obligation.

The second figure is Guan Yin. In Chinese myth, Guan Yin is the goddess of mercy and compassion. Whereas in Indian and Tibetan Buddhism, Avalokitesvara is the male god of mercy and compassion, this figure was transformed into a woman in Chinese Buddhism, which originates from Indian Buddhism but is more widely practiced than Indian and Tibetan Buddhism in contemporary China. This goddess of mercy, Guan Yin, is probably the most valued and honored goddess in Chinese culture. In Chinese myth, Guan Yin was the third daughter of a king who was determined to join a nunnery. Her father was outraged by her decision and tortured her. Later, he had become seriously ill 
and could only be cured by an ointment made from the hands and eyes of his children. In another popular version, the ointment could only be made from the hands and eyes of people who had no anger. Guan Yin did not hesitate to rip out her eyes and to cut off her arms to save her father.

While an extreme story, Guan Yin represents another stereotype of Chinese women: a filial daughter and a selfless beauty. A Chinese woman is expected to be a filial daughter who has no hatred or anger towards her parents no matter how her parents treat her. Moreover, in the myth, Guan Yin hears the cries of the world and helps people when she witnesses miseries, as indicated by a popular image of her with a thousand hands and eyes. Compassion has become a highly desired characteristic for Chinese women. Moreover, Guan Yin is also deified as the figure who sends babies to families. Thus, it is a common practice both in ancient and contemporary China that if a woman wants to get pregnant, she will go to a temple of Guan Yin to beg for help. Thus, although Guan Yin remains unmarried and doesn't have a child of her own, she is still highly respected because she takes care of all families and her maternal love is for all the people in the world. Guan Yin is widely worshipped in contemporary China. In 2005, a 108 meter (354 feet) statue of Guan Yin was enshrined in Sanya, Hainan Province ("Guanyin of Nanshan," n.d.). The statue is one of the highest Buddhist statues in the world. The third figure is Chang E. In Chinese myth, Chang E is the most beautiful goddess. She was married to the expert archer Hou-Yi. After ten suns rose in the sky, which made the living conditions unbearable, Hou-Yi shot down nine of them and left only one in the sky. As a reward, he was given an elixir of immortality, but he was 
unwilling to take it and asked Chang E to keep it safe. However, Chang E could not resist the temptation of being immortal and took the elixir. After, she started to float and fly away until she finally landed on the moon. There, she is the only creature, aside from a companion jade rabbit, and she leads a lonely, regretful life.

The myth of Chang E is very popular in contemporary China because it is often promoted as proof that Chinese people's dream of exploring the universe is deeply rooted. For example, the Chinese government named its four unmanned lunar-orbit spacecraft that have been sent to the moon as Chang E No. 1, Chang E No.2, Chang E No.3, and Chang E No.4 and its lunar rover Yutu, which references the jade rabbit. Moreover, Chinese culture romanticizes Chang E's experience. For example, the MidAutumn Festival, which is a national Chinese holiday for families to gather together, originates from the story of Chang E. Chinese people make cakes as offerings in exchange for Chang E's protection. However, as a feminist, I question the glorified connotation of the story. Living lonely on the moon and being expelled from the community of human beings might be difficult for anyone, including Chang E. It could be viewed as the punishment for Chang E acting on her desire to be immortal and having the courage to betray her husband in taking the elixir without his permission. Thus, instead of solely viewing Chang $\mathrm{E}$ as the ascendant of Chinese astronauts or a protective goddess, I focus as well on Chang E's lived experience and view her as a Chinese woman who is punished because of her quest for independence.

Similar to Chang E, Sao Ba Xing is another stereotype of Chinese women who are not submissive to their husbands. The figure of Sao Ba Xing was crafted in an 
influential Chinese mythical novel, The Investiture of the Gods (Feng Sheng Yan Yi/封神 演义). Before being deified as a goddess of Sao Ba Xing, she was an ordinary woman named Ma Zhaodi/马招娣. She was depicted as a greedy and shrewd woman who often quarreled and fought with her husband Jiang Ziya/姜子牙 because she thought he was not successful and rich enough, which led her to request a divorce. After the divorce, her husband became so successful that he helped to establish the Zhou Dynasty and was bestowed the Feng Sheng Bang, which is a list that empowers him to inaugurate new gods of heaven. Enraged by his ex-wife Mao Zhaodi, who returned to him and bothered him to inaugurate her as a goddess, Jiang Ziya inaugurate her as Sao Ba Xing, the goddess responsible for spreading bad luck. Accordingly, no one wants or likes her. People use water, brooms, and firecrackers to drive Sao Ba Xing out of their homes. Even now, when Chinese people refer to a person, especially a woman, who is believed to bring bad luck to others, they refer to that person as Sao Ba Xing.

These mythical figures reflect how a Chinese woman is expected to behave culturally. She should be beautiful, gentle, a filial daughter, a supportive wife, and a loving mother. Otherwise, she will be expelled, disgraced, and punished. These myths constitute one of the key forces of articulation that emphasizes that Chinese women should be virtuous wives and caring mothers.

\section{Language}

The Chinese language is another force that contributes significantly to the tenacity of the link between Chinese women and their roles as wives and mothers. Chinese 
characters are hieroglyphic, which means they were made based on people's interpretations of images. For example, the number one in Chinese is "一," the number two in Chinese is “二,” the word for wood in Chinese is “木,” the word for many trees in Chinese is “林,” and the word for forest in Chinese is “森林.” The Chinese character for men is “男.” This character includes two parts: “田” means fields and “力” means strength. When we put these two parts together, it is clear that Chinese men are supposed to be powerful and conduct agricultural work. In contrast, the Chinese character of women is “女.” This character reflects the figure of a woman who has full breasts and wide hips, which are believed to be signs of fertility in Chinese culture. The difference between the Chinese characters for men and women reveals the belief that men are strong and are the breadwinners, while women are seen in terms of their reproductive organs. These characterizations can be traced back through thousands of years of Chinese civilization and language.

Moreover, the word “marriage” in Chinese is “婚姻.” Both the character of “婚” and the character of “姻” begin with the radical “女/nv,” which refers to a woman. While the character of men is absent, the close relation between the character of women and the characters of marriage symbolically reinforces that marriage is an indispensable part of a woman's identity. "Wife” in Chinese is “妻." Based on the classical Chinese book Shuo Wen Jie Zi/ 说文解字, which interprets Chinese characters, “妻” refers to a woman doing housework. "Pregnancy” in Chinese is “孕.” This Chinese character includes two parts “乃” and “子.” “乃” not only depicts the body shape of a pregnant woman, but also refers 
to a woman's "container"- the womb. Meanwhile, “子” means boys, so the figure of women contains a male offspring (Xu, 2000). If, as Levi-Strauss states, language works as a hidden structure influencing our behavior and thoughts, then it is - at least in partthrough these Chinese linguistic characters that Chinese women learn their roles and negotiate their lived experience.

\section{Confucianism and Daoism}

The third line of force that contributes to keeping the link between women and the expectation for them to become wives and mothers is Confucianism and Daoism. As discussed in Chapter Two, some aspects of Confucianism and Daoism remain influential in the era of reforms.

Besides promoting people's subordination to authority and the government as well as emphasizing education, the Confucian ideas concerning marriage and family are powerful in contemporary China. Bell (2008) observes that in some provinces, "communist Party officials... are assessed on the basis of Confucian values such as filial piety and family responsibility" (p. 9). Moreover, it is becoming trendy for parents to send their daughters to receive training in Confucianism, a trend that is strongly promoted by some Chinese celebrities. In January 2019, Wei Pan/潘蔚, a famous hostess of the Travel Channel and the wife of a popular Chinese singer, was interviewed. In the interview, Pan explained her reason for quitting her job, leaving her comfortable life in Beijing, moving to a small city, and writing a book recording and reflecting on her daily life: 
[Bothered by my children's education], I said what about moving to Xuzhou where there's a school [named Hua Xia Xue Gong/华夏学宫] focusing on traditional Chinese value[s] [especially Confucianism, thus my children can study there] .... I cooked for the children. I make wonton, stuffed buns, noodles and steamed bread for them. The smell of mom's cooking [represents the best of a home]. ... Our children [have changed] a lot in the past three years [since they have studied in that school]. Like Aibao [, my youngest daughter,] has learned and can recite much [of the] classic literature [in Confucianism].....Now I work as a teacher [in that school]....I teach girls handicrafts. [A girl] [will] become a wife and a mother in the future. [Thus,] it is important for her to express her love and emotion through needle and thread. (Yitiao, 2019).

Besides Pan Wei’s daughters, Tao Hong/陶虹, a famous Chinese actress, also sent her daughter to study in the same school even though this school is not qualified to award students with any degree. Since many Chinese people cannot afford the high tuition of Hua Xia Xue Gong, they send their children, mostly their daughters, to study in other short-term Confucian programs. These programs, which are often titled “nü de ban/女德 班," claim to enable girls to become virtuous by educating them with Confucianism. ${ }^{26}$ "Nü de ban" programs promote the ideas that women should be submissive to their parents, remain chaste before marriage, and show deference to their husbands. These

\footnotetext{
${ }^{26}$ Nü De Ban (女德班): in Chinese character “nü” refers to women, “de” means virtue, and “ban” means classroom. Nü de ban refers to classrooms that center on instructing women to be virtuous.
} 
programs often argue that a virtuous woman who abides by these ideas will be granted a happy life. Despite the criticism of this program by some Chinese people and local governments-for example, in December 13, 2018, Chongqing Wenming Wang, a website sponsored by the government of Chongqing City, published the article "The Brainwash of Nü De Ban Must Be Stopped"-many parents still send their daughters to study there. Furthermore, some sexist ancient Confucian familial practices have been revived. For example, on February 10, 2019, an article titled "The Ridicule of People in Shan Dong Province During the Spring Festival is a Reflection of the Corruption of Chinese Culture" was published on People. com. ${ }^{27}$ The article focused on the criticism of the practice of women preparing food, but not being allowed to eat at the table in Shan Dong Province, which is the birthplace of Confucianism. It argued that this practice reflects Confucian values that can make families live harmoniously and that the criticism against this practice reveals that China's culture is losing its Confucian roots and being degraded. These examples indicate that Confucianism, especially Confucian thoughts on marriage and family, are gradually regaining their influence in Chinese culture in the era of reforms.

The Confucian position on marriage and family strongly promotes two ideas. First, Confucianism emphasizes that people should get married and should have children. Second, Confucianism argues that members in a family should have different roles and responsibilities. The position of women in this system is subordinate.

\footnotetext{
${ }^{27}$ This article was initially published on People.cn, a website that is sponsored by the Chinese government, and was cited by many websites in China. However, in a few hours, it was taken down from People. cn although this article can be still be accessed from other websites.
} 
First and foremost, Confucianism argues that people should get married when they become adults. ${ }^{28}$ Mencius argues that getting married is expected from the time of a baby's birth. In the book Mencius, Mencius writes, "When a boy is born, all parents hope he will someday set up a household, and when a girl is born, they hope she will marry" (pp. 64-65). In many places in China, a related practice used to be popular and is still performed. On the birth date of a girl, her father plants a camphor tree in the yard. When the girl is going to marry, her father cuts the tree down and makes her a suitcase out of the tree. The girl carries this suitcase to her husband's home. This practice demonstrates that parents plan for their daughters' departures from time they are born to join other families through marriage.

Besides emphasizing the expectation for women to marry, Confucianism underscores the importance of women having children in their marriages. In Mencius, there is a sentence “Bu Xiao You San, Wu Hou Wei Da. (不孝有三, 无后为大).” The original meaning of this sentence is: every child should shoulder his/her responsibilities and respect his/her parents. However, the meaning of this sentence was redefined by later Confucian scholars to become "no posterity is the worst of the three unfilial acts." This later version is still widely accepted and has remained the philosophical support for procreation-driven marriage in China. In fact, one of the most important beliefs in ancient

\footnotetext{
${ }^{28}$ I want to emphasize an important detail. Although same-sex love existed in ancient China as expressed by the phrase“Long Yang Zhi Pi/龙阳之癖” that describes homosexual attraction among gay men, only heterosexual marriages are recognized in classic Confucian texts.
} 
Chinese culture was “more sons, more happiness” (Duo Zi Duo Fu/多子多福). Stockard (2002) points out that in ancient China,

It was a moral duty of the highest order to have a son, to assure that the line of your grandfather and father-your line - continued unbroken through the generation. This moral duty gave marriage in Chinese society its primary goal: to produce sons to continue the descent line of the husband. (p. 44)

In this way, women were endowed with the responsibility to bear sons.

Additionally, Confucian scholars set rules for members in a family and required them to follow these rules. Men should work outside and women should stay inside. Men should be breadwinners and women homemakers. Wang (2011) summarizes Confucian thoughts on men's and women's separate roles as “for a woman, bearing and raising children for her family is more important than [all] other things in the world"; in contrast, "for a man, he is supposed to build up [an] establishment outside" (p. 96).

Confucianism also argues that a husband and a wife should help, support, and take care of each other. But this cooperation is contingent on a wife's submissiveness to her husband. An ancient Chinese ritual embodies this emphasis. Mencius describes this ritual:

When a young man is capped, he receives a charge from his father, but when a girl is married, it is her mother who gives her the charge. ${ }^{29}$ As her daughter is

\footnotetext{
${ }^{29} \mathrm{Cap}$ : In ancient China, when a boy became an adult, a ceremony would be held for him. In the ceremony, a cap would be put in his head. This practice signifies that he is recognized as an adult by his community. In the ritual of capping, his father would give him advice and outline his expectations for the newly adult man.
} 
escorted out the gate she admonishes her: "When you reach your new home, be respectful! Be modest! Never disobey your husband!" (Mencius, n.d., p. 64) Even Ban Chao/班超, who advocated for women's education in the Han Dynasty, writes, "If a wife does not serve her husband, then the proper relationship (between men and women) and the natural order of things are neglected and destroyed" (as cited in Swann 1960, p. 83).

Confucianism strongly emphasizes filiality. Parents raise their children; children, in return, should take good care of their parents as they age. To be a filial child, the person should provide his or her parents with clothing, shelter, food, service, and psychological comfort. This means that a boy should respect his parents' opinions, obey his parents' orders, and satisfy his parents' expectations, which usually include having a successful and respected career. For a girl, this means she should marry someone who is chosen by her parents and serve her new family wholeheartedly to win her parents the good reputation of raising a virtuous daughter. The girl is also expected to have children, preferably sons, after she got married.

Historically, the only way for women to become successful and achieve selffulfillment was to be virtuous wives and caring mothers. As a result, husbands and sons could focus on their careers and had more paths open to them to become successful. Given their husbands' and sons' success, women could get credit for being successful in their domestic roles. Accordingly, women were not expected to become knowledgeable or read many books. It was believed that "it is a woman's virtue to be ignorant” (Nü Zi Wu Cai Bian Shi De/女子无才便是德). In contrast, women were expected to be good at 
decorating themselves in order to be aesthetically pleasing and to be skilled at needlework in order to make clothing for their husbands and sons. The rule of "three obedience" (San Cong/三从) clearly revealed how Confucianism planned an ancient Chinese woman's destiny: to obey her father before marriage, to obey her husband when married, and to obey her son in widowhood (Wei Jia Cong Fu, Ji Jia Cong Fu, Fu Si Cong Zi/未嫁从父, 既嫁从夫, 父死从子). ${ }^{30}$

Although these Confucian ideas were more widely practiced in the past, they are rooted in Chinese culture and remain influential in contemporary China. For example, in the era of reforms, many Chinese people are hostile to women who have received higher education. There is a popular saying: "there are three kinds of creatures in the worldmen, women, and women with doctoral degrees/Shi Shang You San Zhong Ren—Nan Ren, Nv Ren, Nv Bo Shi/世上有三种人一男人, 女人，女博士.” This argument indicates that women who receive advanced higher education are not even considered human beings. Moreover, Chinese women with doctoral degrees are often characterized as dinosaurs, which are culturally recognized as ugly and ferocious creatures. These interpretations of Chinese women who receive good education reveal that it is still not preferred for women to become very knowledgeable in contemporary Chinese culture.

In 2018, there was a popular Chinese TV series Mother's Life/娘道, which depicted and celebrated a subordinated woman. The main character Ying Gu sold herself as a slave to buy a coffin and a gravestone for her father. After marrying her husband and

\footnotetext{
${ }^{30}$ To know more about the rule of three obedience, please read Gao, X. (2003). Women Existing For Men: Confucianism and Social Injustice against Women in China. Race, Gender \& Class, 10(3), 114-125.
} 
giving birth to three daughters, she became so ashamed because she failed to produce her husband a baby boy. Her signature phrase, "Chaozong [her husband's given name], let me give you a boy," reflected her dedication to the task of having a baby boy (Guo, 2016). After eight years without conceiving a baby boy, she was expelled by her husband's family. However, she was willing to accept this punishment and believed that it was a fair treatment of her. After the sudden death of her husband, she found out that she was pregnant with her husband's child again, a baby boy. In the end of the story, when her only son, who later became a traitor in the War Against Japanese Invasion, was about to be executed, Ying Gu stood in front of her son and took the bullet in his place. Moreover, through studying the parental matchmaking corners, where hundreds or even thousands of parents get together in parks or in big squares to exchange their children's information (such as age, salary, educational background, height, and weight) in order to find potential satisfactory partners, Zhang and Sun (2013) argue that:

The existence of parental matchmaking corners indicates...the enduring significance of marriage in urban China and the powerful effects of a selective rendering [of] traditional gender ideology— "men leading the outer domain and women the inner domain." (p. 138)

Besides Confucianism, Daoism, especially the Daoist religion, also has exerted profound impacts on Chinese women's role as a wife and a mother. The Daoist religion has many gods and goddess that are responsible for managing marriage and reproduction among human beings, such as Jiu Tian Xuan Nv/九天玄女, Xi Wang Mu/西王母, , Bi Xia Yuan Jun/碧霞元君, and Bao Sheng Da Di/保生大帝. These figures reflect the 
strong emphases of the Daoist religion on the necessity of people getting married and having children.

Moreover, the Daoist religion promotes the philosophy of Tai Ji/太极, also often written as Tai Chi. The Tai Ji Diagram below is recognized as the most thoughtful yet simple reflection of the essence of Tai Ji, which was first put forward by the famous Daoist priest Chen Tuan (871—989):

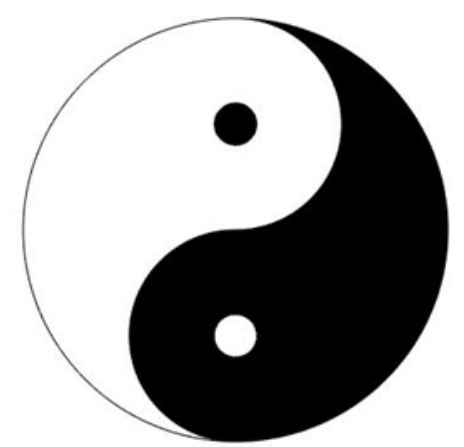

Figure 3. 1 The Image of Tai Ji. This image was drawn by the author.

The Tai Ji diagram includes two main images: a black and a white fish that fuse together by connecting heads and tails. In traditional Chinese culture, the image of fish has a strong connotation of intimacy. For example, the phrase that is used to this day to describe the sexual pleasure between men and women is "the joyful connection between fish and water/yu shui zhi huan/鱼水之欢.” In Tai Ji philosophy, the black fish refers to yin/阴 that can be simplified as femininity, and the white fish refers to yang/阳 that can be simplified as masculinity. The close connection between the two fish signifies the intimacy of yin and yang, which is promoted by the Daoist religion. 
In fact, the Daoist religion pursues an intricate balance between yin and yang, emphasizes that this balance is the beginning of everything, and argues that the marital and reproductive connection between men and women enables the world to achieve this balance. Tai Ping Jing/太平经, one of the earliest but classic books of the Daoist religion, points out that "by performing the duties of husbands and wives, both yin and yang find what they need, and the world can be peaceful" (Wang, 1997, p. 17), and criticizes people who do not get married, stating that "the [so-called] chaste men and women who are eager for the reputation of being pure and who refuse to connect with each other are against the world. This action inhibits the connection between yin and yang, which results in the death of the world" (Wang, 1997, p. 37). In fact, different from Confucianism - especially some Confucian thoughts that were developed during the Song Dynasty that strongly restricted and vilified people's, especially women's, sexual desires - the Daoist religion argues that the sexual connection between men and women is vital.

Due to the Daoist religion's emphases on marriage and reproduction, Chinese women are expected to shoulder their responsibilities to marry men and have babies. According to the Daoist religion, it is necessary for women to do so in order to ensure the peace and the flourishing of everything in the world.

\section{Chinese Governments' Policies}

Besides Chinese myth, language, Confucianism and Daoism, Chinese political practices also contribute to the expectation that Chinese women should be wives and 
mothers. Although the policies have varied in different historical periods, Chinese women have always been disciplined to be wives and mothers.

In ancient China, governments were guided by Confucian thought. Confucianism believes that governors must first and foremost govern families, regarding the individual family as the basis of wider society. Thus, in ancient China, there were many prescriptive policies that required women to get married and have children for the purpose of increasing the labor force and maintaining social stability. For example, under Emperor Taizong of Tang, officials matched single men who were over 20 and single women who were over 15 to find them partners to marry. In the Song Dynasty, the legal minimum age of marriage for men was 15 , and 13 for women. Similarly, for single people over the legal minimum age for marriage, the government intervened to introduce them to partners (Wang J, 2011). Besides getting married, women were also compelled to have children. It was legal for a husband to take concubines or even divorce his wife if she could not produce an heir for his family.

Although the CCP abolished the law that allowed men to divorce their wives based on the grounds of infertility, it continues to discipline women to get married and to have children. Before the era of reforms, in the 1950s, after sending soldiers-mostly men - to Xin Jiang Province to do agricultural work, Mao's government recruited more than 40,000 single women to work in the same province. One of the most important purposes of this recruitment was to provide soldiers with wives. There was a famous slogan for this historical: without wives, the soldiers cannot keep their minds on the work; without sons, the soldiers cannot view Xin Jiang Province as their hometown (Dai 
\& Vingie, n.d.). Additionally, in order to fight against female infanticide, in what might on the surface seem like valuing women for their own sake, Mao's government used some slogans such as "if you don't give birth to baby girls, in the future, your sons cannot find women to marry" (“Striking Slogans in China," 2017).

Moreover, when the PRC was established in 1949, working labor was in shortage because many Chinese people had died in the War Against Japanese Invasion and the Civil War in China. Thus, from 1949-1953, Mao Zedong's government encouraged Chinese couples to give birth to children. Two proverbs reflected the family planning policies at that time. The first is "many hands make light work (Ren Duo Li Liang Da/人 多力量大).” The second, which often appeared in Mao Zedong's conversations, is “when many help to gather firewood, the flames shoot high (Zhong Ren Shi Chai Huo Yan Gao/ 众人拾柴火焰高).” Accordingly, the Chinese government also formulated a series of policies to regulate abortion and birth control. For instance, in 1952, the Chinese Ministry of Health announced that besides special circumstances such as diseases, abortion was prohibited; and individuals could have contraception only if their doctors could prove that birth control was necessary for saving mothers' lives.

In the era of reforms, the CCP's tradition of emphasizing marriage and families continues, as Fincher (2014) argues, "as any Communist Party publication will tell you, marriage and family form 'the basi[c] cell of society' and 'a harmonious family is the foundation of a harmonious society"' (p. 23). The CCP has formulated policies and promoted discourses to discipline women to get married and to have babies. 
The Chinese government has implemented policies that make the living situations of single women difficult. Among many related policies, I want to focus on the CCP's policy regarding buying apartments. As discussed in Chapter Two, Chinese culture strongly emphasizes that an adult should own a decent apartment, which is not easy in China. In the era of reforms, owning an apartment in urban areas has become increasingly difficult. With the growing number of people who move to and work in big cities, and who want to buy an apartment there, there is an increasing demand to buy apartments in cities, which is exacerbated by the limited capacity to develop these spaces further. Furthermore, real estate developers and investors manipulate the housing prices in order to maximize profits. Consequently, apartment prices in big Chinese cities are extremely high. For example, in February 2019, the average price for apartments in Beijing was 45,220 Yuan per $\mathrm{m}^{2}$ ( approximately 724.30 USD per sq ft; in Chao Yang District, the most sought after district in Beijing, the average price reached 102,459 Yuan per $\mathrm{m}^{2}$ (approximately 1641.12 USD per sq ft); in Shanghai, the average price was 47,920 Yuan per $\mathrm{m}^{2}$ (approximately 767.55 USD per sq ft ); and in Huang Pu District, one of the most sought after districts in Shanghai, the average price was 142,100 Yuan per $\mathrm{m}^{2}$ (approximately 2276.06 USD per sq ft) [Anjuke.com(a), 2019; Anjuke.com (b) 2019]. In contrast, by December 31, 2018, the median sale price in Chicago was 245 USD per sq ft; and the median sale price in Manhattan NYC was 1,489 USD per sq ft [Zillow.com (a), n.d.; Zillow (b), n.d.]. These statistics indicate that the housing prices in big Chinese cities are extremely high even compared with big American cities. 
Facing the high housing prices, the Chinese government has formulated policies to regulate the market. The Chinese government argues that the main reason for the high housing prices in big cities is the investors who have bought too many apartments. Driven by this logic, the Chinese government regulates property ownership in order to eliminate speculators. China's central government classifies Chinese people's needs as: necessary requirement (Gang Xu/刚需) and soft requirement (Tan Xing Xu Qiu/弹性需 求). The central government argues that the market of real estate should first serve people's necessary requirements, more importantly Chinese couples' needs for housing. Accordingly, the Chinese local governments have set up their own policies based on the central government. In 2018, the local government of Shanghai announced that no single local residents are allowed to buy apartments. However, married couples that are not local to Shanghai and have submitted their social security fees for 5 consecutive years are allowed to buy a unit, and in some cases even two. Because of this policy, people who want to buy an apartment in Shanghai have to bring their marriage certificates to prove their legitimacy. Besides Shanghai, Guanzhou, another big city in China, also has a similar policy. According to this policy, single non-local people have to submit their social security fees for 5 consecutive years in order to become a candidate to buy a unit. However, married people, even if both of them are not local, only need to submit their social security fees for 3 consecutive years. Single local people are allowed to buy one apartment, but the married locals are allowed to buy two. Similarly, in Beijing, unmarried people are also only allowed to buy one apartment while married people are allowed to buy two ("New! The policies of buying apartment," 2018). 
The Chinese government's policies relating to buying apartments do not favor single people, especially single professional women who work in big cities. This is because compared to single women, most single Chinese men are low-skilled workers who cannot afford the high price of housing in big cities. Thus, these policies are not relevant to them. Men from the middle-class and upper-class can easily find women to marry due to the Chinese tradition that expects women to "marry up," so they are not seriously influenced by these regulatory policies. ${ }^{31}$ However, for many single middleclass Chinese women who want to have a unit of their own and can afford the down payment, the only way for them to buy one is to marry someone and in most cases this involves rushing to find partners. In fact, an increasing number of Chinese single women who work in the big cities expressed their strong desires of buying an apartment of their own in these cities. These women "argue that compared with marriage, an apartment offers them a stronger feeling of security.... They argue that an apartment can significantly improve their living conditions and is also an investment" ("Why? An Increasing Number of Single Women in Big Cities," 2019). This means that due to the Chinese government's regulations, many single professional women have to compromise their singlehood or their dreams of owning apartments. Thus, although on the surface, the Chinese government's policies concerning property acquisition exert negative influence on both single men and women equally; professional women who work in big cities are

\footnotetext{
${ }^{31}$ The cultural expectation for women to marry up will subsequently be discussed in more detail.
} 
the group of people most subject to the discriminatory effects of the government's housing policy.

Besides the policies related to buying apartments, the Chinese government has also formulated other policies that disfavor single people. For example, since June 2017, the Chinese government has established the Special Fund for Marriage Consumption Subsidies (Jie Hun Xiao Fei Bu Tie Zhuan Xiang Ji Jin/结婚消费补贴专项基金). This special fund aims to give subsidies to every newly married Chinese couple. This fund, which comes from social security fees that are paid by both single and married workers, is used exclusively to support newly married Chinese couples regardless of their economic situations. In this way, the Chinese government denies single people's access to funds that they have paid into.

Furthermore, the Chinese government has begun to intervene into people's divorces, making the process more difficult. According to the Chinese Marriage Law, there are two kinds of divorce: negotiated divorce and one-party divorce. Basically, if both husband and wife agree to divorce, they can get the divorce certificate quickly from the government. As explained in the Article 31 in the Marriage Law of China, "divorce shall be granted if husband and wife both desire it. Both parties shall apply to the registration office for divorce" (Commission on China, 2006). However, if only one party desires the divorce, the process is more difficult and time-consuming. For example, local government officials usually intervene by talking with the couple to figure out the reasons that drive them to divorce. Moreover, the Chinese culture strongly opposes divorce, as indicated by the phrase "one should rather damage ten temples than destroy a 
marriage/ ning chai shizuomiao, bu chai yi dun hun/宁拆十座庙,不拆一段婚,” which can be roughly understood as people should not destroy a marriage for any reason. Given this cultural belief, officials usually try to persuade couples to change their minds to avoid divorce. In some places, an official's work performance is even evaluated by the number of couples that he or she successfully persuaded from divorce.

Since August 2018, the Chinese government has experimentally introduced the "calm down" period for divorce. The Chinese government claimed that China's high divorce rate was caused by China's Law of Marriage that made divorce "convenient." Thus, the government needed to intervene to reduce the divorce rate. They set up a month-long calm down period for couples who want to divorce. This means that the couples need to wait for one month between the time that they submit their mutually consensual requests for divorce and the time the government begins to process their requests. Moreover, during this calm down period, either of the partners can withdraw his or her request. Accordingly, a negotiated divorce can turn into a more time-consuming and arduous one-party divorce. In this way, the Chinese government hopes that more Chinese couples, especially young couples, maintain stable partnerships.

Besides implementing policies, the Chinese government has engaged in promoting discourses that oppose single people, such as the discourse that single people are irresponsible and the discourse of the leftover women. The Chinese government openly criticizes single people for being irresponsible, as described in the article "The Population of Single Adults in China Reaches 200,000,000: A Population that Equates to the Entire Populations of Russia and the U.K. Combined" that was published on August 
16, 2017 in People.cn, a website sponsored by the Central Committee of the Communist Youth League. This article claims that "because single people have fewer responsibilities compared with married people, it is much easier for single people to become lazy and lack motivation to work... [Accordingly] they are influencing the Chinese economy in negative ways" (“The Population of Single Adults," 2017).

Additionally, the Chinese government has actively engaged in promoting the discourse of the leftover women. "Leftover women (Sheng Nü/剩女)," a phrase that refers to single professional urban women who are older than 27 years old, first appeared on the internet in 2006. The word "sheng/剩” refers to remains or leftovers, and is often used to describe something that is seen as less desirable. The word "nü/女” refers to women. Chinese people combine these two words and use this derogatory term to describe the group of single Chinese women who are mostly college educated, have successful careers, and earn satisfactory salaries. In 2007, China's Ministry of Education even added the term "leftover women" to its official lexicon and since then, this discourse has become not only more pervasive but also has gained "legitimate" status in Chinese culture.

Before I explain the discourse of the leftover women in detail, I need to clarify one point that it is not the case that China has a surplus of women that results in a large number of single women. Instead, in contemporary China, there are fewer women compared with men. Due to the Chinese culture's preference for boys over girls, there has been a long tradition of female infanticide, especially in rural areas, as demonstrated by Jiang, Li, Feldman, and Sánchez-Barricarte (2012). Driven by some Chinese families' 
devotion to provide their baby boys sufficient resources such as money and parental love to ensure their survival and success, they kill their baby girls. Moreover, due to China's one-child policy that had been implemented since 1980, the policy that required most Chinese households to have only one child, the practice of female infanticide became more prevalent. ${ }^{32}$ Denyer (2016) reported that due to the one-child policy, "there [were] 30 to 60 million "missing girls"” in China who were "apparently killed in the womb or just after the birth.”

A serious consequence of female infanticide is the striking gender imbalance in the era of reforms. By 2017, 51.17\% of the total population was male. This fairly equal distribution was due in part to the surplus of women with longer life spans. However, for young generations, there are more males, which make the gender imbalance increasingly pronounced. For example, from the ages of 15 to 19, the sex ratio was 100 females to 117.7 males; from the ages of 20 to 24 , the sex ratio was 100 females to 110.98 males; and from the ages of 25 to 29 , the sex ratio was 100 females to 104.47 males. In part due to the gender imbalance, there is a lack of single Chinese women. Among the population over 15-years-old who never married, 104,688 were males and 72,470 were females (National Bureau of Statistics of China, 2018). This lack of single women results in a surplus of men who are unable to find female partners.

Additionally, due to the deeply-rooted cultural belief that women should marry up, Chinese women are expected to marry men who are superior to them either in their

\footnotetext{
${ }^{32}$ I will provide a detailed explanation of China's one-child policy later in this chapter and in Chapter Five when I discuss IVF.
} 
educational, economic, or familial backgrounds. Chinese culture argues that through marrying up, a woman not only achieves self-fulfillment but also honors her parents. Moreover, as discussed earlier in this chapter, since Confucianism promotes marriage that subordinates the wife, it is advocated that through marrying up, women will be more likely to be submissive and thereby maintain their marriages. From a cultural standpoint, this kind of marriage is more stable.

Because of the expectation for Chinese women to marry up, many Chinese men from the lower-middle and working classes have the most difficulty finding partners. In Chinese society, these men are referred to as bare branches/ guang gun/光棍. The guang guns are already in the base level of society and cannot fulfill Chinese women's expectation of marrying up. Fincher (2014) points out that "most of [guang guns] are poor, uneducated and rural" (p. 22). Fong (2016) argues that the population of guang guns will continue to increase. She writes, "ten years later [in 2026], one in four men in China will be a low-skilled bachelor" (p. 109). Moreover, in Chinese society, guang guns are viewed as potential disruptors to social harmony. Fincher (2014) recorded an editorial that explains the living situations of guang guns in the People's Daily, a newspaper sponsored by the CCP:

The continual accumulation of unmarried men of legal marrying age greatly increase the risk of social instability and insecurity....[It was reported that] older unmarried men in villages surveyed in the past three years have taken part in activities destroying social order, including gambling, rioting, stealing and gang fighting. (p. 21) 
Thus, single women, who constitute the smaller population in the era of reforms, are expected to "tame" guang guns even though marrying these men is against the cultural expectation of marrying up and possibly their personal inclinations to remain single. The discourse of the leftover women that has emerged in this context, to a large degree serves the purpose of disciplining and compelling single women to marry single men.

The leftover women include two predominant stereotypes and can be classified into several levels. The first stereotype of leftover women can be summarized as ugly, unwanted women. This stereotype is of women who lack physical beauty and thus cannot attract men to marry. Gradually they become jaded, blame men for being evil, and turn into pathetic misandrists. The second stereotype is of women who are unrealistically picky beauties. This stereotype of leftover women is often represented as women who are beautiful but are extremely picky and have unrealistically high expectations for their partners to be perfect people.

Although these two stereotypes are different, they are similar in terms of indicating that single women are problematic and should be educated. The single women who fit into the first stereotype are supposed to understand that it is due to their unattractiveness that they cannot find partners. Thus, they should stop blaming men for their status of being leftover. The single women who fit the second stereotype should be educated to be realistic and understand that the perfect person doesn't exist. In short, these stereotypes contribute to the discourse that argues that leftover women are troublemakers and should be disciplined to marry. 
Moreover, in Chinese society, different terms are used to refer to leftover women, which I believe constitute a hierarchy of discrimination based on women's ages. Below, I list these terms and explain the hierarchy:

Level One (the basic level): single women between 25 and 27 are labeled as "Leftover Women Warriors” (Sheng Dou Shi/剩斗士), which means that they fight in order to find partners.

Level Two: single women between 28 and 30 are labeled as "Leftover Women Who Must Succeed” (Bi Sheng Ke/必剩客), which means that they have no time to waste and must find partners as soon as possible.

Level Three: single women between 31 and 35 are labeled as "Buddhas of Leftover Women” (Dou Zhan Sheng fo/斗战剩佛), which means that they have already surpassed most single women in terms of the difficulties of getting married. Level Four: single women above 35 are labeled as "Great Sages of Leftover Women” (Qi Tian Da Sheng/齐天大剩), which derides these single women for being leftover for so long.

Level Five (the Highest Level): single women above 45 are labeled as "Kings of Leftover Women” (Sheng Zhe Wei Wang/胜者为王), which ridicules these single women for beating all leftover women and becoming their kings by achieving the ultimate "success" in terms of failing to finding partners.

These labels are used to shame single women even though they may have successful careers and belong to the middle or even upper classes. In contrast, most 
middle-class single Chinese men over 30-years-old are labeled as “Uncle” (Da Shu/大叔), a name that often used in Korean romantic dramas that depict how handsome, mature, successful, rich, middle-aged men fall in love with young and poor girls. Thus the connotation of "uncle" is positive and in sharp contrast with the connotations of the labels assigned to unmarried women. A popular Chinese saying explicitly reveals the sharp difference between the cultural interpretation of aged men and women: A man in his forties is a flower in bloom, but a woman is soybean residue (Nan Ren 40 Yi Zhi Hua, Nv Ren $40 \mathrm{Dou} F u$ Zha/男人 40 一枝花, 女人 40 豆腐渣).

Although the discourse of the leftover women is discriminatory, the Chinese government has engaged in promoting this discourse as part of its ongoing practices of disciplining and compelling single women to get married through shaming them and creating psychological burdens for their parents. For example, on March 10, 2011—a few days after International Women's Day — an article titled “How Many Leftover Women Deserve Our Sympathy?" showed up on the website of the All-China Women's Federation. ${ }^{33}$ The article argued that "as women age, they are worth less and less. So by the time they get their Master's and Ph.D., they become old and ugly like white pearls become yellow and lose their shine." The article concluded that "most leftover women do not deserve our sympathy; instead, they need to be educated and be reflective on their behaviors.” When I baidued the keywords “剩女/leftover women” and “新华网

\footnotetext{
${ }^{33}$ The article was original published on the website of All-China Women's Federation, which is a governmental organization that aims to promote gender equality in China. However, this article was revoked later from this website. But I managed to retrieve this article from an online forum (http://m.kdnet.net/share-8839395.html) in which a user copied the content of the article before it was revoked. I translated this article from Chinese into English.
} 
/Xinhua.net," a website sponsored by the Chinese government on June 11, 2019, at 11:30 a.m., I found numerous reports on the leftover women on the Xinhua net. ${ }^{34}$ The following shows the top three articles in the first page that I found:

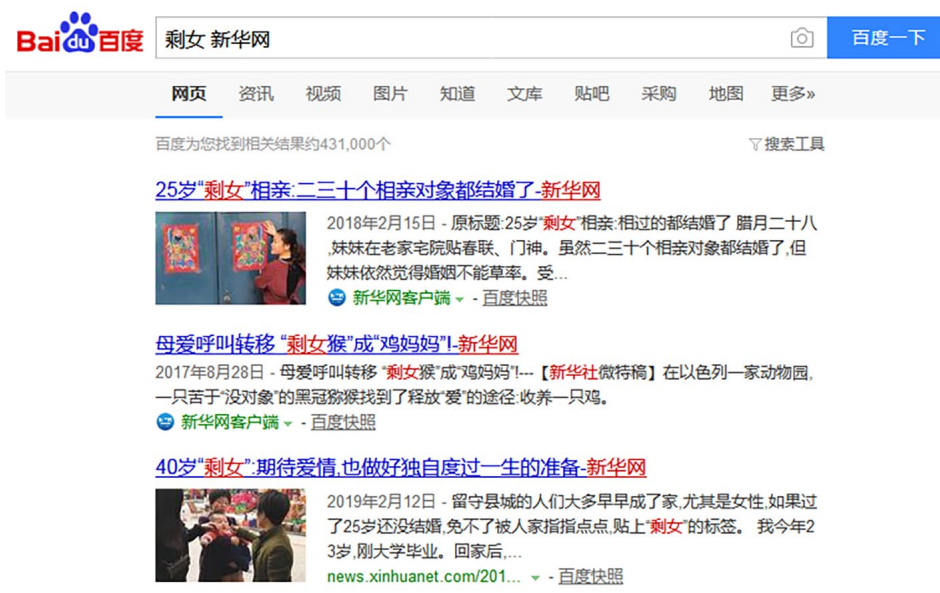

Figure 3. 2 Screen Capture of Online Articles On Xinhua Net. This screen capture was taken by the author.

The first article, "A Blind Date of a 25-Year-old Leftover Woman: All the Dozens of Previous Dating Partners Got Married," describes a 25-year-old single women's dilemma of requesting true love, encountering difficulties finding partners available, and puts forward the statement that "women should engage in blind dates as young as possible" (Li, 2018). The second article, "The Shift of Maternal Love: A Leftover Monkey Becomes a Mother of a Chicken," describes how in a zoo in Israel, a leftover female monkey could not find partners and thus lacked the outlet to release her maternal instinct. Finally, she "adopted" a chicken who ran away from the barn and stayed around her, treating the chicken as her child (Chen, 2017). Although this article focuses on animals, it

\footnotetext{
${ }^{34} \mathrm{Baidu}$ /百度: Baidu is the biggest search engine in China. Because Google is blocked, most Chinese people use Baidu to search for information.
} 
still serves the purpose of shaming single women. The third article, "A 40-Year-Old Leftover Woman: I Am Still Expecting Love, But I Am Prepared to Spend the Rest of My Life Lonely," describes the living situation of a 40-year-old single woman, ending with her decision to travel to Yunnan Province, which is often advertised as a romantic place, where she expects to meet new people (Zhou, 2019).

In recent years, the participation of the Chinese government in promoting the discourse of the leftover women has become less overt. For example, on February17, 2017, China Women's News, sponsored by the All-China Women's Federation, published the article "The word 'Shengnv/Leftover Woman' Should Disappear." The article argues that aged single women are not leftover women; instead, remaining single is merely a woman's choice of lifestyle. Aged single women are strong, independent, brave, and typically lead productive lives (Mo, 2017). However, this doesn't mean that the Chinese government respects single women's decisions of following their hearts to remain single. Three months later, on May 17, 2017, Junke He, one of the primary officials of Central Committee of Chinese Communist Youth League, announced that the Chinese Communist Youth League would begin to educate young Chinese people to have a correct attitude to love and marriage and help aged single Chinese people to find partners. On that day, the hashtag "The Communist Youth Leagues Helps Aged Single People to Find Partners" was trending in Weibo, Chinese Twitter. Some Chinese netizens ridiculed this policy and left comments like, "Thanks for taking care of me. I am waiting for the Communist Youth League to assign me a girlfriend/boyfriend." Since then, local Chinese 
governments have worked to help single people find partners by holding parties and organizing speed dating events.

Besides disciplining Chinese women to get married, the Chinese government also emphasizes that married Chinese women should have children, although the number of children has changed from one child to two children with the implementations of the onechild policy and the two-child policy in the era of reforms. On September 25, 1980, the Chinese government published the document, "A Letter to All the Members of the Communist Party and the Communist Youth League Concerning Controlling Chinese Population Growth.” This document advocated for communist members to voluntarily limit their family size to one child. In December 1982, the one-child policy obtained a nearly constitutional status. This policy was primarily put forward and supported by a group of scientists in STEM. Deng Xiaoping, the head of the Chinese government at that time, believed that one of the most critical tasks of the Chinese government was to develop the economy and to transform China into a global superpower. As discussed in Chapter Two, Deng believed in science and technology and had strong faith in scientists and engineers to help him to solve the country's problems. However, the Cultural Revolution had disrupted the Chinese educational system, which resulted in a scarcity of social and natural scientists available to work with Deng. Thus, he had to turn to "rocketmen"-scholars in military science who were under protection from political violence during the Cultural Revolution—-for help. He appointed Song Jian, a Russiantrained missile specialist, to be the head of a research group, composed mostly of rocketmen and mathematicians, which worked to formulate population policies. 
Song's group argued China's huge population seriously hindered the development of the country. These scientists' solution to China's demographic problem was significantly impacted by Western scientists such as Olsder, Kwakernaak, and Goldsmith (Greenhalgh 2007, Fong 2016). This group laid out:

[A] radical new vision of population control as a giant social-systems-engineering project. In this vision, the problem of population was one of an imminent population-economy-environment crisis. Cybernetics (or control-theoretic) equations showed that the 'scientific' and 'only effective' way to avert it was a drastic one-child-for-all policy to be implemented immediately. (Greenhalgh, 2010, p. 32)

After the implementation of the one-child policy, there were some minor changes. For example, due to the more conservative environment in the rural areas in China, most families wanted to have a boy no matter the cost. Thus, the one-and-half-child policy was implemented in these rural areas. This policy allowed for households to have a second child if their first child was a girl. In this way, the girls signified the half. Furthermore, in order to better connect with Chinese people of minority ethnicities to show that the $\mathrm{CCP}$ emphasized their interests, any families that included one parent of minority ethnicity were allowed to have two children. Despite these minor allowances, millions of Chinese families were under the strict control of the one-child policy.

In order to ensure the implementation of the one-child policy, the Chinese government performed many practices. It began to deliver free contraception to families. Doctors of various specialties were trained to perform abortion and sterilization 
procedures. Scientists and engineers were funded by the Chinese government to develop medicines and technologies of birth control. Hundreds of pills for emergency, short-term, and long-term contraception have become available in the market. Family planning institutions, which focused on developing family planning science and technology and educating specialists, became an indispensable part of almost every medical college in China.

Moreover, the government punished families with multiple children in many ways. Chinese couples who worked in state-owned institutions such as governments, universities, factories, and companies would lose their jobs if they had more than one child. In many rural areas, the families that didn't follow the one-child policy or the oneand-half child policy had their valuables, such as cows, houses, and savings, confiscated. In addition, in some Chinese provinces that more strictly carried out the one-child policy, if a family had more than one child, the father or in some cases the mother was sentenced to jail time. Fong (2016) interviewed a former Sichuan County Official who told her "as long as we kept the quotas, we could do anything: destroy homes, property, jail people" (p. 72).

Furthermore, the Chinese government tried to persuade Chinese couples to only having one child. For example, the Chinese families who only had one child could get a monthly stipend from the government. The Chinese government made the promise that "the government would take care of aged people if they only have one child" (Zhi Sheng Yi Ge Hao, Zhen Fu Lai Yang Lao/只生一个好, 政府来养老), which later became one of the most popular slogans for the one-child policy. This slogan was used to fight against 
the traditional Chinese belief that through raising children, especially sons, parents would have a secure future when they become old because they would be taken care of by their children (Yang Er Fang Lao/养儿防老). The discourse that having only one child is both good for the child who can live better off and good for the parents who can face less economic pressure, can better balance their careers and family lives, and have more spare time to enjoy their lives, was also prevalent.

China's one-child policy had successfully slowed down the rate of population growth. In 1980 the rate of population growth was $1.254 \%$; in contrast, in 2010, the rate of population growth was $0.483 \%$ [The World Bank (c), n.d.]. However, the one-child policy had resulted in two serious issues, which bothered the Chinese government significantly so that they later abolished the one-child policy and implemented the twochild policy, which is the current family planning policy in China. First and foremost, "China's one-child policy so tilted gender and age imbalances that in little under a decade there will be more Chinese bachelors than Saudi Arabians, more Chinese retirees than Europeans" (Fong, 2016, p. 7). In fact, as discussed earlier in this chapter, due to the gender imbalance in China, millions of Chinese men cannot find partners. Moreover, because the number of senior citizens is increasing rapidly, the Chinese government faces considerable pressure in terms of taking care of senior citizens. It was reported that by 2017 the Heilongjiang Province had more than 20 billion Yuan deficit (approximately 2.9 billion USD) in pensions, and 13 more provinces would face fiscal deficit in 2018 (Wu, 2017). On Weibo, in April 2019, one of the highest trending hashtags was "The Chinese government will run out of pension by 2035.” 
Noticing that the growing aged Chinese population poses a serious issue, the Chinese government, instead of keeping their promise to take care of citizens when they become aged if they only have one child, now argues that senior citizens should support themselves through selling their apartments and has raised the retirement age. The Chinese government wants to shift some of their support away from senior citizens toward requiring more people to participate in sharing these responsibilities.

Moreover, another threatening situation that the Chinese government has encountered is that an increasing number of Chinese families refuse to have even a single child. The one-child policy has significantly influenced the views on reproduction in Chinese culture. Many Chinese families have had good experiences of having only one child, so the cultural belief that the more children (especially boys) you have, the more happiness you have has been challenged. Accordingly, many young Chinese people who grew up as the only children of their families have little interest in having more than one child or even one child. In Chinese society, an increasing number of Chinese families have become DINK (Double Income, No Kid) families. According to China.org.cn, "by 2002, nearly 600,000 dink [...]families have appeared in China's large and medium-sized cities, including one in every 10 households in the capital" ("More Dink Families Appear in China," 2002).The DINK families, more importantly the Chinese people's changed ideas concerning reproduction, create a serious issue for the Chinese government. As a country that depends heavily on cheap labor for its production industry and that faces a pension shortage, China needs to have more young working people. 
To boost population growth, the Chinese government implemented the selectivetwo-child policy in 2013. This policy allowed Chinese couples, when at least one of the parents was an only child, to have two children. However, "about 700,000 Chinese couples in which one of the partners is an only child applied to have a second child by the end of August. [...] That's far fewer than previous estimates by the authority, which put the annual births increase due to the policy change at more than 2 million" (Shan, 2014). Witnessing this unsatisfactory result, since January 1, 2016, the universal two-child policy that replaced the selective-two-child policy has been in effect. This policy currently allows every Chinese family to have two children. According to the Chinese government, there are four primary purposes of the two-child policy: to optimize the demographic structure, to increase labor supply, to alleviate the stress caused by the growing aging population, and to improve the health of the economy ("The Universal Two-Child Policy," n.d.).As can be seen, all these purposes are strongly related to China's economic development. In 2018, the Chinese government announced that the department of family planning was dismissed. This decision implies that the Chinese government has completely disregarded the idea of population control.

However, even though all Chinese families are allowed to have two children, many of them still only want to have one child or none at all. Birtles (2018) reported:

China's family planning commission has revealed the country's birth rate dropped by 3.5 per cent [in 2017], despite moves over the past couple of years to fully end the one-child policy. There were just over 17 million new babies born in mainland China in 2017. 
Similarly, Zeng and Hesketh (2018) point out that based on the recent measures of population growth, the effect of the two-child policy in terms of increasing population is not satisfactory and will remain so for a long time (p.1930). Thus, instead of curbing the Chinese population growth, the Chinese government has begun to discipline couples to have two children in order to increase the population. On August 7, 2018, Renming Ri Bao, the official newspaper of the CCP, published the article "Giving Birth is a Familial Matter and a National Issue Too/ Sheng Wa Shi Jia Shi, Ye Shi Guo Shi/生娃既是家事 也是国事” (Zhang, 2018). Shortly thereafter, this way of framing population growth became the slogan of the current CCP's population policy. This article argues that the local governments should employ new strategies to encourage Chinese couples to have two children.

Based on China's lunar calendar, 2016 was the year of the monkey and the year when the universal two-child policy began to take effect. As is their routine, the Chinese government released a commemorative stamp. (See the stamp below):

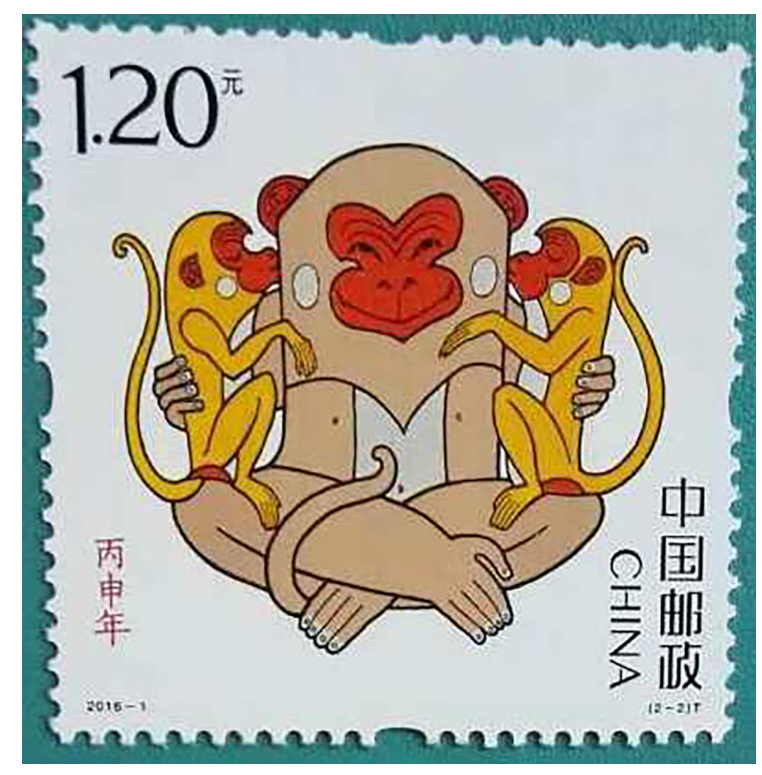


Figure 3. 3 Stamp Of The Year Monkey (2016). This photo was taken by the author. In this stamp, an adult female monkey happily holds two baby monkeys in her arms. The two baby monkeys are kissing the adult monkey. This commemorative stamp was interpreted as the Chinese government's celebration of the two-child policy. In designing and releasing this stamp, the Chinese government implied that having two children would bring a mother tremendous happiness. In the year of 2019, the Chinese year of the pig, the Chinese government released a new commemorative stamp that seems to promote an even larger family. (See the photo below)

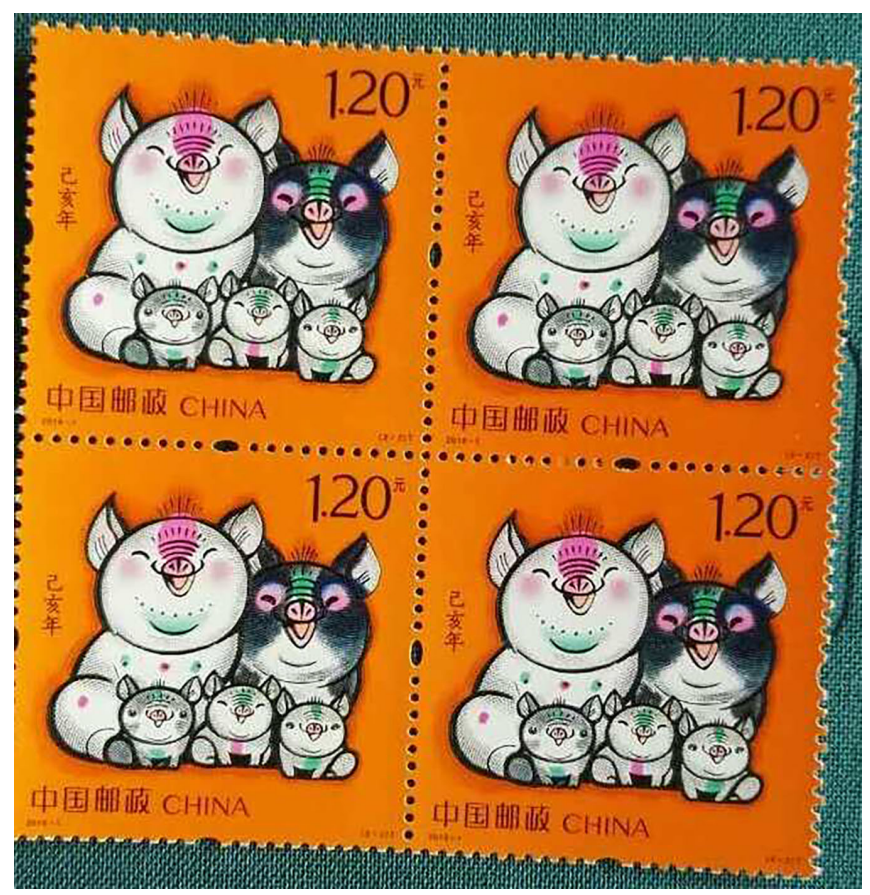

Figure 3. 4 Stamp Of The Year Pig (2019). This photo was taken by the author. In this stamp, there is a smiling pig family that includes two adult pigs and three baby pigs. Although so far the Chinese people are not sure whether this stamp is a hint of the Chinese government's plan to release a three-child policy, it is certain that the era of curbing the population has passed and that China is in the era of boosting birth rate. 
In the beginning of the era of reforms, the one-child policy was implemented, then replaced by the selective two-child policy, and later by the universal two-child policy that is the current law. Despite the changes in the Chinese government's focus, the Chinese government continues to emphasize that a family should have a child or several. To fulfill this purpose, the Chinese government establishes laws and uses media strategically. According to Article 62 of the Labor Law of the People's Republic of China, "after childbirth, female workers shall be entitled to no less than ninety days of maternity leave with pay” (National People's Congress Standing Committee, 1994). Through providing about three months of paid maternity leave, the Chinese government hopes that women are more willing to give birth. Moreover, every year, the Chinese government organizes an event named "Beautiful Chinese Families." In 2017, 991 families were commemorated as "Beautiful Chinese Families." According to Yuancha Li, the vice-chairman of China, a beautiful Chinese family emphasizes moral education for their children by teaching them to love China and Chinese people, to work hard, to respect and be interested in science, and to support and promote socialism ("Beautiful Chinese Family in 2017," 2017). This means that the premise of being a beautiful Chinese family is - first and foremost - to have a child. In fact, in Chinese state media, one can easily find numerous articles and reports that depict the happiness that a child, now two children, brings to a family. This political propaganda makes a distinction between beautiful families with children from "undesirable" families that are without a child. 
There is one more point that I need to clarify here. Although the Chinese government expects newborn babies, it does not welcome babies who come from nontraditional families that do not include a husband and a wife. China has the hukou system, which significantly prevents the birth of illegitimate children by making their living situation difficult in the society. Hukou is a Chinese household legal registration based on a person's birth place. The process includes four crucial steps:

Step one: After 12 weeks of pregnancy, parents should bring their marriage certificate, their national ID cards, and their hukou books to the government to get birth permission. Step Two: Parents bring the birth permission to a hospital. Then the hospital will create a record of the pregnant woman and her baby.

Step Three: After the birth of the baby, the hospital will give parents the birth certificate of the baby.

Step Four: Parents can register their baby for a hukou after showing the government once more their marriage certificate, their national ID cards, their hukou books, along with the birth certificate of their baby.

Accordingly, a baby whose parents do not have a marriage certificate won't have a legitimate birth certificate. This means that the pregnant mother cannot receive treatment in public hospitals that provide more affordable service and even in most private hospitals in China. Moreover, even after the birth of a baby at home or abroad, the baby won't have a Chinese hukou, which is the document that enables the baby to receive social benefits such as the free nine-year education. Moreover, without this document, when the baby grows up, they cannot register for the college entrance examination, which 
makes costly foreign education their only option. This system reinforces the Chinese government's disciplining of women to make them get married first before having babies.

In summary, the Chinese government has a great concern for single women.

Fincher (2014) points out:

Single women threaten the moral fabric..., for being free agents, unnatural in failing to perform their duty to give birth to child and tame a restless man. From the government's perspective, married couples are much less likely to cause trouble. (pp. 22-23).

Thus, the Chinese government makes an effort to discipline single women first into marriages and then to become mothers through implementing a variety of policies and promoting discourses that disfavor and even stigmatize single women and childless married women. In summary, the articulation of Chinese myth, language, Confucianism and Daoism, and the Chinese governments' practices makes being wives and mothers a largely nonnegotiable option for most Chinese women, as stated by To (2015), "the truth [is] — marriage [and family are] still a big deal [for women] in China—both in the past and the present" (p.xv). The link between Chinese women and as being a wife and mother is particularly tenacious, in spite of major shifts in expectations about women as professionals.

\section{Chinese Women's Roles as Professionals}

The previous section focused on one of the Chinese women's primary roles, being a wife and a mother. It argued that due to the articulation of Chinese myth, language, 
Confucianism and Daoism, and the Chinese governments' political practices, Chinese women have always been expected to get married and to have children. This section turns to the second role of Chinese women: being professionals.

Professional women were very rare in ancient China. In China's long history, women were, and largely still are, viewed as inherently not suited as breadwinners. This viewpoint is sometimes attributed to the long history of China as an agricultural nation, in which laborers were mostly men. In reviewing the anthropological research, Stockard (2002) concludes that:

Some [anthropologists] put forward the strength theory, which attributes men's monopoly of plowing to the on-average greater upper-body strength of adult men over women.... Other anthropologists favor the expendability theory, based on the growing need to physically defend agricultural land from outsiders. (p.41)

Stockard's statement clearly indicates that in ancient China, which heavily relied on agriculture, men were preferred as laborers because of their physical strength. Moreover, as discussed previously, Confucianism supports the argument that women should stay inside and merely focus on taking care of their husbands and sons, as indicated by the phrase “pin ji sichen/牝鸡司晨,” which was and is used to criticize female politicians who oppose male emperors as well as women who actively participate in their husbands' or sons' outside affairs, such as making decisions for them. ${ }^{35}$ These women are regarded as an evil power that will bring disasters to the world. In ancient China, few women

\footnotetext{
${ }^{35}$ The phase “牝鸡司晨” can be literally translated as: Hens replace roosters and begin to crow. The hens are understood as abnormal and unnatural.
} 
received any education, and many received the surgery of foot binding to make their feet small, which aligned with the standard of beauty in ancient China. These practices restricted women's ability to move around and to engage in labor. Although in ancient China, some women strived to make a living through producing cloth or being matchmakers, most Chinese women were housewives. ${ }^{36}$

This unfavorable situation in which women were discouraged from and not prepared for becoming professionals has changed since the $1900 \mathrm{~s}$, most significantly in the era of reforms. In order to understand women as professionals, the following analysis lays out two articulated forces, which are comparatively new when compared with myth, Confucianism and Daoism but have begun to exert increasingly important impacts on Chinese society. They have profoundly motivated and prepared Chinese women to join the workplace.

\section{The Discourse of The New Woman}

The first force is the discourse of The New Woman. As discussed in Chapter Two, since the Westernization Movement and the New Culture Movement, Western ideas have travelled to China en masse. Along with the idea that science and technology are important because they are thought to bring positive changes, the Western discourse that advocates for gender equality and for women to be independent also has impacted

\footnotetext{
${ }^{36}$ Francesca Bray in her book Technology and Gender: Fabric of Power in Late Imperial China discusses how women in the Song dynasty managed to work as cloth makers. Bray (1997) writes "Sericulture and silk weaving spread to new areas, so that a large number of women became involved in the production of high-value textiles....But tax demands were high and grew during the Song... women had to work increasingly hard just to pay their taxes" (p. 206). Thus, although it was a great improvement that women could work outside the home, they still struggled to support themselves independently.
} 
Chinese society in significant ways. One of its primary impacts has been the emergence of the discourse of The New Woman.

The key idea of the discourse of The New Woman is that with the development of the Chinese society, modern Chinese women should be different from traditional Chinese women who were generally categorized as submissive, illiterate, and dependent housewives and mothers. In contrast, new Chinese women should be literate, independent especially in terms of their finances, and have their own interests and careers.

Back in the early 1900s, a prominent Chinese scholar, Cai Yuanpei-who later became the president of Peking University, the best Chinese university in the humanities, and whose given name "Yuanpei" was chosen by Peking University as the title of one of its divisions because of his profound influence on Chinese intellect and education — made a famous announcement concerning what kinds of wives he was willing to accept after being bothered by many matchmakers. Cai stated that his potential wife should:

1) Not have bound feet,

2) Be literate,

3) Accept that he won't take concubines,

4) Be open to the option of remarrying after his death, and

5) Agree to divorce if their relationship is filled with irreconcilable struggles. (Shen, Cai's criteria resonated with the argument that Chinese women should make progress and become new women. The woman Cai wanted was fundamentally different from the women who were preferred in the traditional Chinese culture: illiterate women with small 
feet who were happy to accept and take care of their husbands' concubines, and to devote their whole lives to one partner only. Cai's idea, although still centered on a woman's role as wife and mother, promoted Chinese women to be more progressive. Because of his social influence, many Chinese men followed his idea and wanted to marry new women, which in turn motivated women to receive education and become more self-sufficient.

Chen Duxie, the scholar whose quotes "for democracy" and "for science" were the two slogans of the New Culture Movement, also contributed to the discourse of The New Woman in significant ways. In 1916, Chen published an article "the Year of 1916" that criticized traditional Chinese culture for oppressing women and argued that women should fight against their status of being subordinated. Chen (1916) wrote:

As young people of 1916, what should you do?

First, you need to take the position "to conquer" not the position "be conquered". Among all human beings, men conquer and women are conquered; white people conquer and non-white people are conquered....As proud people of 1916, you should wash away shame that is caused by this logic.

Second, you should respect your subjectivity and not become subordinate to others. The Confucian thought of three obedience that requires people to be obedient to rulers; children to be obedient to fathers; and wives to be obedient to husbands...makes people subordinated slaves. Instead, people should center on themselves...both men and women should fight against the status of being subordinate and maintain their independent and autonomous subjectivities.

$\mathrm{Hu}$ Shi, another influential thinker of the early $20^{\text {th }}$ century, also promoted the discourse 
of The New Woman. He made a significant speech, "American Women," that advocated for Chinese women to learn from American women and to become new women at Beijing Normal University. Hu (1918) said:

[When I encountered and observed an American woman at a dinner table that she shared with two Chinese couples, I found out that] these three women are differentiated by their outlooks on life. Chinese women's outlook centers on being virtuous wives and caring mothers, in contrast, the American women's outlook goes beyond being virtuous wives and caring mothers....This expansive outlook of American women is founded based on women' perception of independence...American women all have the idea of being independent....and their life goals are probably about achieving independence....American women think that men and women are equal human beings, and that they should all work hard to be free and independent people.

Later in the speech, Hu discussed how American women received higher education and became career women who actively participated in politics to fight for women's rights. In short, Hu promoted Chinese women to learn from their American counterparts to receive education, to find jobs, and even to engage in politics.

An increasing number of female scholars not only appeared but also began to gain prominence in the society since the late 1800s. Qiu Jin, who was born in 1875 and received education in Japan, a more Westernized country at that time, is regarded as the pioneer of new Chinese women. She devoted to participating in the rebellion against the Qing Dynasty and promoting gender equality regardless of her husband's disagreement. 
She founded Zhong Guo Nv Bao, an influential Chinese newspaper that centered on advancing women's education and rights and opposing oppressive practices such as foot binding. Although Qiu was executed by the Qing government, she inspired many Chinese women to choose different lives from traditional Chinese women. For example, Lü Bicheng, Xiao Hong, Shi Pingmei, and Chang Eileen were four outstanding professional women from 1910s to $1940 \mathrm{~s}$. These four women not only received good education and wrote influential pieces of literature to support themselves, but also openly criticized the oppression of women and advocated for women to receive education and become independent.

In 1935, the release of the film New Women, in which one of the main characters played by Ruan Lingyu, a famous actress at that time, propelled another large scale discussion of The New Woman. The film depicts two images of new women: a female intellectual and a female worker (Cai \& Sun, 1935). Through contrasting the female intellectual's tragic death and the female worker's promising future, this film not only criticizes the society for oppressing women but also states that new Chinese women should also engage in politics and bravely fight against sexism. These historical figures and events helped to articulate being literate and employed to the socio-cultural expectations for a Chinese woman.

In the more recent years, the popularity of the discourse of The New Woman has lessened in Chinese society with the increasing number of women receiving education and having jobs. Thus, career women no longer seem a novel phenomenon. However, contemporary Chinese culture continues to promote the image of a woman who has a 
successful career. For example, in contemporary Chinese society, there is a very popular genre of TV series labeled “Big Female Characters Show/大女主戏”. These TV series focus on depicting the process of how women develop themselves, overcome many difficulties, and have successful careers while at the same time having admirable families.

Besides advocacy by intellectuals and promotion in Chinese popular culture, many Chinese women's organizations also support this idea that career women are preferred in contemporary China. For example, in 1989, The All China Women's Federation (ACWF) used the slogan of women's four selves to represent a new Chinese woman who should have self-respect, self-reliance, self-confidence, and selfimprovement.

The discourse of The New Woman has profoundly impacted women's roles. This discourse has successfully contributed to encouraging many Chinese women to receive education and to join the workplace. However, unfortunately, the persuasiveness of this discourse is significantly based on its articulation with the traditional social expectation for women to be desirable in order to marry men with higher status. For example, TV series that belong to the genre "Big Female Characters Show" often depict how a welleducated professional woman attracts a successful man. In fact, in contemporary Chinese culture, an increasing number of men prefer to get married to women with bachelor's degrees and with respectable jobs such as university professors and civil servants, although some of them want their wives to quit their jobs after getting married. As a result, receiving college education and joining the workplace have become a nonnegotiable option and a crucial step for many women to marry up. 
Additionally, the articulation of the discourse of The New Woman with the socialcultural-historical-political expectation for women to become mothers and wives redefines the meaning of being a Chinese woman in the era of reforms. To be an ideal Chinese woman, the person not only needs to be a virtuous wife, a caring mother, but also a well-educated successful professional at the same time. This expectation creates an almost impossible position for women with its inevitable tensions in terms of the contradictory personality traits that they are expected to embody. For example, as argued previously, being virtuous wives and caring mothers requires women to be dependent and submissive, but being successful professionals requires women to be assertive and independent.

In summary, the discourse of The New Woman has significantly impacted women's roles in contemporary Chinese culture. Because of its promotion for women to receive education, to find jobs, and to be independent, especially economically, being working women has become a trend in contemporary Chinese society. However, to this day, this discourse still fails to undermine the articulation, which I discussed previously, that disciplines women to get married and to have children.

\section{The CCP's Political Practices}

The second force that contributes to women's new roles as professions is the CCP's political practices. Because the CCP claims to follow Marxism, which pursues an egalitarian society in which both men and women equally work and are served, and more importantly because the CCP needs more working laborers to develop its economy, the 
CCP has implemented many political practices to encourage and prepare women to join the workplace.

Mao Zedong, an influential leader of the CCP and the first Chairman of the PRC, made the famous statement, "women can hold up half the sky." In the West, Mao's saying is often translated as “women hold up half of the sky." However, based on Mao's original phrase “妇女能顶半天天,” the modal verb “can” should be included in this sentence. The addition of the word "can" into this sentence changes the connotation that Chinese women are important to the connotation that Chinese women can be important if they work hard enough, which I believe is what Mao argues. However, the fact is that the cultural reality is more complex than the words convey. Under Mao's administration, the two predominant options for women were positions of superficial status and those of intense manual labor. Women in rural areas were encouraged to compete with men and even to surpass men in expending manual labor in agricultural work. Women in urban areas were assigned jobs in state-owned organizations (Dan Wei/单位) by the Chinese government as long as they finished their education. Xian and Woodhams (2008) point out that in Mao's era, many women were "allocated to supporting positions that fitted their perceived abilities regardless of their education background. These positions held little room for promotion and a greater risk of redundancy" (p.411). For example, they worked as salespersons and secretaries, which gave the appearance of including women in organizations, but did not give them actual positions of power. In contrast, the rest of the women were assigned to work in heavy industries such as mining, construction, and petroleum, which were regarded traditionally as men's fields. Most of these women were 
expected to conduct manual work. In fact, from the 1960s to the 1970s, the CCP promoted the image of "iron women" (Tie Gu Niang/铁姑娘). Also known as iron girls, this term referred to women who were strong physically, had visible muscles, were capable and enthusiastic about conducting heavy manual work, and did not have typical female features such as a comparatively smaller body size and long flowing hair. Below is a poster that was released by the Chinese government of an iron woman, a female construction worker. ${ }^{37}$

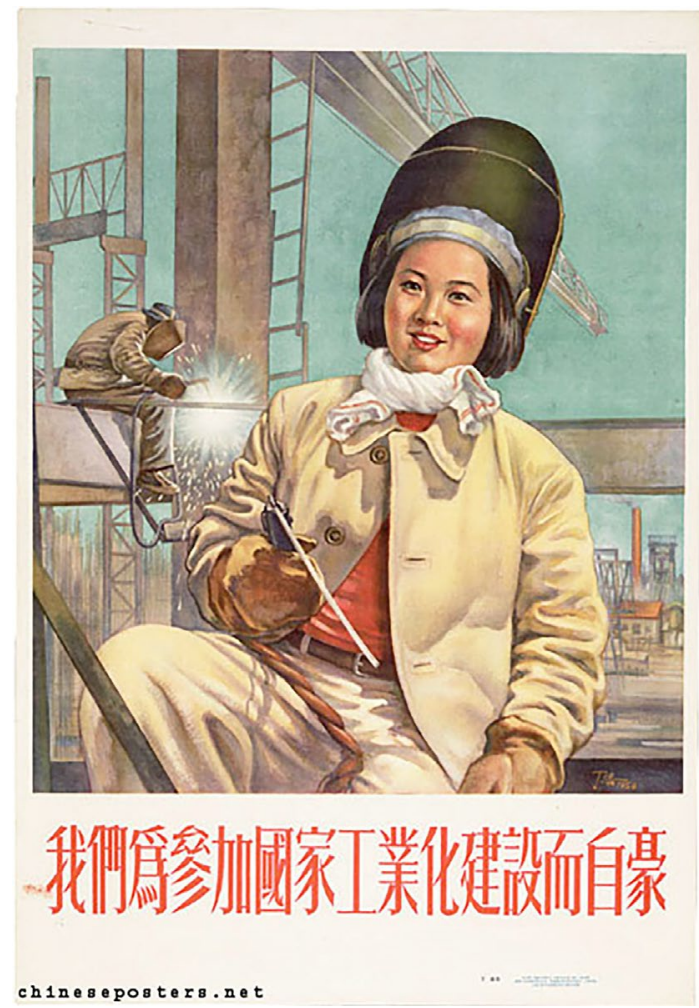

Figure 3. 5 A Poster of An Iron Girl. Title: 我们为参加国家工业化建设而自豪 (We Are Proud Of Participating In The Founding of Our Country's Industrialization). Designer:丁浩(Ding Hao). Date: February, 1954. Publisher:华东人民美术出版社

\footnotetext{
${ }^{37}$ Appendix A is the fair use report to support my use of this image in my dissertation.
} 
(Huadong Renmin MeishuChubanshe, Shanghai). Retrieved from: https://chineseposters.net/posters/e16-17.php.

Although the image of iron women reflected the CCP's endeavor to improve women's status through showing that women are as strong as men, this image failed to empower Chinese women by either crediting their intelligence or advocating for their education. Thus, women were viewed as physically but not intellectually equal. In fact, the image of iron women pressured Chinese women into a situation where they had to conduct heavy manual work in order to fit into this positive image. After studying and interviewing actual iron women, Jin (2006) writes:

A veteran of the Shengli Oil Field women's brigade stressed that there were ways in which the establishment of women's work brigades eroded 'a certain kind of protection' that women had once received in the past [when they worked in heavy industries].... Whereas women's brigades consistently received official recognition, they also performed their share of undesirable tasks and endured considerable discomfort. Gu Yingzhen (pseudonym), a former brigade leader in Nanjing's Shuang Zha Township, pointedly noted that Iron Girls performed work that was at once shunned and arduous: "The women's brigade specialised in things that other people did not want to do. In the spring we planted seedlings, watered the plants and worked on the water treadmills ... during the harvest we worked day and night. Two strong young men collapsed from exhaustion. They fell asleep in the fields and refused to get up. We were stronger than them. (p. $620-621)$ 
This competition for women to be stronger than men in performing manual labor resulted in many women suffering from serious health issues from exhausting their bodies when they were young. Furthermore, due to the overemphasis on manual labor, other aspects of women, especially their intelligence, were ignored. As a consequence of this persuasive anti-intellectual image, many women were not enthusiastic about receiving education and thus were trapped in their situations as manual laborers rather than decision makers.

It was not until 1986 that the CCP implemented the Compulsory Education Law, after which an increasing number of Chinese women have been able to support themselves by utilizing their intelligence. In general, this policy states that Chinese children who are around the age of 7 should attend schools and all Chinese citizens should receive at least 9 years of education. In order to fulfill this task, the Chinese government has initiated several strategies. For example, the government covers all children's tuition from public elementary school (about 6 years) to middle school (about 3 years), has built more schools (especially schools in rural areas), and recruits college students to teach several years in rural schools as a condition to waive their university educational and living costs. This policy fundamentally changed the situation in which many Chinese people, especially Chinese women from poor rural areas, were illiterate and denied educational opportunities due to their families' inferior economic situation and their comparatively isolated geographical location. In $1982,51.137 \%$ of Chinese women aged 15 or above were literate; in 1990, $68.072 \%$ of Chinese women aged 15 or above were literate; and in $2010,92.711 \%$ of Chinese women aged 15 or above were literate [ The World Bank (d), n.d ]. These 9 years of school enable women to be able to 
read and write, which is a crucial prerequisite to joining the job market. Moreover, some girls who demonstrate their intelligence in elementary school and middle school also change their parents' minds from the notion that girls are inherently not as smart as boys and will have difficulties finding satisfactory jobs to support themselves and their parents. These girls sometimes reverse the notion that girls do not need to receive much education but rather need to focus on finding breadwinners. Impressed by their daughters' academic performance, which means that there exist great possibilities for their daughters to become prosperous in the future, many families, even including some rural poor families, decide to support their daughters to receive higher education even though this requires the parents to work harder. According to Martin (2018), "in 2012, female college students made up 51.4 percent of the total university student population." College education not only potentially provides these women more job opportunities but also sometimes requires them to find jobs to repay their families' educational investment. In this way, women are not only prepared but also motivated and pressured to become professionals.

In addition to the implementation of the Compulsory Education Law, the Chinese government has formulated policies to protect women's interests in the job market. For example, in 1992, the Chinese government announced the "Protection of Women's Rights and Interests Law of People's Republic of China.” This law guarantees that women should enjoy equal rights to men in the spheres of politics, education, work, ownership of property, personal rights, and rights of marriage and family. This law emphasizes that women and men should be paid equally for equal work. In 2007, the government issued "Employment Promotion Law of the People's Republic of China," in 
which the government explicitly states its objective to prohibit discrimination based on a person's gender, ethnicity, religious belief, or race in the workplace.

In February 2019, the Chinese government announced that it is illegal to list the gender requirements or gender preferences in job advertisements, to reject job applicants merely based on their gender, or to ask about a woman's marital and childbearing status in job interviews. Although this practice is partly motivated by the Chinese government's purpose of propelling women to join the workplace and by the Chinese government's current two-child policy that aims to encourage women to have babies, this political practice signifies great progress with regard to protecting women's workplace rights.

The CCP's political practices are significant in China because they articulate to the Chinese societal hierarchy, in which the government occupies the highest level of the pyramid. Thus, the CCP's policies not only profoundly influence Chinese politics, but also Chinese people's perceptions and the culture. Since the CCP requires women to receive education, encourages women to join the job market, and educates women to be prepared as professionals, a growing number of Chinese women are eager to do so because it not only may fit their interests but also because they have been educated in Chinese culture, which emphasizes people's obedience to the government. Hence, many women want to be "model" citizens and to support the government's decision by joining the workplace. Additionally, many Chinese men have more open attitudes to working with female colleagues and marrying career women, and a growing number of workplaces decide to accept female workers at least in order to follow the government's regulation in order to avoid trouble. Overall, the society has become increasingly tolerant 
and supportive of female workers. All these positive changes provide women opportunities to make a living themselves, enjoy more freedom, and gain some sovereignty over their destinies.

However, the CCP's political practices that encourage and prepare Chinese women to join the workplace are also articulated with its political practices of disciplining women to get married and to have children, which creates many tensions and contradictions in women's lives. Moreover, due to this articulation, it is hard for Chinese women to completely focus on their careers and become independent not only financially but also in the sense of following their wishes to not get married or become mothers.

\section{Chinese Women as Wives, Mothers, and Professionals in the Era of Reforms}

As argued previously, in the era of reforms, Chinese women are still expected to become wives and mothers due to the articulation of Chinese myth, Confucianism and Daoism, and the Chinese governments' political practices that require and discipline them to get married and have children. However, at the same time, impacted by the discourse of The New Woman and the CCP's political practices that encourage and prepare Chinese women to receive education and to join the workplace, they are also expected to become professionals. The traditional roles of mother and wife as well as the emerging new role of professional create tremendous tensions and contradictions that Chinese women have to navigate. For example, the famous line from the popular film Lost, Found, spoken by a successful female lawyer, captures the tensions that many Chinese 
women have experienced due to the articulation of their traditional roles and new roles in the era of reforms:

Today's society has extremely high expectations for women. If you decide to focus on your career, people will criticize you for being bad and irresponsible; if you decide to focus on your familial life, people will criticize you for having no career and merely doing what you are supposed to do. (Lü \& Qin, 2018).

In fact, housewives, who still account for a large population of Chinese women, have become more vulnerable in contemporary Chinese society because they not only have to conduct all housework and rely on their husbands but they have also often been criticized in comparison with career women for being lazy, noncompetitive, and dependent, as argued by Liu and Ma (2009). But at the same time, as indicated by the discourse of the Leftover Woman, single professional women are not preferred by society or the government. They are also criticized for being irresponsible, extremely picky, and sometime even stigmatized as ugly and unattractive creatures, as analyzed previously. Cai and Feng (2013) focus on late marriage in Shanghai and find out that an increasing number of women who receive college and even graduate education, which leads to them to be able to find decent jobs to support themselves, decided to remain single and enjoy their singlehood. Obviously, these professional women become the "undesirable" leftover women from the perspectives of society and the government.

Moreover, while the society and the government expect married women to maintain their families, many women, especially professionals, hold more open attitudes toward divorce. As Zhang (2006) has argued, due to an increasing number of Chinese 
women becoming professionals, their improved material status changes their viewpoints towards divorce. Thus, the phrases that have been used to describe divorce have changed from "divorce wife," to "make a divorce," and "to negotiate divorce," which signifies women's growing agency concerning this practice. In part because of this cultural shift, as argued previously, the Chinese government introduced the experimental "calm-down" divorce period for the purpose of reducing the divorce rate in China, which consequently prevents some women from ending their unsatisfactory marriages.

Additionally, traditional Chinese culture expects Chinese women to be virtuous wives, which require women to preserve their virginities before marriage. However, many women who leave their hometowns and support themselves independently as bluecollar workers decide to have "temporary husbands." These are short-term male partners from the same cities who work to support and take care of each other. Liu (2014) points out the action of having a temporary husband reflects Chinese women's improved agency in terms of choosing their partners. However, this relation is temporary and often won't last long; many women eventually have to marry the partners preferred by their families and become traditional wives and mothers to take good care of their husbands, their husbands' families, and their children.

Moreover, many Chinese women have shifted their energy and time to their careers instead of merely focusing on their families. In response to this, the discourse that the most important thing for a woman is to be a virtuous wife and a caring mother becomes increasingly salient in popular culture. Hershatter (2007) argues that in recent years the discourse that a woman's essential role is to be a virtuous wife and a caring mother has 
regained popularity even though this discourse had become less prominent in the mid twentieth century. Hershatter (2007) writes:

The phrase 'virtuous wife and good mother,' which had circulated in the early twentieth century, enjoyed a resurgence [in recent years], as did the notion that women were primarily responsible for the healthy development and moral education of children. (p. 48)

Moreover, as pointed out by Zuo (2016), due to the hardship and discrimination many professional women experience in the workplace, many of them have to quit their careers and "retreat to the home [as] a refuge" (pp. 112-113).

In the era of reforms, the expectation of being a wife and a mother are articulated with the expectation to become professionals, which complicates Chinese women's lived experiences in significant ways. This articulation creates strong tensions and contradictions that require women to negotiate in order to fulfill their traditional roles as well as emerging ones. Thus, it is common in China that women prefer certain occupations, the two most predominant of which are teachers and civil servants, which usually do not require them to work extra time, are more permanent even when some women's performance is infringed upon by their familial duties, and have regular, usually longer holidays. Because of these affordances, women can have time and energy to take care of their families while maintaining their jobs. Through choosing these specific occupations, Chinese women try to negotiate their two roles.

Moreover, instead of understanding women's struggles and helping women to deal with difficulties by providing them with concrete strategies such as promoting men's 
responsibilities to share household chores and extending women's paid maternity leave, society promotes the image of the "super mother," which basically argues that ideal Chinese women are able to be perfect both in their careers and their familial lives. Back in 2013, there was a popular Chinese TV series Hot Mom! that describes how a fashionable, professional woman has successfully balanced her career and familial life after giving birth to her unexpected child. At the end of the TV series, the female main character who used to not like babies is happily pregnant with her second child (Shen \& Qin, 2013). Another example is the popularity of the reality show Super Mom. This reality show, which aired from 2016 to 2018 , has focused on 12 pairs of mothers and their children. All the mothers are beautiful and highly successful professional women (Yuan, 2016-2018). In fact, Guo and Zhang (2017) point out that a super mother is fundamentally different from a traditional Chinese mother who doesn't have a career and a working mother who seems to suffer from great pressures of balancing her career and familial life. Instead, a super mother is confident, knowledgeable, has an elite career, and not only raises her child, but also emphasizes her child's education to make her child successful in the future. Despite these many demands, super mothers supposedly enjoy their lives and become prosperous while performing both of their roles.

This chapter has explored Chinese women's roles as wives and mothers as well as professionals in the era of reforms and maps the tensions caused by the conflicting aspects of these two roles, which complicate women's lived experiences. As argued in the previous chapters, science and technology, which are promoted uncritically for bringing positive changes and solving all problems, have become integral in people's 
lives and integrated into the Chinese government's political practices. Thus, in order to better understand women's lived experiences as well as the status of science and technology in contemporary China, it is important to explore how the beliefs about, as well as the applications of, science and technology are articulated with women's roles in the era of reforms. The next chapter will bring the previous three chapters together and map the implications of the science and technology for Chinese women from a Cultural studies perspective. 


\section{Chapter Four: Putting It All Together: The Implications of Science and Technology for Women's Roles in the Era of Reforms}

Chapter One introduced the many changes that happened in the era of reforms, explained the analytical perspectives of cultural studies and feminism, and laid out the methods of articulation and mapping, which are the two major analytical tools I use in this dissertation. Chapter Two explored the status of science and technology in the era of reforms. It argued that science and technology are venerated. People believe that science and technology have nearly omnipotent power that can bring positive changes, resulting in their rapid development sometimes without regard to the human costs. Chapter Three maps the two prominent roles that many Chinese women have in the era of reforms. It argued that Chinese women are always expected to be wives and mothers. However, in the era of reforms, they are also expected to become professionals. Chapter Three concluded with an analysis of the tensions and conflicts, with which many Chinese women have struggled, that are generated by the articulation of Chinese women's traditional roles of being wives and mothers with their new roles as being professionals.

This chapter brings all the previous chapters together and explores the implications of science and technology for women's roles as wives and mothers as well as professionals in the era of reforms from a cultural studies perspective. As revealed in previous chapters, many elements are articulated to women's lived experiences. Among them, four elements warrant particular attention. They are: 1) traditional Chinese culture 
that includes myth, Chinese language, Confucianism, and Daoism, 2) the CCP's political practices, 3) the discourse of The New Woman, and 4) science and technology. By focusing on these four, I demonstrate how they are articulated to influence Chinese women's roles.

As discussed in detail in Chapter Three, traditional Chinese culture has significantly contributed to the expectation for Chinese women to be virtuous wives and caring mothers. Traditional Chinese women, since their birth, were expected to get married and to give birth to children, which should include at least a baby boy. Besides being subordinate daughters that marry partners arranged by their parents, submissive wives who take good care of their husbands and their parents-in-law, and caring mothers who would be willing to sacrifice themselves for their children, most traditional Chinese women had no other access to self-fulfillment. Even in the era of reforms, the influences of myth, language, Confucianism, and Daoism remain strong in terms of disciplining women to get married and to have children. Moreover, the CCP also expects women to "tame" bachelors who are viewed as potential disruptive forces and to produce babies who significantly influence the economic future of China. The cultural and the political forces are tenaciously articulated, which make it difficult for women to remain single and childless.

However, at the same time, the discourse of The New Woman urges contemporary Chinese women to be different from their traditional counterparts through receiving education and having jobs. It argues that illiterate women who have no careers are not welcomed and not preferred by good Chinese men. Thus, not only in order to 
keep up with the times, but also to marry up, women should no longer confine themselves exclusively in the domestic sphere. Instead, they should be literate and join the workplace. Furthermore, facing the economic-political environment of the era of reforms that needs female workers to demonstrate the party's care for gender equality and to contribute to the Chinese economy that heavily depends on mass labor, the CCP also prepares and encourages women to join the workplace. Through implementing the free nine-year compulsory educational system, an increasing number of Chinese women have become literate. Through promoting the image of the Iron Girl and implementing policies that aim to protect women's rights in the workplace, the CCP tries to persuade women to have careers. The discursive and the political forces have articulated with increasing insistence and impact in the era of reforms, which makes being a professional gradually become an important role shaping many Chinese women's identities.

While the previous two paragraphs illustrate how traditional Chinese culture, the CCP's political practices, and the discourse of The New Woman have been articulated to impact women's lived experiences in the era of reforms. However, one force is missing: science and technology. As discussed in Chapter Two, the era of reforms is strongly characterized by the veneration of science and technology. This means that the idea that science and technology are nearly omnipotent and are intrinsically positioned to bring positive changes is deeply rooted in contemporary Chinese culture, and that Chinese people and government have become increasingly dependent on science and technology, hoping they can solve all problems. Thus, science and technology have influenced Chinese politics, culture, society, and people in significant ways in the era of reforms. 
Obviously, along with all Chinese people, Chinese women cannot resist this pervasive scientific and technological influence.

In fact, some scholars have discussed the impacts of science and technology for Chinese women. For example, Zhou and Guo (1995) point out scientific and technological developments in China on the one hand create more industries, thus providing additional job opportunities for women; on the other hand, they reduce some job opportunities that previously depended on human labor and they make some jobs require advanced skills, which result in some women losing their jobs. When Pei and Ho (2008) discuss cybersex, they mention the case of the housewife "Xiao Feng" who had been empowered to discuss her "sexual coldness," which was diagnosed by her husband, with her netfriends who not only give her advice, but also supported her in resisting her husband's criticism. Hu et al. (2016) explore the use of neuraxial labor analgesia in China, which is a method of providing pain relief for labor. They highly evaluate the nongovernmental No Pain Labor \& Delivery Program (NPLD) for bringing labor analgesia and better perinatal care to Chinese women. Li, Qu, and Lü (2017) claim that many women who get married late have difficulties conceiving naturally and have to use reproductive science and technology for assistance. This stressful process of conception leads to an increasing number of female patients with postpartum depression.

In more recent years, more people have engaged in this discussion. Xie (2018) argues that the rise of internet matchmaking agencies in recent years contributes to changes in Chinese matchmaking and dating culture from 1988 to 2018. Fincher (2018) recognizes the important role of the internet and social media in feminist movements in 
China, and writes "even as the Chinese government tightened ideological controls on university campuses across the country, more and more young women were starting feminist social-media accounts” (p.50). In March 2019, to celebrate International Women's Day, many highly successful career women gathered together in Shanghai to discuss their working and familial experiences and some of them talked about the influences of science and technology for career women. For example, Zhai Fang pointed out that science and technology enable career women to better take of their families since they can work in offices at home, and Sun Jie used the case of handling tigers and argued that science and technology significantly benefit women because they increase women's power and enable them to do many things that previously were only designated to men ("Sun Jie - CEO of Ctrip: Science and Technology Enable Women to Do What Men Can Do,” 2019).

In general, the previous literature reveals that science and technology have impacted Chinese women's lived experience in the era of reforms in three significant ways. First, science and technology empower women, as indicated by Pei and Ho (2008), Fincher (2018), and other scholars. This mainstream viewpoint has been argued extensively by many Chinese researchers. Second, science and technology are doubleedged swords, which means that they can benefit some women but at the same time can hurt other women, as indicated by Zhou and Guo (1995). Third, as argued by Li, Qu, and Lü, science and technology can also create problems for women. Although this previous literature is helpful, there still lacks sufficient and in-depth scholarship concerning the implications of science and technology for women. 
To engage in and contribute to this scholarship, this chapter explores how science and technology are articulated with the elements of traditional Chinese culture, the CCP's political practices, and the discourse of The New Woman to influence both Chinese women's traditional roles of being wives and mothers and their emerging roles of being professionals in the era of reforms. To demonstrate the impacts of these articulations, this chapter focuses on the following four examples of the developments and uses of science and technology to promote marriage and family, for population control and family design, to promote the discourse of the super mother, and for women to gain independence and resist sexual violence.

\section{The Development and Use of Science and Technology to Promote Marriage and Family}

As discussed in Chapter Three, traditional Chinese culture argues that women should get married and the CCP also wants single women to marry, to "tame" single men, and to give birth to babies. However, compared with many single women who are professionals that receive good education, many single men do not have much money and do not fit many Chinese women's expectation of marrying up, which is preferred in traditional Chinese culture. In order to increase these single men's chances to find partners, the Chinese government has implemented several policies, such as providing subsidies for marriage. The government also has participated in promoting the discourse of the leftover women, which originated from contemporary Chinese popular internet culture. This section continues to explore the articulation of the government's political 
practices with the traditional Chinese culture through adding the element of science and technology. In general, through analyzing the cases of the "Apply for Marriage Certificate" function on the App Alipay, the ways that dating websites promote themselves and women's experiences of using dating websites, and the government's prohibition for single women to receive the treatment of egg freezing, this section maps how science and technology are articulated with the political and cultural forces and how this articulation impacts Chinese women in significant ways.

\section{The "Apply for Marriage Certificate" Function on the App Alipay}

As discussed in Chapter Two, the Chinese government emphasizes its control over science and technology as a means to surveil and discipline people. For example, through implementing the Great Firewall of China, the government tries to monitor information flows and filter information, so that the Chinese people can only access the information that the government prefers them to see. The "apply for marriage certificate" function on the App Alipay is another effort by the Chinese government to achieve its political purposes through manipulating people's access to science and technology.

As discussed in Chapter Three, the Chinese government prefers single Chinese people to get married and to set up stable families. Thus, it introduced the experimental "calm-down" period for the purpose of reducing the divorce rate in China. However, apart from preventing people from getting divorced too easily, the government also endeavors to encourage people to get married. The government believes that the highexpense and time-consuming procedures of getting married in China have profoundly contributed to China's low marriage rate. 
In fact, the expensive and time-consuming nature of getting married is due in part to the influence of traditional Chinese culture. The traditional Chinese process of getting married, which was strongly viewed as a ritualistic practice and is still practiced by some Chinese families to this day, includes three letters and six etiquettes. ${ }^{38}$ In the era of reforms, although this process has been simplified for some families, getting married still remains costly and time intensive. Thus, the government thinks that what they need to do is to reduce the cost. Accordingly, the government provides subsidies to newlywed couples regardless of their economic situations. Moreover, the Chinese government announced that since April 1, 2017, the service fee for getting a marriage certificate in mainland China has been eliminated. This means that basically Chinese people do not need to pay for anything to apply for marriage certificates.

\footnotetext{
${ }^{38}$ The three letters were: a) the betrothal letter that the bridegroom's family gives to the girl's family to signify the mutual agreements by the families permitting the marriage,b) the gift letter in which the bridegroom's family lists the gifts that they are giving to the girl's family, and c) the wedding letter.
}

The six etiquettes were:

a) Proposing: the boy's family should hire a matchmaker to bring around thirty different things to the girl's family, amongwhich a unique but necessary gift is a pair of life swan geese, which is symbolic because they maintain monogamous pairing throughout their entire lives.

b) Matching birth dates: For this step, the boy's and the girl's birth dates and times are brought to a fortune-teller to calculate if they match, which basically verifies whether the god approves their marriage.

c) Setting up the date for the boy's family to send the betrothal letter to the girl's family.

d) Presenting the wedding gifts.

e) Arranging the marriage for an auspicious date.

f) Holding the wedding ceremony.

This elaborate process of getting married reveals how the ritualistic aspects of marriage were emphasized in traditional Chinese culture. 
In this context, in 2018, the local governments of Jiangsu Province, Fujian Province, Anhui Province, Sichuan Province, Zhejiang Province, Jiangxi Province, Guangzhou City, Wuhan City, and Haikou City announced that people from these regions can apply for marriage certificates using their cellphones. This option became available after the government's collaboration with the company Alibaba, which developed the popular app Alipay that had more than 700 million active Chinese users in 2018 ("China's Alipay," 2018). Basically, the government added the function "Apply for Marriage Certificate" into this app. This enables the users of Alipay to finish almost all of the administrative process using their cellphones such as taking pictures, filling out forms, and booking the date and time to get their marriage certificates, although they still need to be present in the government's civil affairs office to get their certificates. ${ }^{39}$ It is believed that this technological innovation will save people time waiting in the line and dealing with administrative procedures and thus encourage marriages. In 2019, to celebrate the Chinese Valentine's Day (August 7), the local governments of Zhejiang Province, Jiangsu Province, Jiangxi Province, Fujian Province, and Chongqing City announced again that residents of these places can apply for marriage certificates online. CCTV news, the most authoritative channel that is sponsored by the CCP, used the hashtag "This is How Love Looks" to celebrate this news on its Weibo platform. It is

\footnotetext{
${ }^{39}$ Different from the marriage documentation in the U.S., the marriage certificate in China includes a photo of the husband and the wife. Thus, in order to get the marriage certificate in China, couples must first take a photo of themselves and submit the photo to the government. Previously, the photo could only be taken in certain governmentaffiliated photo studios.
} 
reported that more regions will follow this practice, and in the near future all Chinese people will be able to apply for marriage certificates through their cellphones.

The function of "Apply for Marriage Certificate" online reflects the Chinese government's tradition of turning to science and technology to reduce the cost, time, and energy required for a marriage, hoping they can solve the "problem" of China's low rate of marriage. It is interesting that although both the traditional cultural force and the contemporary political force promote marriage, tensions still emerge due to their different viewpoints concerning marriage. For the traditional Chinese culture, marriage is significantly ritualistic, as evidenced by its long, highly-detailed codes of conduct. However, for the Chinese government, marriage is more about utilitarianism. It hopes people get married because they believe married couples have a lower chance of becoming social disruptors and they need children since the shortage of pension and future laborers pose increasingly serious threats to the economy.

However, the government's effort has not been particularly effective. According to the statistics released by the government in 2019 , the marriage rate in 2018 in mainland China was the lowest in the past decade. In 2018, the average marriage rate in China was7.2\%, in Shanghai City was 4.35\%, and in Zhejiang Province was 5.9\%o (“Shanghai Has the Lowest Marriage Rate,” 2019).

The blame for the low marriage rate is heavily placed on women, while many single men are seen as the victims of women's desires for better lives. As analyzed previously, the crucial purpose of developing this science and technology is to help men, especially the men whose economic situations are not favorable. Through promoting the 
idea that marriage should be simple and not associated with money, the government makes women who have material requirements for their partners, such as having apartments or cars, the target of attack for being unwelcome women who have too many desires. To be clear, I am not trying to judge these women. In fact, facing the situation that many Chinese women have to shoulder all the household chores alone, to take good care of their husbands and parents-in-law, are fired from their workplaces when they are pregnant, and often are questioned in terms of their abilities, time, and energy to handle jobs when they have children, it is understandable that some Chinese women have material requirements for their future husbands to lessen some of their financial burdens. Thus, probably in order to "recruit" more women to get married and reduce the impacts of traditional Chinese culture, besides introducing science and technology to make getting marriage certificates convenient, the government should better protect women's rights in their marriages and their workplaces.

\section{Dating Websites}

As discussed in Chapter Three, great tension in contemporary China arises between the increasing number of Chinese women inclined to remain single until they really want and are well-prepared to get married and the traditional cultural forces and the CCP's political practices that urge women to get married in their early or middle $20 \mathrm{~s}$. In fact, for the traditional Chinese culture and the $\mathrm{CCP}$, for women, marriage is more important than being professionals. However, many single professional women have the

polar opposite idea. In response to this tension, cultural-political forces have created the label "leftover women" to stigmatize single professional women who are over 27-years- 
old for the purpose of compelling them into marriages. To understand the roles of science and technology in this tension-filled context, I turn to dating websites and explore the impacts of dating websites for Chinese single women.

Dating websites did not exist in China until the late 1990s. Despite its short history, the business of online dating websites has expanded rapidly. According to iResearch, which is a professional market research and consulting company in China, the profit of the online dating industry was 4,000,000,000 Yuan in 2017(approximately $580,000,000$ USD). iResearch estimated that by 2020 , the income of the online dating industry would be over 50,000,000,000 Yuan (approximately 730,000,000 USD) (iResearch, 2018, p. 12). Among the hundreds of different dating websites in China, I focus on the three most influential ones: Jiayuan Wang/世纪佳缘网, Baihe Wang/百合 网, and Zhenai Wang/珍爱网. They have comparatively good reputations and have the largest numbers of users.

Jiayuan Wang, which is also often known as ShijiJiayuan Wang, was founded in 2003 by Haiyan Gong who at the time was a second-year graduate student at Fudan University, which is one of the best universities in China. Jiayuan Wang claimed that it has gained the largest number of users among all dating websites. Baihe Wang was founded by Fanjiang Tian and Yan Mu in May 2005. Among the three websites, Baihe Wang works most closely with the Chinese government. Since March 2007, it has cooperated with the Ministry of State Security of the PRC to request all its users to provide their national ID numbers. Since April 2007, Baihe Wang has cooperated with the All-China Women's Federation. In February 2008, Fanjiang Tian, a founder of Baihe 
Wang, was appointed as a secretary in the Ministry of Civil Affairs of the PRC. Zhenai Wang was founded by Song Li and Si Chen who used to work for Morgan Stanley and Dell respectively. Different from Jiayuan Wang and Baihe Wang that were initially designed to provide a free online platform for strangers to meet, Zhenai Wang has focused on providing a fee-based service from the beginning. Users have to work with matchmakers from the company, send messages to strangers through matchmakers, and pay at least 18,880 Yuan (around 3,000 USD) to have the chance meet a stranger in person, which is also arranged and accompanied by matchmakers.

Although these three websites have their own unique features, all the them promote their products through exploiting the tensions between the cultural-political force that urges single women to get married in their early or middle twenties and many single women's situations of being financially independent and the targets of the culturalpolitical force. For example, in 2014, a commercial released by Baihe Wang explicitly reveals how Baihe Wang took advantage of this tension to make a profit from single women and their parents. The 30-second-long commercial “Because Love Won't Wait/因 为爱不等待” begins with a single young woman's monologue “This year I must get married. I should do so considering my grandma's wishes and health condition. Whenever she meets me, she only asks me one question 'Have you gotten married?"' (“Because Love Won't Wait," 2014). ${ }^{40}$ Then the camera shows how this young woman's grandma, who becomes increasingly old and sick, keeps on asking her the same question.

\footnotetext{
${ }^{40}$ Appendix B is the fair use report that demonstrates my fair use of images from this commercial in my dissertation.
} 
The grandma is not happy even though her grandchild got her degree (see screen capture 1) and found a job (see screen capture 2). The only thing this grandma cares about is her granddaughter's marriage (see screen capture 3 and screen capture 4). Screen captures are below:

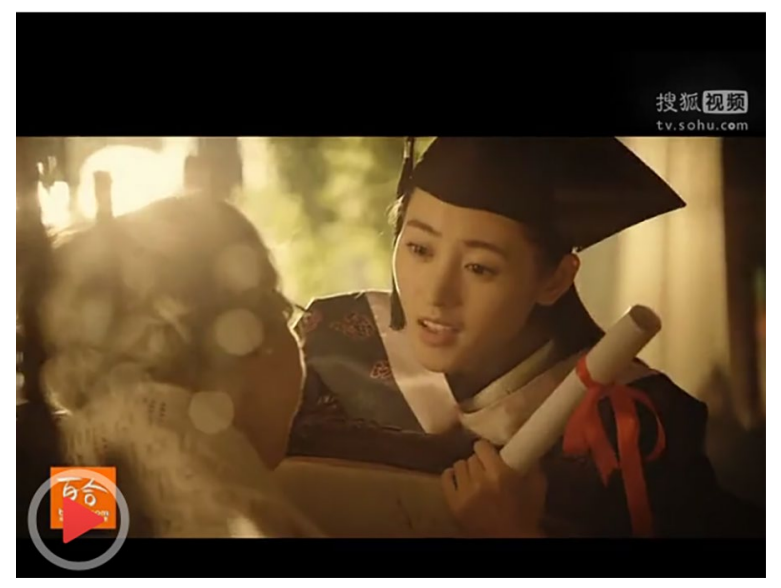

Figure 4. 1 Screen Capture 1 Of The Commercial "Because Love Won't Wait."This commercial was openly accessed from http://www.iqiyi.com/w_19rrbikxx9.html.This screen capture was taken by the author.

In this screen capture, the woman shows her grandma her diploma, but her grandma is indifferent.

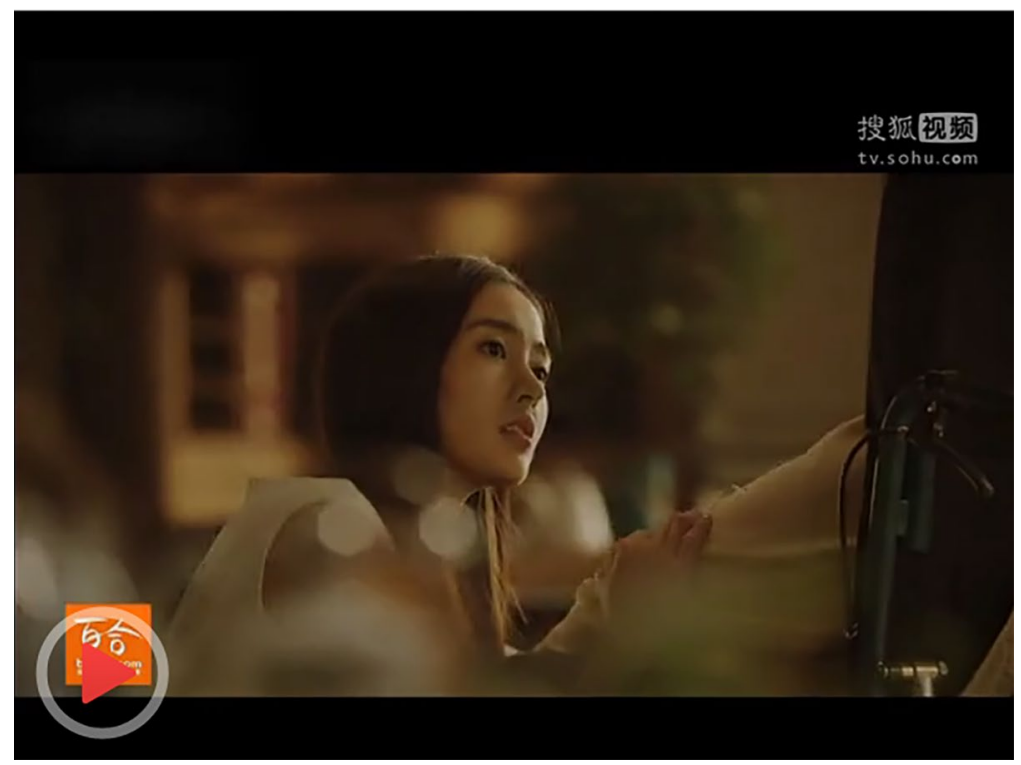


Figure 4. 2 Screen Capture 2 Of The Commercial "Because Love Won't Wait."This commercial was openly accessed from http://www.iqiyi.com/w_19rrbikxx9.html. This screen capture was taken by the author.

In this screen capture, the woman who has already become a professional is not happy since she is still not celebrated by her grandma.

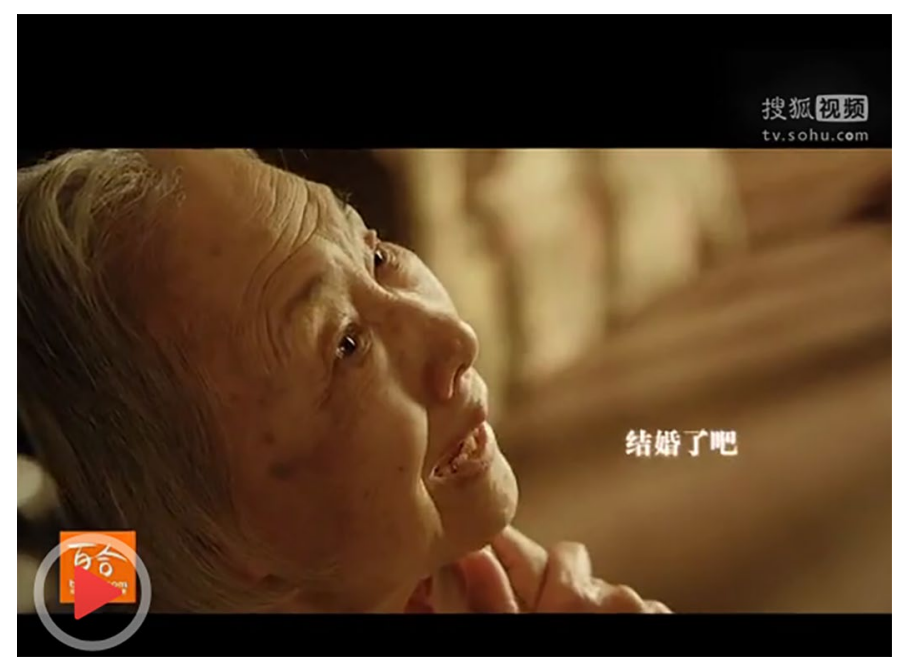

Figure 4. 3 Screen Capture 3 Of The Commercial "Because Love Won't Wait."This commercial was openly accessed from http://www.iqiyi.com/w_19rrbikxx9.html. This screen capture was taken by the author.

In this screen capture, the grandma is getting older and appears visibly distressed and asks her granddaughter "Have you gotten married?(结婚了吧)"

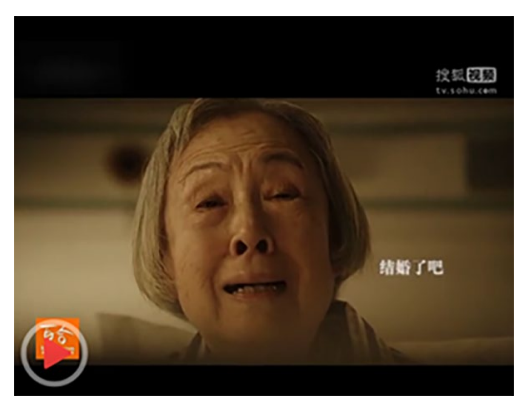

Figure 4. 4 Screen Capture 4 Of The Commercial "Because Love Won't Wait."This commercial was openly accessed from http://www.iqiyi.com/w_19rrbikxx9.html. This screen capture was taken by the author. 
In this screen capture, the grandma is already in the hospital. She is on the verge of tears. She asks her granddaughter the same question "Have you gotten married? (结婚了吧)” The woman continues her monologue "I shouldn't be picky and wait for my soul mate. I should visit an offline store of Baihe Wang quickly." At the end of the commercial, the woman and her husband visit her grandma who stays at a hospital; she wears a wedding dress, and tells her grandma with happy tears "Grandma, I got married" proudly and affectionately. (see screen capture 5)

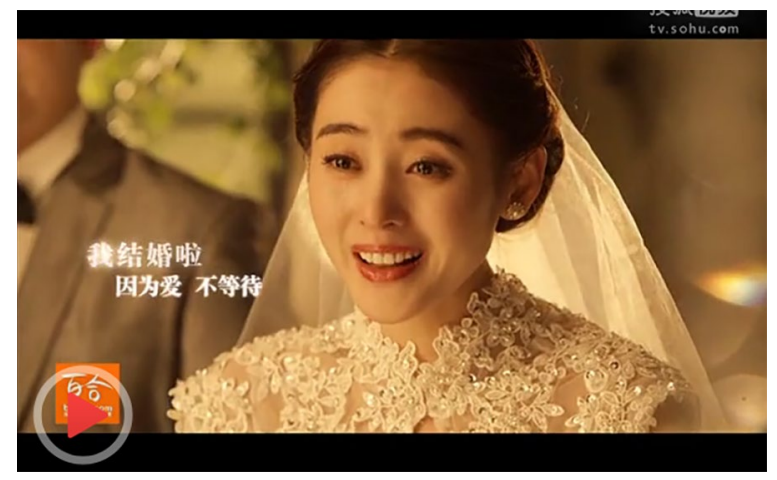

Figure 4. 5 Screen Capture 5 Of The Commercial "Because Love Won't Wait."This commercial was openly accessed from http://www.iqiyi.com/w_19rrbikxx9.html. This screen capture was taken by the author.

This commercial promotes the idea that Baihe Wang can help single women find partners. It resonates with the cultural-political expectation for women to get married, arguing it is both in women's and their family members' best interests to get married before they enter middle-age since for women, nothing is more important than marriage and that this technology can help them fulfill this purpose. After being played ubiquitously on screens of family TVs, subways, airports, and shopping malls during the Spring Festival in February 2014, a time when Chinese families usually reunite, cook and 
eat together, sit in front of TVs, talk about their experiences in the past year, and set up their plans for the coming year, this commercial reinforced this expectation and the necessity to use its service, as indicated by women's comments online. On Tianya Luntan, which is a popular Chinese open-access Reddit-style online forum, a user under the pseudonym "nekoaisiteru" (2014) wrote "I feel very uncomfortable whenever I see this commercial. As a single woman, I face lots of pressure. My mom has always wanted me to find a husband. After watching this commercial, her expectation became even stronger.” “俞艾维”/Yu Aiwei (2014) wrote “When I first saw this commercial I was watching TV with my mom. My skin crawled and I knew something bad might happen. Just as I thought: my mom turned to me and asked me to register for Baihe Wang.” “抹茶 红豆糯米糍”/Mocha Hongdou Nuomi Ci (2014) wrote:

Because of this commercial, in the eight days of my Spring Festival holiday, I did not dare leave my room and watch TV with my family. The first moment I saw this commercial, I realized that I am screwed. I poured myself a cup of water and retreated into my room. In three minutes, my mom approached me and asked me to have a blind date.

Similar to Baihe Wang, Zhenai Wang promotes its product through articulating with the cultural-political expectation for women to find a husband who can be the breadwinner of the family. In order to understand the process of using dating websites to find partners, I registered for several Chinese dating websites, which include Zhenai Wang. After submitting some of my information online such as my age, height, weight, educational level, and place of work (I used my hometown Wuhan City instead of 
Houghton), matchmakers began to contact me. Below is a screen capture of a message that a matchmaker from Zhenai Wang sent to me on February 16, 2019:

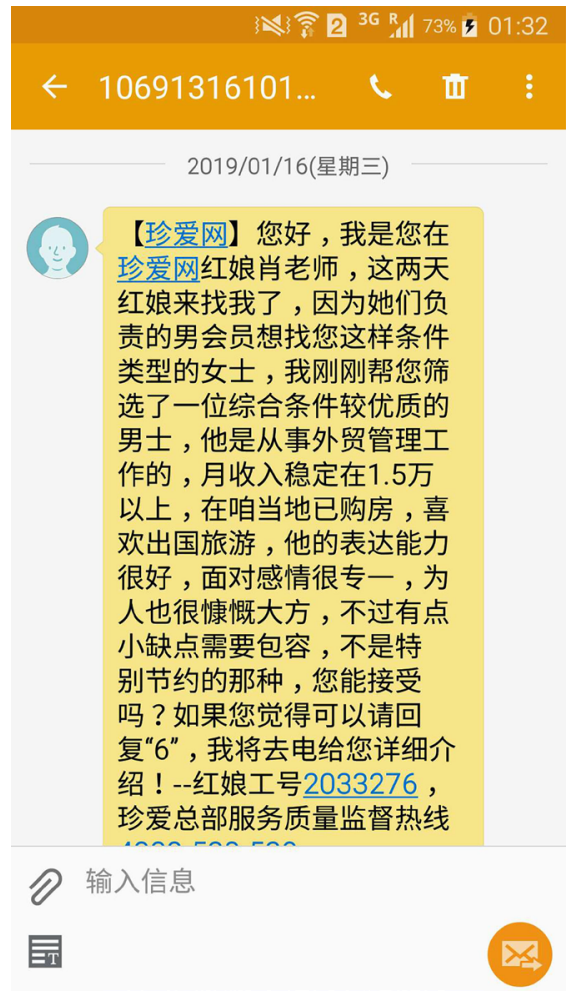

Figure 4. 6 Screen Capture Of The Message From Zhenai Wang. This screen capture was taken by the author.

The message reads: Hello, I am the matchmaker Teacher Xiao from Zhenai Wang...I want to introduce you to a partner. He is a manager of a company in the foreign trade industry. His monthly salary is above 1,5000 Yuan (approximately 2181 USD), he has an apartment of his own in Wuhan, and he is interested in travelling abroad.... ${ }^{41}$

\footnotetext{
${ }^{41}$ In 2018, the average annual salary for people who work in Wuhan City was 73,671 Yuan (approximately 10,760 USD). This means that the average monthly salary was about 6139 Yuan (approximately 896 USD) (Statistics Bureau of Wuhan, 2019).
} 
Aiming to allure me to pay for the service to meet the man, this concise message primarily focuses on the man's economic situation, as indicated by his job, his salary, his property acquisition, and his luxurious interest, all of which reveal that he is a desirable breadwinner. Through attracting women by advertising that many of its male users are rich enough to support and lead a family, Zhenai Wang not only reinforces the necessity for women to get married but also contributes to the gendered pattern of power and authority.

Many women reported being discriminated against and shamed when they used online dating services. In fact, many online dating websites intentionally choose to shame single women, hoping this anxiety will compel them to buy expensive fee-based services. On Zhihu, which is a Chinese version of Quora, in answering questions about using ShijiJiayuan Wang, Baihe Wang, and Zhenai Wang, many women talked about their negative experiences. For example, “维尼”/Wei Ni (2016) who described herself as a 29year-old single woman wrote "In an offline store of Zhenai Wang, a matchmaker told me that it is unbelievable that I haven't had a boyfriend for so long, so I need more help, thus I should choose the service that costs 48,888Yuan (approximately 7,271 USD).” “英英” /Ying Ying (2017) wrote "I never encountered such an evil website as Baihe Wang. I paid more than 300 Yuan (approximately 45 USD), they called me again and asked me to pay 600 Yuan (approximately 90 USD) more to update my service. They asked me whether my family members had pressured me to get married recently since I am no longer young." On Douban, another popular open-access Chinese online forum, some women also posted about their experiences using dating websites. “我组 lvlv 说不得”/ 
Erzu Lvlvshuobude(2019) wrote "I received a message from ShijiJiayuan Wang. It wrote 'if you don't get married before you become aged, your womb becomes worthless'.” “郭 又欠”/ Guo Youqin (2019) wrote:

When I visited the offline store of ShijiJiayuan Wang, the matchmaker there asked me whether I am a virgin... Then he told me that because I am no good at decorating myself and am not willing to spend money, men don't like me...He told me that I lacked social responsibility....I talked back. He became angry and was about to beat me. I was so scared.

My analysis reveals that although dating websites acknowledge professionalismfor example the commercial released by Baihe Wang includes the image of a professional woman and Zhenai Wang solicit its users' information concerning their occupations and places of work - many dating websites' approach to resolve the tension between single women and the cultural-political force that urges them to get married is to reinforce the necessity for women to get married and to claim that their products can help single women to get rid of their singlehood. In this way, many dating websites are articulated with the cultural-political force that disciplines and even shames single women to find partners before they become old like stale food that will expire soon. This approach significantly ignores many single women's inclination for late marriage or remaining single for the rest of their lives.

Consequently, for some single women, dating websites reduce the pressure on them to get married by offering them another option to meet new people; however, for others, the dating websites' approach of seizing on that tension creates extra burdens for 
them and their parents, contributing to these tensions. For example, triggered by the commercial released by Baihe Wang, many single women shared online their terrible past experiences of blind dates, their determination to avoid marrying merely because they are aging, and openly criticized Baihe Wang for exacerbating their sufferings as single women and the Chinese culture for being sexist. For instance, on Tianya Luntan, the user “树蛙躲雨”/Shuwa Duoyu (2014) wrote “Marriage is important. But what is more important is to be happy with our lives.” The user “小马甲 818”/ Xiao Majia818 (2014) wrote "We, women, Let us be strong!" The user "20120207" wrote "It seems the whole Chinese society begins to commercialize leftover women. It is disgusting. Single sisters, watch out. Instead of marrying a wrong husband, we should remain single. Don't be manipulated by the propaganda...It is never too late to get married." At the same time, some single women channeled this incident of online boycotting of Baihe Wang and even the discourse of the leftover women into a street campaign. On Valentine's Day of 2014, they protested outside the company of Baihe Wang and in subways. They held signs such as "Don't push me to get married," and "Why Can't I Remain Single? I Will Only Get Married When I Want To.” A few single men also joined the campaign and held posters like "Don't Marry Me Because of Your Grandma." ("Feminist Voice in Valentine's Day to Against Baihe Wang," 2014). Through this radical protest, these single women justify their decisions to remain single and request respect from the Chinese society and government, which have contributed to the already existing tensions. 


\section{The Treatment of Egg Freezing}

As argued previously, an increasing number of single professional women prioritize careers over marriages, resulting in the phenomenon of late marriage among professional women in China. However, cultural-political forces also disfavor late marriage and argue that if women get married late, there will be lower chances for them to get pregnant or to have healthy babies, a claim that is said to be proved by medical research. It is argued that this situation will detrimentally influence the relationship between couples. Moreover, with the improvement of their economic situations, professional women have more sovereignty over their lives, resulting in their confidence facing divorce or determination to reject marrying men in order to avoid bad experiences in marriages such as the conflict between daughters-in-law and parents-in-law. ${ }^{42}$

However, some of the women who refuse to have husbands still want to become mothers and to have biological children who can accompany them and take care of them when they become old.

In this context, the treatment of egg freezing has attracted the attention of many single professional Chinese women. On the website of UCLA Obstetrics and Gynecology, egg freezing (or oocyte cryopreservation) is explained as "a process in which a woman's eggs (oocytes) are extracted, frozen and stored as a method to preserve reproductive potential in women of reproductive age" ("Egg Freezing," n.d.). According

\footnotetext{
${ }^{42}$ Due to the influence of the traditional Chinese culture, many daughters-in-law have to stay with their parents-in-law in order to take care of them in contemporary China. However, staying together can be hard due to the differences between their backgrounds.
} 
to Dr. Bergman (2016), “once frozen, embryos can remain viable for many years, with cases of live birth resulting as long as 15 years after freezing”.

In general, this treatment enables Chinese women to fulfill two purposes. The first one is that freezing eggs allows women to be less anxious about getting married early, since they still have plentiful opportunities to have children even if they get married in their 40s. Lake (2018) records the pressure concerning women's fertility that Christy, a professional Chinese woman, experienced: “"I don't mean to stress you, but I simply cannot relax until you are married,' Christy's mom recently said to her. 'You're thirtyfour already. How can you be sure you're still ovulating?"' (p. 21). This episode clearly reflects the anxieties that are generated for single Chinese women by the issue of women's constrained biological clock when it comes to active fertility. With the help of egg freezing, women can better focus on their careers and remain single until they find people that they really want to marry. Second, this treatment enables women to have biological children without getting married or having permanent partners. Reproductive science and technology enable women's frozen eggs to turn into fertilized eggs in test tubes. After transplanting the fertilized eggs into a woman's womb, it is possible for the woman to have a child.

Egg freezing was largely unknown to most Chinese women until the 2010s, when the internet enables celebrities to effectively exert one-to-many influence. In 2015, the famous Chinese actress and director Jinglei Xu revealed that in 2013 when she was 39, she flew to the U.S. to freeze nine of her eggs. Since then, Xu has promoted the treatment of egg freezing, arguing that through freezing eggs a woman saves herself a future option 
of being a mother even if she becomes too old to ovulate. Xu's argument has become widely circulated in society and been viewed as extremely persuasive. For example, searching the two key terms "Xu Jinglei" and "egg freezing" on Baidu, the largest search engine in China, generated 419,000 results. Xu is regarded as the first Chinese celebrity to receive the treatment of egg freezing, a pioneer for Chinese women to likewise seek this medical treatment. Since Jinglei Xu's revelation, some other famous Chinese actresses such as Xuan Ye and Zhiling Ling also publically revealed that they had frozen their eggs. These famous actresses have helped an increasing number of Chinese women to become familiar with the treatment of egg freezing.

While the treatment of egg freezing can enable many Chinese women to fulfill their dreams of better focusing on their jobs when they are young without being pressured into getting married and having children or having children of their own without being trapped into marriage, the Chinese government doesn't favor either of these situations. As discussed in Chapter Three, the Chinese government wants single women to get married in their early or mid-twenties. Moreover, the Chinese government doesn't welcome "illegitimate" children—-"out-of-state-family-plan" babies or babies whose parents are not legally couples. In 2013, facing the situation that in some big Chinese cities an increasing number of women have children without getting married, the document "Population and Family Planning Management in Wuhan," which was proposed by the 
local government of Wuhan city, argues that unmarried women who give birth to children should be charged twice the social compensation fee. ${ }^{43}$

Facing the popularity of the egg freezing, the Chinese government continues its practice of challenging single women's right to give birth through limiting access to egg freezing exclusively to married couples since 2015. Accordingly, it became illegal for a single Chinese woman to freeze her eggs in any Chinese hospital. The Chinese government requires all the hospitals and medical institutions that provide the service of egg freezing to mandate their female patients to provide three documents: 1) national ID card, 2) marriage certificate, 3) and birth permission. If any of the three documents are missing, the woman cannot receive this treatment ("It is not easy to freeze eggs in China," 2019 ).

That the government bans single women from egg freezing while allowing single men access to sperm freezing has irritated many Chinese women. For example, on Tianya Luntan, many Chinese netizens criticized this gender-based difference. The netizen “捷纪 天鹰”/Jieji Tianying (2015) wrote “Unbelievable country always has unbelievable policies.” The netizen “冷月无声 1985”/Lengyue Wusheng1985 (2015) wrote: In China, women should get married before turning 25 , or they will become leftover women; women should give birth to children before turning 30 , or they will be categorized as aged pregnant women. If you want to have a biological

\footnotetext{
${ }^{43}$ Social compensation fee/she hui fu yang fei/社会抚养费: according to the Chinese government, parents of "illegitimate" children need to pay this fee to compensate their children's "illegitimate" uses of social and natural resources.
} 
child, sorry, you cannot freeze your eggs, instead, you have to show your marriage certificate, reproductive certificate, and many other certificates. For mothers, if you want your children enrolled in elementary schools, you have to show schools the proofs that you have an IUD inserted. For married women who only have baby girls, you have to work hard to become pregnant with baby boys regardless of your health condition.

Obviously, the government's political practice conflicts with many single women's interests, resulting in a great tension.

Despite many Chinese women's strong reaction against the government's ban in recent years, the ban is still in place. Facing this situation, some privileged Chinese single women respond this tension through traveling abroad to access egg freezing in foreign countries. According to Kyle Francis, the CEO of the Southern California Reproduction Center, due to the increasing number of Chinese women who want to utilize egg freezing, this industry has become an expanding, profitable market in the U.S.. When Francis was interviewed, he said, "fertility preservation is a growing factor, due in part to the fact that [Chinese] people are waiting longer to get married, particularly as women's career opportunities have expanded.... We are seeing patients in their early 30 s to early 40 s" (“More Chinese women seeking," 2018). In 2017, Ctrip, one of the biggest travel websites in China, even began to provide a special travel plan, "The Trip for Egg Freezing to Los Angeles, the U.S.A.” This trip lasted for seven days, and cost 218,888 Yuan (approximately 34,603 USD) (Tao, 2017). 
While travel abroad addresses the tension between the government's ban and the desires of many women to freeze their eggs, most Chinese women don't have enough money and resources to receive this treatment abroad. ${ }^{44}$ Thus, although egg freezing treatment provides single women important access to focusing on their careers without worrying too much about getting married early, it does not fundamentally resolve the tension produced between some single Chinese women's prioritization of becoming professionals over getting married and the cultural-political force that disciplines them to get married early even at the cost of sacrificing their careers.

\section{The Development and Use of Science and Technology for Population Control and Family Design}

While the previous section explored how science and technology are developed and used to promote marriage and family in the era of reforms, this section maps the development and application of science and technology for population control and family design. As discussed in Chapter Two, many Chinese people believe in the nearly omnipotent power of science and technology, which can enable them to fulfill their wishes. For example, during the Westernization Movement, they wished to fend off the Western invasions in order to live peacefully, and in the era of reforms, they wish to become rich and prosperous, consequently turning to science and technology for help.

\footnotetext{
${ }^{44}$ If a Chinese woman wants to receive the treatment of egg freezing abroad, she must first successfully obtain a visa from her destination country. For some countries, such as the U.S., it is very hard for single women to get visas because single women, given that they are available to marry, are suspected to have strong intentions of immigration.
} 
Moreover, the Chinese government has heavily relied on science and technology to achieve its political purposes such as surveilling its citizens, as evidenced by its projects of the Great Firewall and the Tian Wang System. This section analyzes the issue of population control and family design, which have been emphasized both by Chinese people and the Chinese government. Through exploring the cases of governmentsponsored abortion, sterilization, IUD insertion, and use of IVF - which are the predominant means of population control and family design in contemporary Chinathis section considers how science and technology are articulated with politics and the traditional Chinese culture to exert significant impacts on Chinese women's lives.

\section{Government-Sponsored Abortion, Sterilization, and IUD Insertion}

Chapter Two stated that the Chinese government has a long tradition of utilizing science and technology to achieve its various political purposes. Chapter Three pointed out that in order to control the Chinese population, the Chinese government has implemented several family planning policies, all of which regulate the number of babies that a Chinese family is allowed to have. Additionally, Chapter Three stated that the Chinese government has adopted several strategies to discipline people to follow the government's family planning policies strictly. For example, it is normal for parents who have out-of-plan children to be fired if they work for the government-affiliated companies, universities, labs, or other entities.

Besides these strategies discussed in Chapter Three, the Chinese government has turned to science and technology, especially the procedures of abortion, sterilization, and IUD insertion. In order to achieve the desired effects of its family planning policies, the 
Chinese government has disciplined and even forced millions of Chinese people to receive these procedures. In most cases, it is Chinese women that are subject to this discipline. In Chinese culture, men are viewed as breadwinners and their strength is closely associated with their reproductive organs, so their bodies, especially their reproductive organs, are expected to remain intact. Moreover, because of the long history of treating and viewing eunuchs as sub-human beings in ancient China, it is common that men with damaged reproductive organs are mocked, discriminated aganist, and stigmatized even in contemporary society. Thus, whether for abortion, inserting an IUD, or receiving sterilization, Chinese women become the designated subjects. Rabinovitch (2013) reported that due to the one-child policy:

Since 1971, doctors have performed 336m [million] abortions and 196m sterilisations, the data reveal. They have also inserted $403 \mathrm{~m}$ intrauterine devices, a normal birth control procedure in the west but one that local officials often force on women in China.

The many cruelties that occur in this process have been widely discussed. The most representative work of Mo Yan, the only Chinese writer who has won the Nobel Prize in Literature, is Frog/蛙, which touches on this subject. The pronunciation of frog is "wa," which is very similar to the word "baby/娃." Yan's book describes the range of lived experiences of an obstetrician in Shandong Province (China): from helping women with obstructed labor to deliver their babies, which saved many women's lives, to aborting women's out-of-plan children, which led to the death of many women (Mo, 2016). The practice of forced abortion still exists in the years since China has 
implemented the more "relaxed" two-child policy. Sudworth (2016), who works for the $B B C$ News, interviewed a Chinese man who was hiding with his family because his wife was going to give birth to their third child. The man explained his reason for hiding: "A third baby is not allowed...so we are renting a home away from our village. The local government carries out pregnancy examinations every three months. If we weren't in hiding, they would have forced us to have an abortion." Similarly, Mosher (2017), from the Population Research Institute, states that "forced abortions in China continue despite the two-child policy."

Besides forcing some Chinese women to abort their out-of-plan babies, the Chinese government also has disciplined and even compelled women to receive the procedures of IUD insertion and sterilization. Fong (2016) points out:

China in particular favored sterilization because it was a virtually foolproof way of lowering fertility. Nonpermanent barrier methods like condoms, the Pill, IUDs, which gave individuals more choice and control, were not so trustworthy, even though the IUD used—a stainless steel ring with no string—was specially modified so women could not remove it themselves. In one year alone, 1983, China sterilized over 20 million people. (p. 68)

To persuade and discipline women to have IUDs inserted, besides using force, the government promotes the discourse that claims scientific studies reveal that an IUD has no ill effects on a woman's body; rather an IUD is beneficial for a woman's health. Thus, many Chinese women have IUDs placed in their bodies after giving birth to their first children, and now after their second children. 
To ensure that the procedures of abortion, IUD insertion, and sterilization are systematically carried out, there used to be a special governmental "Office Specialized at Dealing with Women” (Fu Nv Shi Wu Ban Gong Shi/妇女事务办公室), and in some regions this office still exists. An important purpose of this office was and, in some cases, still is, to discipline women to follow the government's family planning policies and receive these "proper" treatments. Lili, a woman who I interviewed about her experience when she encountered government officials, conveyed: ${ }^{45}$

At first, they (village government officials) talked to us (all the wives in the village). They told us we should sacrifice ourselves for the nation...They mentioned many medical terms, I could not understand what I supposed to do....They said "just do it, and stop asking questions. How could you understand all the information, some of you haven't even finished your middle-school education"...I had to receive the surgery to have an IUD inserted.

Furthermore, because not all doctors had received enough training in gynecological procedures and Chinese women were expected to receive the operation of abortion, IUD insertion, and sterilization locally as an additional mode of corporeal

\footnotetext{
45 This interview was approved by the IRB \#614903-1, “A Study of Chinese 'Shidu' Mothers.” Appendix C contains the IRB approval of this project. Shidu mothers refer to Chinese women whose only child died. They followed the Chinese government's one-child policy to only have one child. However, their only children died usually when the mothers were in their late $40 \mathrm{~s}$ and $50 \mathrm{~s}$ - an age at which they would struggle more to get pregnant again naturally. I interviewed six shidu mothers. Four of them were located through a Chinese organization of shidu people that include both shidu mothers and fathers "Hand in Hand," and two of them were found through my personal connections. My interviews were organized based on three main questions: 1) How does shidu affect your life? 2) How does shidu impact you and your husband or ex-husband differently? 3) What are your future plans? All interviewees were assigned pseudonyms. This interview was conducted in Chinese. I translated it from Chinese into English. I will talk more about the issue of shidu mothers later in this chapter.
} 
control, the procedures were sometimes carried out in an unsanitary environment by unqualified physicians. As a result, these procedures could result in serious side effects.

The case of the government-sponsored abortion, sterilization, and IUD insertion reveals how the Chinese government uses technology to disciplines women to follow the family planning policies to have the right number of babies. Moreover, it also demonstrates the impacts of the articulation of politics, the traditional Chinese culture, and science and technology on women. Due to the traditional Chinese culture, Chinese women are expected to give birth to more than one child; however, the Chinese government only allowed them to have one child. Subsequently, tensions emerged and the government introduces policies and uses technology to both respond to and add to these tensions. As indicated in my analysis, although science and technology probably have successfully enabled the government to achieve its purpose of population control, they fail to resolve the tension between the political and the cultural forces, as evidenced by many Chinese people's complaints and resistance. In this process, many women remain the subjects and objects of control: first expected to give birth to many babies by their husbands' families, and then expected to give birth to only one child by the government. Moreover, the introduction of science and technology in this process has exacerbated many women's suffering, sometimes endangering their health and even their lives. For these women, science and technology fail to fulfill the expected roles of bringing positive changes to their lives. 


\section{In Vitro Fertilization (IVF) Treatment}

As discussed in Chapter Three, the Chinese culture has a long tradition of family design through focusing on the necessity of a baby for a family and promoting gender selection of babies. For example, in ancient China, it was legitimate for a husband to divorce his wife merely based on the ground that she failed to produce an heir for his family.

Even in contemporary China, having babies remains crucial for Chinese women. For example, after collecting the narratives of Chinese shidu mothers, the mothers whose only children died and thus leave them childless, I revealed that without a child, it can be very hard for a Chinese woman to maintain her family and thrive in her community in contemporary Chinese society. For example, Yan, a 57-year-old worker told me her experience after the death of her only child:

My son left me when I was 48 years old...At that time, I had finished menopause. I could not reproduce a child. My husband was 50 years old. Soon, we divorced. He married a younger woman from a rural area. She produced a baby for him...I don't blame my husband; he also faced a lot of stress at that time. (as cited in Liu \& Slack, 2014, p. 41)

Yan is not the only shidu mother who was deserted by her husband. "Fang, a shidu mother and leader of the shidu family organization 'Hand in Hand,' explained that of the more than 500 people in the organization, 2/3 are females and more than half of them are divorced" (Liu \& Slack, 2014, p. 41). 
Another shidu mother, Feng, reveals that in contemporary society, having a child is still important for women if they want to be accepted by their communities. She mentioned her experience after the death of her child:

In 2000, my best friend's daughter made plans to get married. She called me and told me this piece of news. I felt so excited because I finally found someone who was still willing to share blissful events with me. I asked her for the location of the wedding. She just smiled. At that time, I was so stupid. I asked someone else and found the location ultimately. I knew her daughter, and I liked her daughter very much. I wanted to go to her wedding to give her my sincere wishes. On the wedding day, when I showed up, I saw anger and fear in my friend's and daughter's faces. My friend took me away from the wedding and begged me to leave. Her words hurt me a lot. Since then, I never go to any weddings or birthday parties. (as cited in Liu \& Slack, 2014, p. 44)

In fact, as discussed in Chapter Three, the tenacious connection between women and childbirth can be traced back into Chinese myth. Due to this mythical influence, many Chinese people believe that childless women are unlucky or even evil because God refuses to send them a child. Moreover, as Chapter Three makes clear, the mythical person who is responsible for spreading bad luck is the goddess Sao Ba Xing. Childless women, the women who can be viewed as the potential manifestations of Sao Ba Xing, are often discriminated against in the communities.

While the expectation to have children has remained constant, the number and genders of the children that women are expected to bear have shifted over time. In the 
beginning of the era of reforms when China's one-child policy was implemented, due to the strong influence of traditional Chinese culture that argues that the more children, especially baby boys that you have, the more blessed you are, many Chinese families wanted to have more than one child, preferably baby boys. This meant that many Chinese families had to break the government's law or tried to circumvent the law. Thus, some families decided to pay the government the fines for their out-of-plan babies, other families wanted to be pregnant with twins since according to China's one-child policy a family was allowed to keep both children if they were twins. For some families who do not want to break the law and do not want to have twins conceived with the help of reproductive science and technology, which was still a risky practice that could potentially endanger the parents' careers if they worked for the government, they wanted to guarantee their only children were boys. In order to meet many Chinese people's demanding expectations of family design, such as having twins and having a boy with their only chance, they had to turn to reproductive technology for help because, as argued in Chapter Two, many people rely on science and technology to solve their problems.

However, Chinese people's notion of an ideal family has changed significantly in recent years. After the implementation of China's most recent two-child policy, Chinese families are allowed to have two children, and many of them want their babies to include one boy and one girl. The need for a baby boy follows the long Chinese cultural tradition of preferring boys over girls, as discussed in Chapter Three. However, for the other child, an increasing number of Chinese families hope that it will be a girl. This preference has resulted in part from two reasons. First, as discussed in Chapter Three, due to the lack of 
single Chinese women, many Chinese men's families have to pay large sums of money to their sons' girlfriends' families to get permission for marriage from the girls' parents. Moreover, it is Chinese tradition that it is a bridegroom's family's responsibility to buy at least one living unit for the newlywed couple. Fong (2016) points out that due to the expense for a boy to get married in contemporary China, marriage has gradually become "a matter of money, valuation, and investment" (p. 117). Thus, many Chinese families now do not want to have two boys because they would have to face severe economic pressure when their boys become adults. Instead, they want to have a boy and a girl: the girl can obtain money for the family, which can be used to pay her brother's girlfriend's family. This makes prenatal gender selection to have baby girls an investment for their families, especially for their sons.

Additionally, the discourse that having a boy and a girl makes a happy family began to gain popularity in Chinese society recently. For example, on January 15, 2016, Sohu —one of the most popular websites in China — published the article "Having a Boy and a Girl, That's a Perfect Life." In the article, the mother Yaling Li presented her happy life by showing photos of her son and daughter. She concluded that her most meaningful and proud job was to take care of her children and witness their growth (Chen, 2016). On April 24, 2017, when the famous Chinese diver Jingjing Guo gave birth to a baby girl as her second child, Jingjing Guo was widely recognized as a super lucky woman who have a baby boy as her first child and a baby girl as her second child. She is regarded as a female role model because she had a successful career that enabled her to attract and 
marry a rich man, and after her retirement she secured her position in a well-endowed family by having two babies of different sexes.

In fact, nowadays in China, it is widely argued that since the Chinese character “好” (good) is made of two parts “女” (girl) and “子” (boy), having a boy and a girl will bring a family great wellbeing. This discourse tries to promote a new image of an ideal contemporary Chinese family to replace the prior image that a happy Chinese family has only one child that is ideally a son. On the one hand, this discourse reflects the improvement of a girl's status in Chinese culture because she is no longer viewed as a money-losing property (Pei Qian Huo) as in ancient China or a half person as in the time of China's one-and-half child policy. On the other hand, it reinforces the necessity of using reproductive science and technologies in order to have the right number of babies of the right genders. In this context of emphasizing family design, IVF has become prevalently used in Chinese society. In fact, China has the largest population of test-tube babies in the world (“China Has World's," 2018). ${ }^{46}$

The science and technology of IVF first appeared and were used in Western countries since the late 1970s. The first test-tube baby was born on July 25, 1978 in the U.K. Just one year after, the first test-tube baby in China was born on March 10, 1988. According to Nordqvist (2018), IVF includes five crucial steps:

\footnotetext{
${ }^{46}$ Test-tube babies: this term refer to babies conceived by in vitro fertilization.
} 
[The first step is to] suppress the natural menstrual cycle: The woman receives a drug, usually in the form of a daily injection for about 2 weeks, to suppress their natural menstrual cycle.

[The second step is called] super ovulation. [In this step,] fertility drugs containing the fertility hormone follicle stimulating hormone (FSH) are given to the woman. FSH makes the ovaries produce more eggs than usual. Vaginal ultrasound scans can monitor the process in the ovaries.

[The third step involves] retrieving the eggs. The eggs are collected through a minor surgical procedure known as "follicular aspiration." A very thin needle is inserted through the vagina and into an ovary. The needle is which is connected to a suction device. This sucks the eggs out. This process is repeated for each ovary. In 2011, researchers suggested that collecting 15 eggs from the ovaries in one cycle gives the highest chance of a successful pregnancy. Frozen or donated eggs may also be used.

[The fourth step involves] insemination and fertilization. The eggs that have been collected are placed together with male sperm and kept in an environmentally controlled chamber. After a few hours, the sperm should enter the egg. Sometimes the sperm is directly injected into the egg. This is known as an intracytoplasmic sperm injection (ICSI). Frozen sperm, retrieved through testicular biopsy, may be used. This is believed to be as effective as fresh sperm in achieving a successful pregnancy. The fertilized egg divides and becomes an embryo. At this point, some centers offer pre-implantation genetic diagnosis (PGD) which can screen an 
embryo for genetic disorders. This is somewhat controversial and is not always used. One or two of the best embryos are selected for transfer. The woman is then given progesterone or human chorionic gonadotrophin (hCG) to help the lining of the womb receive the embryo.

[The final step is to transfer the] embryo. Sometimes, more than one embryo is placed in the womb. It is important that the doctor and the couple wishing to have a child discuss how many embryos should be transferred. Normally, a doctor will only transfer more than one embryo if no ideal embryos are available. The transfer of the embryo is done using a thin tube, or catheter. It enters the womb through the vagina. When the embryo sticks to the lining of the womb, healthy embryo growth can begin.

IVF treatment mainly can enable its recipients to achieve two purposes. First, as a significant medical breakthrough, it provides an efficient way to overcome infertility. Second, IVF is also used for the purpose of embryo gender selection as well as conceiving twins. In the fourth step "insemination and fertilization" of IVF treatment, doctors can identify the gender of the fertilized eggs, allowing them to filter out female embryos so that only male embryos remain. Fetal sex selection is prohibited in mainland China since the Chinese government is afraid that if it is legal, many Chinese couples would not want to have baby girls. However, it is a common practice that bribed Chinese doctors will perform the embryo gender selection secretly even in Chinese public hospitals. Moreover, in many other countries such as the U.S. and Thailand, it is legal for doctors to reveal the gender of an embryo and the parents can then decide whether they 
want to discard the female embryo. Additionally, IVF treatment increases the chance for women to have twins since usually several fertilized eggs will be transplanted into women's wombs.

Although IVF treatment can be very efficient, it is costly in China due to the complex procedure involved. On Zhihu, the Chinese Quora, many people used their experiences answer the question "How much does it cost to receive IVF treatment?" For example, “随遇而安”/ Suiyu Eran (2018) wrote, “In 2014, I received IVF treatment twice. The first time, I paid for 72,000 Yuan (10,700 USD), and the second time I paid 96,000 Yuan (approximately 14,300 USD). However, both treatments failed.” Samson (2019), a doctor in reproductive science, pointed out that to receive the IVF treatment in China will cost in average 140,000Yuan (approximately 19,737 USD).

Moreover, besides its cost, IVF treatment can result in female patients suffering from serious pains. As described in the detailed process of IVF, the only step in which a man is involved is providing his sperm. However, the woman's work is much more complicated. First, she has to take pills to suppress her natural menstrual cycle, then to have FSH to produce more than one egg at a time, after that to receive surgeries to retrieve her eggs and to have the embryo transferred to her womb, and finally to carry the[se] embryo[s]to term. While men's participation does not require much effort, the treatment for women is painful and lasts for several months. In this process, unlike the man who follows his natural proclivities, the woman is fighting against her own

\footnotetext{
${ }^{47}$ The question and its answers were written in Chinese. They can be openly accessed from https://www.zhihu.com/question/26900811. I translated them from Chinese into English.
} 
biological cycle. A report from sohu. com recorded many female patients' miserable experiences of receiving IVF treatment. It wrote "in this process, a mother received 236 injection. She definitely chooses to sacrifice herself in order to have a baby...A woman even cannot leave the hospital after she received the treatment of fertilized egg transplantation because she felt so much pain" ("The complete process of receiving IVF treatment,” 2017). A woman “安素簽”/An Suxiao (2016) posted a long article “TestTube Baby: How Brave Can a Woman Be?” on Tianya Luntan, which recorded her friends' and her experiences. In her post, she quotes her friend Z's comment to summarize women's experience when they receive IVF treatment: "I am treatedas a lifeless machine."

However, for the purpose of overcoming infertility, to have twins, and to have babies in preferred genders, many Chinese women are willing to or have to endure all the pains caused and cost incurred by the procedure of IVF. For instance, Lili, one of my interviewees, talked about her experience of using IVF and trying to become a mother again after the death of her son. Lili said:

I want to have a baby again. I don't care about how much I need to pay for it. I would sell everything I have; I just want to have a baby....[Lili told me that] I beg God and the doctors to please give me a child. You asked me what my wish is now? I have no wish but to get pregnant soon.... [I asked her: if you get pregnant successfully, what are your plans for yourself and the baby? Lili thought for a while and said] I have no plan. I just want to have a baby. (as cited in Liu \& Slack, 2014, pp. 40-41) 
In contemporary China, not only do infertile women receive IVF treatment, those who are healthy also receive this treatment. Chinese people's obsession with receiving IVF treatment to have babies and to peform fetal sex selection even has resulted in the flourishing of the international market of reproductive science and technology. It was reported that "more Chinese women are visiting fertility centers in countries like Singapore, Malaysia and Thailand, and even as far as the United States, as they look to start, or expand, their families"("More Chinese Women," 2018).

The case of IVF treatment reveals how science and technology are articulated with the CCP's family-planning policies and Chinese cultural beliefs concerning ideal Chinese families to discipline Chinese women. In this context, IVF significantly affects Chinese women even though some of them do not use it. Based on Wajcman's (1991) argument that "the very existence of [the reproductive science and technologies] changes the situation...[A woman's] 'infertility' is now treatable, and she must in a sense actively decide not to be treated," I argue the due to its articulation with the Chinese policies and culture, the very existence of IVF treatment not only makes a woman's infertility treatable but also enables women to have babies in the "right" genders that are often determined by the Chinese socio-cultural expectations, thus women must in a sense actively decide not to receive this treatment (p. 62). It is ironic that IVF, which is often viewed as an emancipatory reproductive science and technology that free women from the situation of being infertile and provide women opportunities to choose their babies in their preferred sexes, in reality traps Chinese women. On the surface, Chinese women can decide whether they want to receive IVF treatment or not; in reality, many of them are 
pressured to receive this treatment. Additionally, the process of compelling is often disguised as women's choice. After being articulated with the socio-cultural expectation for women to become mothers, IVF treatment has gained popularity in the Chinese society, turning into a non-negotiable option for many Chinese women and reinforcing the socio-cultural-political expectation for women to be mothers of the right number of babies in the preferred genders.

\section{The Development and Use of Science and Technology to Promote the Discourse of the Super Mother}

As discussed at the end of Chapter Three, in the era of reforms women are expected to be caring mothers and at the same time professionals, which are roles that often conflict. In response, though not necessarily intentionally, the media as well as the government began to promote the ideal image of a woman as a super mother, which essentially argues that women can balance these two roles and if a woman fails to do so, it is her fault because she does not work hard enough or lacks ability.

It is not easy to become a super mother, a fact that is even recognized by the government, which holds events to find and celebrate them. Thus how to become a super mother is a crucial question, one that relates to science and technology. As discussed in Chapter Two, in the era of reforms, many people believe that science and technology can solve all problems, including the task of being super mothers that has emerged in this context. This section explores the role of science and technology developed and used to 
this end by focusing on the examples of breast pumps and children's medicine made by Johnson \& Johnson.

\section{Breast Pumps}

Breast pumps are significant in terms of helping professional women balance their careers and their responsibility to breastfeed their children. The main function of the breast pump is to enable lactating women to extract milk from their breasts and refrigerate it for their babies to drink when the mothers are at work. This technological device can be powered by hand, batteries, or electrical outlet.

Breast pumps are very popular in China. Taobao, the biggest online market in China, sold more than 30, 000 electric breast pumps from the company Rusch and more than 20,000 from Xenbea monthly in 2019. Many customers who described themselves as working women left comments expressing how breast pumps are their must-have devices. In fact, in contemporary Chinese society, due to the increasing number of women who carry breast pumps in their working bags, a specific term "bei nai ma ma/背 奶妈妈," which can literally be translated as “mothers who are carrying milk in their briefcases" was created to refer to lactating women in the workplace. By putting breast pumps in their briefcases, these bei nai ma mas try to shoulder their mothering responsibilities when they work outside their homes.

There is a significant difference between the promising advertisements for breast pumps, which claim that they solve all the difficulties that bei nai ma mas' have experienced and the actual lived experience of many women who use breast pumps. They 
argue that their difficulties cannot be easily solved merely through using these technological devices. Commercials for breast pumps often convey the message that they significantly improve bei nai ma mas' experiences, making their lives enjoyable and enabling them to take good care of their babies by providing fresh nutritious milk in their mothers' absence. For example, the commercial for Rusch's breast pump emphasizes that this product is easy to use, won't cause any pain, and even can massage breasts sore from breastfeeding. Moreover, by giving its customers free storage bags for milk, it claims that it provides a complete high-quality service that meets all of its customers' needs and saves bei nai ma mas from worrying about their babies' food when they are away.

However, many women reported uncomfortable experiences using breast pumps and argued that breast pumps, although necessary, do not fundamentally better their experiences of being bei nai ma mas. On Zhihu, the Chinese Quora, when women discussed their lived experiences of using breast pumps in the workplace, they often mentioned that besides the physical pains caused by breast pumps, they suffered from the psychological stress of being embarrassed in front of others, a situation that cannot be simply solved by using advanced breast pumps. ${ }^{48}$ For example, “三姐”/ San Jie (2019) wrote: "being a bei nai ma ma, you must have to face many difficulties....Moreover, whenever you go to any online forums, you can see people criticize career women who do not want to be bei nai ma mas.” “晴天”/Qing Tian (2016) posted her record of extracting $16,510 \mathrm{ml}$ of breast milk during the first two months following her return to 
the workplace and summarized, "I am so tired. I have tried many different environments to extract my milk." ${ }^{49}$ In fact, most workplaces in China do not have a lactation room. Moreover, many toilets in China do not have electric outlets. Thus, some mothers have to use conference rooms, a comparatively more private space, when they need to use electric pumps.

As discussed previously, super mothers are characterized as caring mothers who take very good care of their children confidently and happily. Breast pumps have helped many career women fulfill the purpose of continuing to breastfeed their babies after they have finished their maternity leave, which is a prerequisite of being a super mother. In fact, the idea that a responsible mother should breastfeed her baby for at least six months to make her baby smarter and healthier is very popular in Chinese society. Mothers who don't meet this expectation are often criticized as being irresponsible and selfish. Chinese society, which strongly discriminates against large framed women, accepts and even respects lactating women with a larger body shape since they are culturally viewed as mothers who have plentiful milk. In this case, their large bodies serve as the evidence of their sacrifice for their children.

Although breastfeeding for young babies is strongly promoted, an increasing number of women cannot be around their babies at all the times. According to Chinese law, paid maternity leave for women is 98 days. Moreover, it is common that in order to maintain their positions, many professional women who work for private companies

\footnotetext{
${ }^{49}$ These comments can be openly accessed from https://www.zhihu.com/question/21325360/answer/59183635. I translated this comment from Chinese to English.
} 
return even before they finish their maternal leave. This means that most professional women, have to use breast pumps and become bei nai ma mas if they want to have careers and at the same time be caring mothers. In this way, breast pumps provide these women an important tool to becoming super mothers, and therefore highly respected figures in society. But, at the same time, breast pumps lead to the simplification of bei nai ma mas' difficulties, framing their struggles as ones that can be easily solved by using science and technology. Moreover, because of the possibility afforded by breast pumps, many women are trapped. Many bei nai ma mas indicated that after returning to their workplaces, they suffered from stress and anxiety, which resulted in reduced milk flow. Thus, no matter how diligently they used breast pumps, they could not produce sufficient milk. This circumstance leads to even more physical pain and anxieties for them (“An investigation of lived experiences of bei nai ma mas,” 2015).

While mothers with careers have to use breast pumps and to endure physical discomfort and psychological stress in order to raise their children in accordance with the society's expectations, fathers are largely absent from those responsibilities. In fact, while the image of a super mother, which sets up an "exemplary" model for contemporary Chinese women, emphasizes that women should prioritize their mothering responsibilities over their careers, the image of the super father is negative and mocks men who waste their time and life taking care of their babies. It is ironic that compared with the society's strong emphasis on women shouldering all kinds of obligations for 
child care such as breastfeeding, the paternal role is significantly ignored.$^{50}$ As a result, some breast pump companies such as Xenbea even go so far to excuse paternal responsibility by promoting their products as being quiet and therefore not impacting other family members' sleep in the middle of the night when the mother uses it. As revealed in my analysis, although breast pumps provide important resources for women to become super mothers, they do not resolve the fundamental tensions that many bei nai ma mas face.

\section{Children's Medicines Produced by Johnson \& Johnson}

As discussed previously, super mothers are different from traditional mothers who usually do not have jobs as well as working mothers who are often overburdened by their responsibilities. Instead, super mothers are supposedly to be confident and professional both in their careers and in raising their children. Science and technology, especially science and technology focused on children's medicines, strongly promote the quality of professionalism super mothers should have.

Johnson \& Johnson, in order to promote its fever reducer for children named "Mei Lin/美林,” released a series of short commercials over the past few years. These commercials depict mothers who "fly" quickly from their offices to homes to take care their children when they are needed and show how these mothers turn to Mei Lin to provide care for their children while maintaining their professionalism. Mothers in these

\footnotetext{
${ }^{50}$ In contemporary Chinese society, it is normal that mothers and grandmothers are responsible for taking care of the babies exclusively.
} 
commercials are depicted as beautiful, knowledgeable, and confident professional women who can singlehandedly take good care of their children. These commercials always conclude with the statement that "Every mother is a firefighter/Mei Ge Ma Ma Dou Shi Xiao Fang Yuan/每个妈妈都是消防员.” In fact, the most typical image of mothers in Mei Lin's commercials is a mother who wears a firefighter's suit, happily holding her son and facing the camera with confidence. Below is the image of the mother in Mei Lin's advertisements: ${ }^{51}$

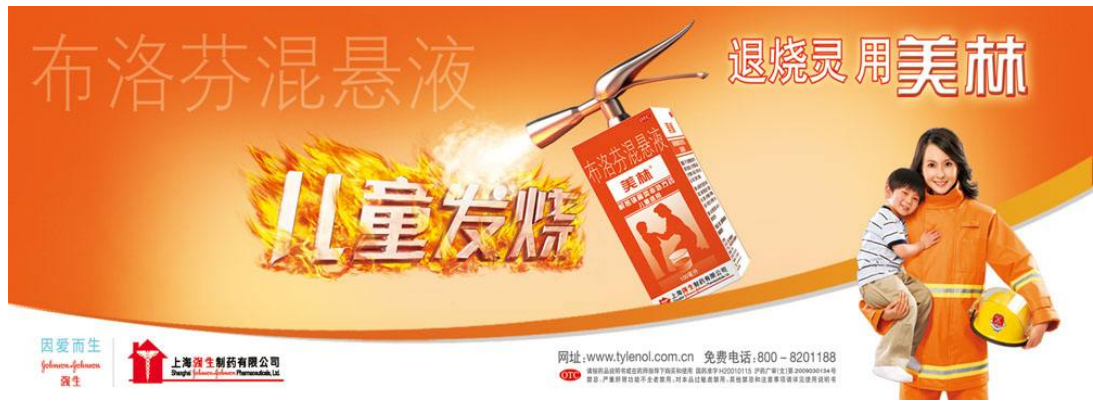

Figure 4. 7 An Advertisement To Promote The Children's Fever Reducer Mei Lin. This image can be publicly accessed from http://sucai.redocn.com/psd/553017.html.

In 2018, Johnson \& Johnson released a long commercial to promote its product Mei Lin, which was well received. This commercial depicts three generations of women who live together: a grandma who is responsible for all housework; a mother who is a highly successful, professional who often finishes her work at 2 am and at the same time takes good care of and teaches her baby girl; and the young girl. The commercial begins with the conflicts between these three generations of women: the professional woman complained about her mother for not listening to her and the baby girl cried because her

\footnotetext{
${ }^{51}$ Appendix D contains the fair use report to demonstrate my fair use of this image.
} 
mother refused to wear clothes for her. With the sickness of the baby girl, who later was cured using Mei Lin, these three women reconciled and expressed their love for each other: the grandmother understands her daughter's requests and the professional woman explicitly shows her deep love for her daughter after staying awake the whole night to take care of her ("Let love be right," 2018).

Besides the father's voice calling his family and asking the routine daily question "How is everything today?", the image of a father is absent in this commercial. While promoting the effectiveness of its medicine and celebrating maternal love, the commercial clearly sends out the message that women are responsible for taking care of children, doing all housework, and if they need help, turning to science and technology and their female family members. Additionally, this commercial promotes the way of a high level of professionalism a woman should have to take care of her baby, which adds extra demands for many women. As revealed in my analysis, children's medicine, such as Mei Lin manufactured by Johnson \& Johnson, reinforces the image of the super mothers, which reframe mothers to accommodate to the current culture, economic, and political climate but still maintains the traditional Chinese family dynamics.

Besides breast pumps and children's medicine, an increasing number of technological products, such as smart home devices and mobile apps have been designed to help mothers who are also professionals. These technologies are meant to help mothers manage their time and take good care of their children, resolving the tension produced by women's roles of being mothers and at the same time professionals. However, with the popularity of these products, extra burdens are added for women and the image of the 
super mother becomes more demanding. As revealed in my analysis, the image of a super mother does not resolve the tension produced by women's simultaneous roles as professionals and mothers. Moreover, although science and technology can be helpful in terms of enabling women to balance their careers and familial lives, the ways they are promoted in China significantly reinforce the absence of the role of the father and complicate the demands for women, which can even exacerbate women's already stressful lives.

\section{The Development and Use of Science and Technology By Women to Gain Independence and Resist Sexual Violence}

As discussed in Chapter Three, the discourse of The New Woman advocates for Chinese women to resist their subordinated status, to receive education, and to join the workplace. It points out that since the late $18^{\text {th }}$ century, feminist movements that primarily promote gender equality and request for eliminating gender-based violence such as foot binding have occurred in China. Chapter Three also pointed out that the CCP encouraged and prepared women to join the workplace, as evidenced in its various political practices. Accordingly, an increasing number of Chinese women have received education and become professionals, which in turn have enabled them to better resist sexism. However, as discussed previously, some sexist practices are still prevalent in Chinese culture and are even supported by the Chinese government. Thus, tensions have emerged between women's independence and demands for gender equality and the sexist attitudes associated with the tenacious cultural-political force. This section explores the 
roles of science and technology in this tension-filled context through focusing on women's job opportunities in the era of reforms and online feminist activism against sexual violence in China.

\section{Job Opportunities}

As argued in Chapter Two, science and technology have developed rapidly in the era of reforms and have influenced Chinese people significantly. One of their important influences is the job opportunities they create. In fact, the development of science and technology has offered Chinese women from various backgrounds valuable job opportunities that increase their chances to gain independence.

Chapter Three argued that with the implementation of the nine-year compulsory educational system, an increasing number of Chinese women have been able to receive education. Additionally, according to Chapter Two, due to the Chinese government's emphasis on developing science and technology, STEM education is also prioritized compared with education in the humanities and the arts, which results in many Chinese women becoming scientists and engineers. In 2015, the Nobel Prize in Medicine was awarded to $\mathrm{Tu}$ Youyou, a Chinese female scientist. Tu is the first and the only scientist in China who has ever won the Nobel Prize in STEM. Tu and her team discovered the key chemical element "artemisinin" in the plant of Artemisia Annua, which was commonly used in traditional Chinese medicine to cure malaria. Her team successfully extracted artemisinin from the plant. Tu's discovery is recognized as significant worldwide. On the website of the Nobel Prize, Tu's work is explained as follows: 
A number of serious infectious diseases are caused by parasites spread by insects. Malaria is caused by a single-cell parasite that causes severe fever. Traditional Chinese medicine uses sweet wormwood to treat fever. In the 1970s, after studies of traditional herbal medicines, Youyou Tu managed to extract a substance, artemisinin, which inhibits the malaria parasite. Drugs based on artemisinin have led to the survival and improved health of millions of people. ("Tu Youyou Facts," n.d.)

Chinese people are proud of $\mathrm{Tu}$, since unlike many other scientists who have experiences studying or working in Western countries, Tu finished all her education in China and her achievement was significantly influenced by traditional Chinese medicine. Thus, Tu's success signifies that China has the ability to cultivate its own scholars in STEM and that there is valuable scientific and technological knowledge in traditional Chinese culture, resisting the stereotype that it is a backward culture reliant on superstitions.

Tu's case also directed people's attention to female Chinese scientists and engineers. On 10 January, 2017, CCTV.com, a website sponsored by the Chinese government published the article" $1+15+50 \%$ : 'Hua Mulan' in STEM.” The article celebrates $\mathrm{Tu}$ as the most representative female scientist along with 15 other female scientists and engineers who were PIs on projects that won top Chinese prizes in STEM and the $50 \%$ of female scientists and engineers who have also worked on most of the renowned projects in STEM. The article likens them to Hua Mulanin contemporary 
China. ${ }^{52}$ The article states, "these female scientists and engineers who are active in different disciplines are blooming, working hard, and creating [legends]" (Liu, 2017). In fact, female scientists and engineers have important roles that will become increasingly indispensable in China, as indicated by Ma et al. (2018). They write:

China is focused explicitly on building its own research and development (R\&D) and innovation. Its R\&D staff swelled from 3.2 million in 2009 to 5.8 million in 2016, and the increased demand for talent has highlighted the need for more female scientists....after age limits for female grant applicants [for Young Scientist Fund] were extended [from 35 to 40 by the Chinese government as a strategy to attracting many women to work in STEM and to improve gender equality in 2011], The percentage of female award recipients jumped from $33 \%$ to $43 \%$ in $2011 \ldots$ Women's representation on review panels [in STEM] went up by 45\% between 2010 and 2017, to $13.3 \%$. That is still low, but consistently higher than rates seen from 1986 to 2009, which fluctuated around 6\%.

Although the development of science and technology has afforded women who receive advanced education in STEM chances to become scientists and engineers, female scientists and engineers are still strongly discriminated against in their workplace. For example, in 2018, 177 male scientists were elected as Outstanding Young Scholars in

\footnotetext{
${ }^{52}$ Hua Mulan: Hua Mulan (花木兰) is famous female hero in Chinese culture. Although it is believed that she lived as a woman warrior in the Northern and the Southern Dynasties (420-589), she was treated as a legendary figure instead of a real person in Chinese culture. The legend of Mulan describes how she camouflaged as a man to replace her father who was old and sick and her younger brother to serve in the army because in that period of time every family with more than one male was required by the government to send a man to serve in the army. Mulan was very brave and her performances were outstanding during the wars. Mulan is not only known by Chinese people. In 1998, Disney released the film Mulan based on the story of Hua Mulan in Chinese culture. In 2004, Disney released the film Mulan II which continues Hua Mulan's story in the 1998 film.
} 
China; in contrast, only 23 female scientists were elected. Until 2017, female scientists only constituted 6\% of the members of the Chinese Academy of Science ("The First Female Chief Editor of Nature,”2018). Moreover, outstanding female scientists are often derogatorily labeled as “Abbess Mie Jie /灭绝师太." ${ }^{53}$ Thus, although female scientists and researchers are valuable, they are not as valued as they deserve to be due to the cultural-political forces that prioritize men over women in the workplace.

Besides offering women who receive good educations job opportunities in STEM, the development of science and technology also has provided migrant job opportunities to Chinese women who only receive middle school, high school, and vocational education. These women are known as rural migrant workers/Nong Min Gong/农民工. They leave their hometowns, usually villages and small towns, and come to big cities to conduct manual and low-skilled work. In 2018, there were 115.7 million migrant workers in China and more than one third of them were employed in the manufacturing industry (National Bureau of Statistics, April 2019). Moreover, among these workers, 34.8\% were women (National Bureau of Statistics, May 2019). Foxconn, a manufacturing company that is famous for its role in producing electronics, including mobile phones, laptops, and tablets, is one of China's largest private companies that has employed considerable number of migrant workers. According to Foxconn's 2017 Suicidal and Environmental

\footnotetext{
${ }^{53}$ Abbess Mie Jie is a female figure from an influential swordsman novel The Heaven Sword and Dragon Saber/倚天屠 龙记. “Mie jie" means “destroy and eliminate." Abbess Mie Jie is depicted as a stubborn and high-skilled female leader who has an extreme idea of success. In order to fulfill her dream of leading her team to be the best, she is willing to sacrifice her students' love and happiness and even to kill her closest student (Jin, 2013).
} 
Responsibility Report, an official document released by the company, it had 988,000 workers in China as of December 31, 2017; among them, 35\% were women (pp. 11-23).

The phenomenon of large numbers of Chinese women from rural areas becoming migrant workers is quite recent and began to emerge during the mid-1980s when China began to cooperate with Western countries to build modern factories equipped with assembly lines. These modern factories attracted companies to move their factories from Western countries to China where labor is cheap, the exchange rate favors U.S. and European currencies, and many poor Chinese people are desperate to take any kind of job. Due to the expanding population of migrant workers, in 1991, a TV series Wai Lai Mei/ 外来妹 showcased this group through depicting the experience of six female migrant workers in the manufacturing industry (Chen, 1991). This TV series was highly successful and is still regarded as one of the best Chinese TV series. It applauded female migrant workers' bravery in leaving their hometowns and making irreplaceable contributions to the development of the city, even though they were suffering from discrimination and homesickness.

The discussions concerning the issue of female migrant workers always center on two words: "opportunity" and "hardship." The opportunities for these women from poor rural areas to find jobs as factory workers as well as waitresses, cleaners, and other menial laborers in cities are crucial for them to achieve economic independence. After interviewing and surveying migrant women in Beijing, Jacka (2005) points out that many female migrant workers suffer from poverty and sexism before their migrations to Beijing. They intentionally decide to work in cities for the following reasons: to leave their 
backward, poor hometowns and/or families; to develop themselves; to broaden their horizons; to exercise independence; and to receive education. Jacka concluded that these urban job opportunities enable women to explore the world, to gain independence, and to redefine their identity as someone more than a daughter and a wife (pp. 55-62). Similarly, Goodburn (2015) also believes that urban job opportunities improve rural women's living situations significantly:

While [migrant] women's burden of work in cities may not be much less [compared with their burden of agricultural work in their hometowns], their subordinate status is subtly changed, at least societally if not necessarily within each household, with the increase in participation in paid labour and the distance from husbands' parents. (p. 336)

While many female migrant workers develop a sense of autonomy, they are struggling at the same time. For example, Pun and Chan (2012) explore the hardships of migrant workers after discussing the case of Tian $\mathrm{Yu}$, a female migrant worker in Foxconn, who survived after attempting to commit suicide. To and Tam (2014) write, "the fact is that they [migrant workers] still receive poorer welfare benefits... [and] they are also blamed as the causes of social problems." (p. 1329)

Whether or not women from rural China choose to become migrant workers, the development of science and technology, which results in the rapid expansion of the manufacturing industry in China, provides women - especially rural women who only receive minimal education - an extra option besides conducting agricultural work in their hometowns. Besides female scientists, engineers, and migrant workers, the 
development of science and technology also contributes to the increasing number of businesswomen. Dong Mingzhu (董明珠) and Hu Weiwei (胡玮炜) are the two most representative figures whose success significantly resulted from the development of science and technology. Dong began her career as a salesperson in 1990 at Gree Company, which is famous for producing air conditioners. In 2012, she became the chairperson of this company. As a highly successful company, in 2017 the revenue from Gree air conditioners in China was 123.41 billion Yuan (approximately 18.3 billion USD) (“Gree," 2018). Moreover, air conditioners produced by Gree have been exported to other Asian, African, Latin American, and European countries. Gree's success is widely attributed to Dong's efforts and intelligence. At the same time, Dong is also widely recognized as a highly successful Chinese professional woman.

Compared with Dong Mingzhu, Hu Weiwei’s path to success has been different, even though both of them took advantage of scientific and technological developments. Hu began her career by building an online platform while Dong began her career as a traditional salesperson. Inspired by the rapid development of information and communication science and technologies, Hu set up the company Mobike. This company centers on a bike-sharing scheme. People download the Mobike App into their smartphones in order to use it to unlock bikes. When they finish using the bikes, they can leave the bikes almost anywhere and finish the rental process by using the app again. By December, 31, 2017 there were 200 million registered users, and Mobike was active in 16 countries by May 2018 (Smith, 2019). Because of the success of Mobike, Hu, who was born in 1982, became one of the youngest and most prosperous businesswomen in China. 
Although not many businesswomen are as successful as Dong Mingzhu and $\mathrm{Hu}$ Weiwei, many Chinese women set up small businesses, especially online shops, to become self-employed workers. Previously, it was expensive and complex to own a shop, because the person needed to pay rent for a store and get a set of licenses from the government. However, the development of the Internet makes the path to opening a shop much cheaper and easier. Alibaba, a world renowned company in e-commerce, was founded in 1999 in Hang Zhou China. Alibaba enables businesspeople to sell products without renting a physical place and without needing to obtain the many required licenses from the government. In this way, Alibaba provides many people, including women, job opportunities. As Jack Ma, the founder of Alibaba has said, Alibaba contributes significantly to female entrepreneurship. Ma (2017) claimed that

More than one-third of its founders were women, with a similar percentage taking senior management roles. Women are well-represented within Alibaba, with the ratio of female employees once nearing 50 percent, and is only slightly watered down after a wave of mergers and acquisitions of overseas assets.

Also, half of the sellers on its gigantic Tmall and Taobao marketplaces are women, and a greater proportion of storefronts with higher positive user ratings have female owners.

These are clear manifestations that the internet has helped equalize the playing field and enabled women to create and pursue opportunities to flourish in their own right. (as cited in He, 2017) 
By running online shops, some women have become rich and successful. For example, in 2018, the Wall Street China reported on the successful career of Zhang Dayi, who began her business as an owner of an online clothing shop. Using pictures of herself wearing the clothing she sold in her shop as a guide for how to be fashionable, Zhang's online shop has become famous and has gained many loyal followers. On 11, November 2017, the sales of Zhang's online shop exceeded 170,000,000 Yuan (about 25,000,000 USD) daily ("Will Zhang Dayi's Company," 2018). In fact, it has become a trend for many Chinese women to become self-employed as owners of online shops. They focus on their interests such as clothing, cosmetics, and specialized talents (e.g. painting and language skills), to achieve economic independence and gain self-fulfillment.

However, we should notice that despite their successes, many female online shop owners are being strongly denounced. They are labeled as "Internet Red/ Wang Hong/网 红”, which has a derogatory connotation. They are accused of using their influence to make Chinese women obsessed with superficial concerns such as buying excessive clothes to chase fashion trends and of commercializing their bodies to make profit. Moreover, since their businesses are primarily women-related, they are not viewed as seriously as other businesses. In addition, in order to attract customers, many of these women try to build personal connections with their customers, which results in them being vulnerable to overwork and abuse. For example, in 2012, a 24-year-old female online shop owner “艾珺 Aj,” whose shop won recognition as a diamond shop since it was deemed high-quality and trustworthy, died from overwork. It was reported that in order to run her shop, she took only five hours of sleep and put all the rest of her time 
into her shop (“A 24-years-old online shop owner," 2012). However, because she was self-employed as an online shop owner, her death from overwork did not receive any material compensation. Furthermore, in 2015, "Xiao Mei," an owner of an online homeware shop, was raped by five men who lured her out to discuss her products ("Beautiful Online Shop Owner Was Raped," 2015). These two cases reveal that the working conditions for owners of online shops are not necessarily stable or safe.

Although the development of e-commerce has not avoided or eliminated sexism or provided sufficient protections for women who are self-employed, it offers Chinese women another opportunity to make a living independently. With the development of science and technology, an increasing number of Chinese women have more opportunities to become career women whether they are in cities or in rural areas and whether they receive college education or not, although sexism continues to be a problem. Consequently, despite discrimination against women in the workplace, Chinese women are more likely to become independent working women who take control of their lives.

\section{Online Feminist Activism Against Sexual Violence}

As argued in Chapter Three, traditional Chinese women were expected to be submissive in their marital and familial lives. However, with an increasing number of women receiving education and becoming professionals accompanied by the popularity of the discourse of The New Woman that criticizes traditional submissive women in contemporary China, many women began to question the legitimacy of the requirement for women to be submissive and to realize that, like men, they should be equally respected. This change is explicitly reflected in Chinese women's increasingly strong 
attitudes against sexual violence. For example, on March, 2015, five young feminist women protested against sexual harassment on public transportation in Beijing, the capital city of China. However, on March 6, they were arrested, which happened two days ahead of International Women's Day. This case reveals the serious tension that is created by the increasing number of Chinese women who engage in feminist movements and the Chinese government's political goal of building a society that is stable and free from conflicts, activism, and complaints.

In this context, many women shift their locations of resistance against sexual violence from offline to online spaces, utilizing the internet and social media. For example, a group of feminist activists imitated the play Chicago to make a video "China Scumbag Illustration" that lists and criticizes the six most typical forms of sexual violence in China and posted it online ( $\mathrm{Tu} \& \mathrm{Hu}, 2018$ ). In the video, Tu and $\mathrm{Hu}$ replay the life experiences of six women who killed their boyfriends and husbands due to the unendurable sexual violence they suffered. The first women was betrayed by her husband who not only slept with many women but also categorized these women based on their sexual behaviors and labeled his wife as dead hutong. ${ }^{54}$ The second woman was suffering from domestic violence. She was beaten frequently and violently by her husband using his favorite instrument: a saxophone. The third woman was driven to kill her husband because he killed her adopted children since she wanted to have a child but her husband lacked the ability to reproduce. The fourth woman was used by her boyfriend as the

\footnotetext{
${ }^{54}$ Hutong/胡同 means alley. Through comparing the woman to a dead alley, her husband criticized the woman for his betrayal of their marriage, arguing that it is the woman's fault because she lacked sexual attraction for him.
} 
scapegoat for his crime of transporting and hiding heroin in her apartment. Moreover, in order to escape from the punishment, her boyfriend called the police to report her address. The fifth woman was suffering from her ex-boyfriend who stalked, harassed, and threatened her every day since their first encounter following their breakup. The next woman killed her husband because he killed their baby girl since someone was willing to pay for their baby girl for a ghost marriage. ${ }^{55}$ This video was widely discussed online. For example, due to its high search frequency, in November 2018, the hashtag "China Scumbag Illustration" was the highest trending topic on Weibo, the Chinese Twitter. Despite many Chinese netizens' disagreements with the radical approach that the six women took to end their suffering by killing these men, most viewers commented that this video truthfully depicts the predominant forms of sexual violence that are prevalent in Chinese society and that Chinese women have the right to fight against sexual violence. This video reveals how Chinese women utilize the internet and social media to resist sexism, to criticize sexual violence, and to exert feminist influence over the society.

In fact, in recent years, many social activist movements that target sexual violence have happened online. One of the most successful movements is online anti-domestic violence activism, which significantly contributed to the implementation of China's first anti-domestic violence law on March 1, 2016. Legette (2017) focuses on the discussion of domestic violence on Chinese online platforms, especially the Weibo account Feminist

\footnotetext{
${ }^{55}$ Ghost marriage is a traditional Chinese cultural practice of sending a wife to accompany the dead male members of their families, which is still performed in some Chinese areas. To perform ghost marriage, people usually hold wedding ceremonies for dead men and women to announce that they are couples. Some people also kill women and baby girls and bury them with men to perform ghost marriage.
} 
Voices, and argues that the online platforms have contributed to China's politics and society in the ways as "raising awareness and fostering normativity of an anti-domestic violence stance; [forming] anti-domestic violence CSO [Chinese Civil Society Organization] network; [and]linking the online discourse to offline action" (pp. 22702272). Similarly, Tan (2017) highly evaluates the impacts of the online anti-domestic violence activism, stating:

During the 16 Days of Activism against Gender-Based Violence campaign and the International Day for the Elimination of Violence against Women in November 2012, feminist activists in China launched a petition for legislation against domestic violence which was eventually enacted in December 2015. (p. 178).

In this activism, many women use their bodies as the battleground. For example, many of them post their nude photos online with words written on their bodies with their faces covered or absent, which can hardly be done offline in the conservative Chinese society. Tan (2017) analyzes this action and describes one of the pictures as "inscribed on her [Xiao Meili who is a Chinese feminist] torso were two columns of Chinese characters: 'Shame on domestic violence / Proud to have [a] flat chest"' (p. 178). Tan argues that in this way, Xiao Meili asserts that women should never be held responsible in any way for being victims of domestic violence for any reason. In arguing that social media has become the core political resource for young Chinese feminists, $\mathrm{Li}$ and $\mathrm{Li}$ (2017) also invoke the example of the online activity of women uncovering breasts to fight against domestic violence. They point out that Chinese women use this activity, as 
well as other similar strategies to attract the most public attention in order to efficiently send out their messages regarding their intolerance of domestic violence, and to create strong public pressure for the Chinese government to respond and to make legal changes.

In short, the online anti-domestic violence activism has helped Chinese women to identify the manifestations of domestic violence, thus they realize that violence includes both physical and mental abuse. Additionally, this online activism enables many Chinese women to express their requests for being legally protected and respected in their marriages and families, provides victims of domestic violence with resources to seek help such as China's Anti-Domestic Violence Network, and creates strong social pressure for the Chinese government to address the issue of domestic violence. These efforts have later resulted in the enactment of the anti-domestic violence law that has the potential to save millions of women and children from being abused.

Although the internet and social media are helpful in terms of providing a safer, relatively anonymous space for women to bravely and openly criticize sexual violence and advocate for social changes, these technologies do not resolve the tensions between women's demands for equality and independence and the government's conservative attitude towards social activism. For example, although the video "China Scumbag Illustration" was popular and recognized by most of its viewers as Chinese women's determination to demand for social justice that they deserve, one day after it became trending on Weibo, it was banned all over the Chinese internet by the government. Although the government hasn't provided an explanation for this action, it is likely that the part of the video that depicts the way the women end intolerable sexual violence 
irritated the government. It is possible that the six women who killed the men that suppressed them can be interpreted more as social disruptors rather than feminist fighters. Consequently, this video was banned likely because the government prioritizes stability of the society over ending sexism. Besides banning this video, the government also banned the Weibo account Feminist Voices, which had significantly contributed to the online activism against domestic violence in March 2018. Fincher (2018) interviewed a Chinese feminist and borrowed her words to explain the ban, writing:

[The feminist Lü Pin] says the fact that the Chinese government felt the need to crack down so harshly on feminist social-media accounts was a sign of just how successful the feminists had been in tapping into the urgent needs of women across China and striking a nerve with the mainstream public. (p. 51)

Despite the government's increasingly strict censorship concerning online comments that indicate and demand for social change, Chinese women are resilient and try to speak out against sexism. For example, many Chinese women still engage in the \#MeToo movement, a topic that is strongly censored by the government through deleting comments and even banning some participants' social media accounts. In order to avoid being caught, instead of using the hashtag "\#MeToo," many Chinese women used two emojis $\theta$ and 5 when they talked about their past experiences of being sexually harassed and even damaged on campuses, in their workplaces, and in public spaces. refers to rice, which in Chinese sounds like "me." $\&$ refers to rabbit, which in Chinese sounds like "too." So when put these two emojis together, it refer to "Me Too." Through this code, they demand for social change. 
The online activism against sexual violence reveals how the internet and social media have empowered Chinese women through providing them an important space to build solidarity and more importantly to resist sexism and make political demands. In fact, as indicated by Kuah-Pearce (2008), "by embracing the Internet and the cyberspace, [many] women have accumulated significant socio-cultural capital and are creating a feminized virtual space for their use" (p. 43). However, while serving Chinese women, the internet and social media are under the strict control of the Chinese government. Consequently, although the internet and social media mediate the tension to some degree between women's engagement with feminist activism and the government's conservative attitude towards any social activist movements, they have not resolved the tension in a fundamental way.

This chapter has explored the implications of science and technology for Chinese women's lived experiences as wives, mothers, and professionals. Through focusing on the developments and uses of science and technology to promote marriage and family, for population control and family design, to promote the discourse of the super mother, and for women to gain independence and resist sexual violence, this chapter has demonstrated that science and technology are closely articulated with traditional Chinese culture, the Chinese politics, and the discourse of The New Women to exert gendered influences. 


\section{Chapter Five: Conclusion}

This final chapter includes three sections. The first summarizes the main arguments in this dissertation. The second explores the theoretical and practical implications of my findings. The third addresses a limitation of this dissertation and my future directions of research.

\section{Summary: Cultural Stories of Science and Technology and Chinese Women}

This dissertation has brought together scholarship from cultural studies, gender studies, contemporary Chinese studies, and science and technology studies to explore the implications of science and technology for Chinese women. More specifically, this dissertation answers the following questions: what's going on with regard to science and technology in the era of reforms? What are Chinese women's lived experiences in the era of reforms, and how do science and technology impact them? I tell two stories — one about science and technology and the other about women in contemporary China- to summarize the main arguments in the previous chapters.

The first story is about science and technology. They have existed in Chinese culture for thousands of years. The ancestors of the Chinese people deeply respected science and technology, which for them were mysterious powers that were difficult to control, figuring the people who mastered scientific and technological skills as gods and goddesses. Over time, Confucianism gradually replaced myth as the ideological foundation of Chinese culture. As a philosophy that strongly emphasizes people's 
subordination to the government and education but humanities education exclusively, critical thinking as well as STEM education were profoundly underscored. However, this doesn't mean that Confucianism had only negative impacts on science and technology. In fact, due to its two emphases, Confucianism contributes significantly to the STEM fields in contemporary China, as the Chinese government promotes STEM. Besides Confucianism, Daoism, as the most traditional Chinese religion, also impacts science and technology in Chinese culture. In order to survive in the society to attract followers, Daoism shifted from a philosophy that promotes the idea that people should not pursue scientific and technological knowledge, which would not be beneficial, to a religion that focuses on exploring scientific and technological world to find out ways to live healthily and remain immortal. Due to this shift, Daoism has made significant contributions to STEM, especially medical science.

In the 18th century, with invasions from Western countries equipped with advanced weapons, two socio-cultural and political movements, the Westernization Movement and the New Culture Movement, emerged, arguing that science and technology should be highly prioritized. Since then, Chinese society has increasingly emphasized science and technology. In the era of reforms, with the Chinese government's promotion of science and technology and strong support of STEM projects and education, science and technology are venerated as being nearly omnipotent, able to solve almost all social, economic, cultural, and political problems. An increasing number of Chinese people believe that through using advanced scientific and technological artifacts, they can better their living situations, and the Chinese government believes that science 
and technology are crucial to achieve almost any political purpose. At the risk of oversimplification, contemporary Chinese culture strongly celebrates science and technology.

My first story is about science and technology, and my second one is about Chinese women. Chinese myth promotes the image of a good woman: she should have babies and be willing to sacrifice herself for her babies. Moreover, she should be a caring beauty who is subordinate to her parents and her husband. The Chinese language reinforces the idea that as a woman, your reproductive function is most crucial. Confucianism states that women are restricted to the domestic sphere and should not receive much education or find jobs since their destinies are pre-arranged as marrying men chosen by their parents and sacrificing themselves for their husbands, their babies (especially baby boys), and their parents-in-law. Daoism, at the same time, argues that unmarried women unbalance society and nature. Besides these social and cultural pressures, the Chinese government also supports the idea that women should get married and have babies, expecting that women will "tame" unmarried men, who are viewed as potential social disruptors, and will give birth to future laborers who are important for Chinese economic development. Accordingly, the Chinese government has conducted many political practices to persuade, compel, and discipline women to become wives and mothers. The social, cultural, and political expectation for women to get married and have babies is strong to this day. As a result, similarly to Chinese people's emphasis on food, which results in them greeting each other with "Have you eaten?" it is common that 
Chinese women will be asked about their marital and reproductive status when they meet new people.

While Chinese women are expected to become wives and mothers, they are also expected to become professionals in the era of reforms. The discourse of The New Woman promotes the image of an independent and well-educated Chinese woman. Facing the political and economic needs to include women into the workplace, the Chinese government has implemented several policies to promote women's education and encourage them to find jobs. The traditional roles and the new role often conflict, requiring women to navigate tensions. For example, many Chinese women prefer to become teachers because these positions are more stable and usually have longer holidays, so they can have more time to take care of their families. The discourse of the super mother, which argues that women have the ability to have good careers and at the same time to become good mothers single-handedly, has become popular. This discourse basically argues that if women fail to balance their families and careers without complaint, they are not capable enough.

My third story puts my first story about science and technology and my second story about Chinese women's roles together. In the context of the veneration of science and technology in contemporary Chinese culture and women's expected roles as wives, mothers, and professionals, science and technology have significantly impacted women's lived experiences, especially by promoting marriages and families, population control and family design, and the discourse of the super mother; while also helping some gain independence and fight against sexual violence. 
Through focusing on several technological artifacts, these implications were revealed. For example, through inserting the function "Apply for Marriage Certificate" into the popular app Alipay, the Chinese government aims to encourage more Chinese people to get married. The government also prohibits single women to receive the treatment of egg freezing, hoping through limiting single women's access to have biological babies they will get married and have "normal" families. Moreover, many dating websites in China promote their products by reinforcing the social, cultural, and political pressure for single women to get married.

For the aspect of population control and family design, the Chinese government has disciplined and even compelled women to undergo abortion, sterilization, and IUD insertion to ensure the implementation of China's family-planning policies, which restrict the number of babies a family is allowed to have. Additionally, due to the Chinese long tradition of emphasizing women being mothers and gender selection, many Chinese women have been trapped by IVF, which makes their infertility "treatable" and gender selection "easy and accurate."

Breast pumps, as well as children's medicines, are promoted by taking advantage of the discourse of the super mother, which reinforces the traditional gender roles in a family as only mothers should be children's caretakers. For instance, breast pumps, often advertised as making professional women in the period of lactation worry-free, represent these women's struggles as something that can be easily solved by science and technology, but it is not this simple. Companies that manufacture children's medicine often promote their products by emphasizing how their products can enable women to 
provide professional care for their children efficiently. Thus women can not only be professional in their careers but also in their families. However, there lacks an emphasis on fathers' roles in child rearing, which reinforces the tensions that many women have experienced between their careers and familial responsibilities.

The development of science and technology also enables some women to gain independence through offering them job opportunities, even though sexism in the workplace has seriously impacted their professional development. For example, an increasing number of Chinese women become scientists and engineers, and with the industrialization of China many rural women who receive little education are able to leave their hometowns and to work as migrant workers in cities. Moreover, internet and social media, though they are under the strict censorship of the Chinese government, still provide Chinese women a crucial site to engage in social activism to fight against sexual violence in their families and workplaces.

This dissertation narrates cultural stories of science and technology and Chinese women in the era of reforms. It reveals that in this era, some traditional forces continue to have profound impacts, but new forces have emerged; some old articulations are being dis-articulated while new articulations are beginning to take effect. As a result of this process of maintenance and change, science and technology are elevated to supreme status and influence contemporary Chinese culture in significant ways. Various forces and articulations, which have created alignments, tensions, and conflicts, have also affected Chinese women's lived experiences, resulting in the perpetuation of some of their traditional roles and responsibilities as well as the introduction of new ones. My 
cultural stories explore the impacts of science and technology for Chinese women's lived experiences in the era of reforms: not only their powerless positions, reinforced by science and technology and resistant to change, but also their resilience against sexism and their efforts to better their living situations through strategic use of science and technology.

\section{Theoretical and Practical Significance}

This dissertation contributes to the field of cultural studies mainly through discussing the gendered implications of science and technology, which have been explored by many Western cultural theorists but rarely by Chinese scholars. This discussion is important since as discussed in Chapter Two in the recent decades science and technology have developed rapidly in China. Moreover, unlike the Western context in which there are many voices arguing that the impacts of science and technology are not good overall, the main discourse in China applauds the general goodness of science and technology. This one-sided discussion can be harmful. As a cultural researcher, I hope this dissertation, which maps some implications of science and technology for contemporary Chinese women, will invite other Chinese cultural theorists to engage not by asking whether science and technology are beneficial or harmful, but exploring how science and technology affect people's lived experiences and rethinking the roles and impacts of science and technology in contemporary Chinese culture.

My analysis reveals that in contemporary Chinese society, science and technology articulate with many elements, especially the Chinese government's policies and traditional Chinese culture. These two articulations have exerted significant impacts on 
Chinese women's lives, such as disciplining them to conform to sexist cultural and political expectations. Thus, researchers who aim to understand the gendered influences of science and technology in China should pay special attention to the elements of Chinese politics and Confucianism, realizing that science and technology are most tenaciously articulated with these two elements. In summary, instead of asking whether science and technology influence Chinese women positively or negatively; researchers should first attend to the Chinese government's political practices, since in Chinese society, the government's attitude fundamentally shapes women's access to and use of science and technology. Then, researchers should turn to traditional Chinese culture to explore how traditional cultural ideas, which play crucial roles in Chinese society, have become articulated with science and technology in ways that impact women. After that, researchers can examine other elements, such as class and economic background, to study the various impacts of science and technology for different women.

Besides the theoretical significance of this dissertation to the field of cultural studies, this dissertation also contributes to the field of women's studies in China. Women's studies, which is often known as fu nv yan jiu/妇女研究, emerged in the era of reforms. $\mathrm{Du}(2005)$ records the history of the development of women's studies: [The field of women's studies] arose out of the "Open \& Reform Policy" in China in 1980s.... In 1982, Social Science Abroad...first mentioned women's studies.... At present, women's studies in mainland China is still in the early stage of development. (p. 40) 
As described by $\mathrm{Du}$, this field is still young, thus it needs researchers to bring different perspectives to facilitate its continued development. This dissertation is my effort to engage in the scholarship in women's studies through addressing several primary commitments of this field. Based on Chow, Zhang, and Wang (2004), the field of women's studies in China has the following commitments:

(1) a commitment to make feminism and gender the theoretical and the principal analytical concepts of women's studies; (2) an engagement [with] scholarship from outside China through a series of reading/discussion[s] [to] evaluate the relevance of this scholarship to the Chinese context; (3) [education] and faculty development by combining scholarship with teaching inside and outside China for theory building, curriculum development, [and] pedagogy; and (4) multidisciplinary and interdisciplinary approaches targeting [the following] disciplines: history, sociology, and education. (p.167)

My dissertation brings in the method of "articulation" from the field of cultural studies; a field that was born and has been mainly developed in the West, to explore how gender matters in the era of reforms. My dissertation shows that this field provides a useful analytical framework that can be used to analyze culture in other contexts. Thus, cultural studies can be fruitfully incorporated into the field of women's studies. Moreover, by focusing on the issue of science and technology, this dissertation enriches women's studies by adding an important analytical perspective, which is crucial in contemporary China, which elevates science and technology above many else. However, in China there 
is a lack of researchers in women's studies to investigate the gendered impacts of science and technology. I hope to encourage more to join the field.

In the global context, an increasing number of scholars (e.g. Lykke 2002;

Haraway 2003; McNeil 2007) have noticed that the intersection of feminist studies, science and technology studies, and cultural studies is worthy of research and have proceeded to explore it. Thus, this dissertation, which forms the early scholarship in the Chinese context, contributes to women's studies by laying groundwork that scholars from women's studies can further develop.

Besides this theoretical significance, this dissertation makes two major practical advancements. First, through exploring women's lived experiences in contemporary China, this dissertation sheds light on the trajectory of Chinese women's empowerment and specifically their fight against sexism. This dissertation reveals that in contemporary Chinese society, gender is articulated with other issues such as the Chinese government's political practices and traditional Chinese culture to influence gender asymmetrically. Thus, in order to better women's living situations, the Chinese government should carefully consider the gendered influences of its policies before implementing them. Moreover, as discussed in Chapter Two, due to the deeply-rooted idea that Chinese people should be subordinate to the government, the Chinese government's role in counteracting sexism is crucial. Thus, the Chinese government should recruit more feminist politicians, not in decorative positions, but in positions that can enable women to voice their requests. 
Apart from the government, Chinese people, especially people who work for the mass media industry, should promote ideas that support gender equality to supplant old, sexist ideas. For example, TV series that depict real independent women who are successful without relying on their fathers or partners should replace the current popular TV series that often depict how women become successful only after attracting rich, loyal, and sophisticated men to help them. Moreover, some successful TV series from foreign countries that focus on career women who solve problems independently should be imported into China to replace the current popular Korean TV series that often celebrate love between poor young women and successful middle-age men. Promoting the image of independent women in popular culture is important for changing the traditional Chinese idea of women as being subordinate.

This dissertation also reveals that some Chinese women have used effective strategies to fight against sexism. For instance, they have used feminist theories to argue that sexism is not legitimate; and used science and technologies to form solidarities, engage in activism, and open options for themselves. Thus, Chinese women should remain receptive to feminist ideas. Moreover, the women who can have closer interactions with feminist ideas and theories, such as scholars in women's studies, should work on interpreting these ideas to make them more accessible and should promote these ideas to other women. If more Chinese women can participate in social movements to voice their requests for gender equality, this collective power would not be easily ignored and could promote change over time. 
Second, through analyzing the status of science and technology and mapping the living situations of Chinese women in the era of reforms, this dissertation presents my understanding of contemporary Chinese culture, the reform and opening-up policy, and Chinese women, which can help other Chinese people as well as foreigners to understand contemporary China from a cultural studies perspective. With the rapid rise of China as an influential global power, many people have become curious about the reasons for China's accelerated development and the trajectory of China's future. This dissertation suggests that science and technology play important roles in terms of propelling China to become prosperous. Because of this, it is very likely that the Chinese government will continue to promote science and technology, hoping that they can further facilitate China's development. Accordingly, the Chinese government will most likely further strengthen its practices of encouraging Chinese people to receive higher education in STEM, investing a large sum of money in Chinese people's education and STEM fields, bringing in foreign experts in STEM, and cooperating with other countries on STEM projects.

This dissertation also reveals that despite China's rapid developments in the past decades, sexist ideas still remain tenacious in Chinese society and even more so in the era of reforms. In Mao's era, promoting gender equality was a key focus of the Chinese government, resulting in the political propaganda of iron women and the abolishment of arranged marriage. However, in the era of reforms, since the Chinese government primarily concentrates on developing the economy and evaluates the country's performance and Chinese people's living situations mainly through numbers, many 
humanistic aspects are trivialized. Accordingly, although the government still claims that men and women are equal, they have not implemented as many significant political practices as Mao's government did to empower Chinese women. The lack of government attention to the issue of sexism will affect Chinese women in increasingly detrimental ways, resulting in more unfair treatment of women in their workplaces and in their marital and familial lives. I believe that besides developing the economy, the Chinese government needs to put more effort into the humanistic aspects of the Chinese society, such as fighting against sexism. Although economic performance is crucial for a country, what enables people to live happily also includes the government's efforts to make the country a fairer and more just place where people, regardless of their gender, can gain more access to self-fulfillment and live their best lives.

\section{Limitations and Further Directions}

This dissertation can be expanded by incorporating a more detailed discussion concerning the differences between the lived experiences of rural women and urban women. Although Chapter Four, which argues in one section that science and technology have provided working opportunities for women, points out that an increasing number of rural Chinese women have left their hometowns to do menial labor in cities, Chapter Three, which focuses on women's lived experiences, as well as other sections in Chapter Four, could benefit from more discussion concerning the unique experiences of urban and rural women.

This discussion is crucial when researchers want to study Chinese culture because the differences between rural and urban women's living situations are striking. For 
example, according to the International Labour Organization, Chinese women are "more likely to be in agriculture than men," which "signals a greater sticky floor for women impeding their mobility" (Dasgupta, Matsumoto, \& Xia, 2015, p.10). This means that compared with urban women who have more freedom and access to earn livings through their intelligence, many rural women are still limited to their households and to agricultural work. Moreover, unlike many urban women who are able to receive college and even graduate education, a large number of rural women can only receive middleschool or at most high-school educations after which they are expected to work as lowskilled migrant workers or to get married and have babies. Accordingly, the impacts of science and technology can vary profoundly for rural and urban women. I should pay more attention to the aspect of geographical difference, which would make my analysis of women's lived experiences in the era of reforms more careful, detailed, and persuasive.

Because of this limitation of my dissertation, I plan to conduct more work to explore rural women's lived experiences in my future research. More specifically, I want to focus on the group of left-behind women, who are also known as Niu Shou Fu Nv/留 守妇女, to explore how science and technology have impacted them.

Left-behind women are rural Chinese women whose husbands are away from their hometowns as migrant workers. These women are left behind to take care of their aged parents and parents-in-law, raise their young children, and do agricultural work. Even before the era of reforms, some women were left behind by their husbands who worked away from their hometowns. But in the era of reforms, left-behind wives have become a pronounced social phenomenon as the government's relaxed control over 
population mobility, the building of many foreign factories in China, and the development of transportation science and technology have made it easier for working men to travel. According to Zhang and Zhang (2006), the number of left-behind women had reached 47 million in 2006 (p.15). Moreover, many researchers (e.g. Chen, Qin, and Zhu 2005) have reported that these women often suffer from heavy workloads, psychological stress, and no safety. To understand the implications of science and technology for rural women, it is important to explore how science and technology influence left-behind women by mapping the ways that these women are using them and the differences they have created in their lives. I believe a comparison and contrast study of the implications of science and technology for leftover women, who as I discussed in Chapter Three, are single, professional, urban women and for left-behind women who are married, poorly-educated, rural women will not only help to map a more comprehensive landscape of the living situations of Chinese women in the era of reforms, but will also generate some inspiring new understandings of how science and technology are articulated with genders, classes, educational backgrounds, and economic situations to impact these women in diverse ways.

Moreover, I believe my dissertation could be strongly enhanced by including additional first-hand data collected through further fieldwork, such as observing some Chinese women's daily lives as well as conducting interviews and surveys with them, which is also my future research direction. I plan to interview 30 Chinese women who have used the internet, dating websites, IVF, egg freezing, and/or breast pumps. My interviews will be organized based on the following five questions: what motivates you to 
use these technologies? What is your experience of using them? Based on your experience, how do you think science and technology are influencing women? What is your understanding of women's constraints in contemporary Chinese society? Do you think science and technology help you to overcome these constraints? I want to combine Chinese women's narratives of using science and technology with the interpretations of the implications of science and technology for them that I have made in this dissertation, which were developed mainly based on my analysis cultural artifacts such as songs, films, and TV series.

Last but not least, I am also considering studying the implications of science and technology for men as my follow-up project of this dissertation, in which I map the gendered the implications of science and technology for women exclusively. As with women, Chinese men are also strongly influenced by science and technology. For example, the increasing number of Chinese male homebodies/Zhai Nan/宅男—the group of men formed in part by the availability of the internet who usually have jobs or are supported financially by their parents, prefer to spend their money and time on videogames, and are fascinated with fictional women in these games and in comic books, but have no interest in marrying real women or having children — reveals that science and technology have also influenced Chinese men's lived experiences in significant ways. Thus, it will be interesting to explore how science and technology impact Chinese men and women differently. I believe this exploration will enable me to better understand the gendered influences of science and technology. 
In general, this dissertation explores the implications of science and technology for Chinese women. In doing so, this dissertation sheds light on contemporary Chinese culture. Through laying out a groundwork, this dissertation invites more research that can contribute to gender studies, cultural studies, and science and technology studies in the context of contemporary China. 


\section{References}

In this section, I have listed my references based on three categories: 1 . scholarly sources that include journal articles, academic books, thesis, and dissertations 2 . archives and documents from governments, intergovernmental Organizations (IGOs), and nongovernmental organizations (NGOs) 3. other sources including but not limited to articles from magazines and newspaper, novels, websites, videos, and etc.

\section{Scholarly Sources}

Bell, D. A. (2008). China's new Confucianism: politics and everyday life in a changing society. Princeton and Oxford: Princeton University Press.

Benjamin, D.; Brendt, L., Giles, J., \& Wang S. (2008). Income inequality during China's economic transition. In L. Brandt, \& T.G. Rawski (eds.), China's great economic transformation (pp. 729-775). New York: Cambridge University Press.

Birrell, A.(1993). Chinese mythology. Baltimore: Johns Hopkins.

Bray, F. (1997). Technology and gender: fabrics of power in late imperial China. Berkeley, Los Angeles, \& London: University of California Press.

Cai, Y., \& Feng, W. (2014). (Re)emergency of late marriage in Shanghai: from collective synchronization to individual choice. In D. S. Davis, \& S. L. Friedman (Eds.), Wives, husbands, and lovers: marriage and sexuality in Hong Kong, Taiwan, and urban China (pp. 97-117). Stanford: Stanford University Press.

Chen, D. (1916). The year of 1916. The Journal of Youth, 1(5). Retrieved from http://news.southcn.com/community/shzt/youth/forerunner/200404280814.htm. 
Chen, D. (1919). My response to the criticism. New Youth, 6 (1). Retrieved from https://www.marxists.org/chinese/chenduxiu/marxist.org-chinese-chen 19190115.htm

Chen, H., Y. (1999). Confucianism encounters religion: the formation of religious discourse and the Confucian movement in modern China (Doctoral dissertation, Harvard University). Retrieved from ProQuest Dissertation and Theses database.

Chow, C. G. (2004). Economic reform and growth in China. Annals of Economics and Finance, 5, 127-152.

Chow, E.N.L, Zhang, N., \& Wang, J. (2004). Promising and contested fields: women's studies and sociology of women/gender in contemporary China. Gender \& Society, $18(2), 161-188$.

Christie, A.(1968). Chinese mythology. Feltham: Hamlyn Publishing.

Confucius (2016). Confucianism: the four books and five classics. (J. Legge Trans.). East Sussex: Delphi Classics.

Deleuze, G., \& Guattari, F. (1987). A thousand plateaus: capitalism and schizophrenia. Minneapolis: University of Minnesota Press.

Dolla, V., S. (2015). Science and technology in contemporary China: interrogating policies and progress. Delhi: Cambridge University Press.

Du, F. (2005). Developing women's studies at universities in China: Research, curriculum and institution. Asian Journal of Women's Studies, 11(4), 35-71. 
Elman, B. (2008). A cultural history of modern science in China. Cambridge, MA: Harvard University Press.

Fan, F. T. (2017). The people's war against earthquakes: cultures of mass science in Mao's China. In K. Chemla \& E. F. Keller (Eds.). Cultures without culturalism: the making of scientific knowledge (pp. 296-323). Durham \& London: Duke University Press.

Fan, L., \& Chen, N. (2015). The religiousness of "Confucianism", and the revival of Confucian religion in China today. Cultural Diversity in China, 1(1), 27-43.

Fincher, L.H. (2014). Leftover women: the resurgence of gender inequality in China. London: Zed Books.

Fincher, L., H. (2018). Betraying big brother: the feminist awakening in China. London \& New York: Verso.

Fong, M. (2016). One child: the story of China's most radical experiment. New York: Houghton Mifflin Harcourt.

Fung, Y. (1922). Why China has no science—an interpretation of the history and consequences of Chinese philosophy. The International Journal of Ethics, April, pp. 237-263.

Fung, Y. (1948). A short history of Chinese philosophy. D. Bodde (Ed.). New York: The Free Press.

Gao, X. (2003). Women existing for men: Confucianism and social injustice against women in China. Race, Gender \& Class, 10(3), 114-125.

Gale, T. (2005). Confucian perspectives. Encyclopedia of Science, Technology, and 
Ethics. Retrieved from https://www.encyclopedia.com/science/encyclopediasalmanacs-transcripts-and-maps/confucian-perspectives

Gardner, D. K. (2014). Confucianism: a very short introduction. New York: Oxford University Press.

Goldman, M., \& Simon, D., F. (1989). The onset of China's new technological revolution. In D. F. Simon \& M. Goldman (Eds.). Science and technology in postMao China (pp. 3-20). Cambridge: Harvard University.

Gong, P. (2012). Cultural history holds back Chinese research. Nature, 481, p. 411.

Goodburn, C. (2015). Migrant girls in Shenzhen: gender, education and the urbanization of aspiration. The China Quarterly, 222 (June), 320-338.

Grossberg, L. (1992). Articulation and culture. In We gotta get out of this place: popular conservatism and postmodern culture (pp. 37-67). New York \& London: Routledge.

Grossberg, L. (1997). Bring it all back home. Raleigh: Duke University Press.

Grossberg, L. (2010). Cultural studies in future tense. Raleigh: Duke University Press.

Hall, S. (1980). Cultural studies: Two paradigms. Media, Culture, and Society, 2, 57-72.

Hall, S. (1983). The problem of ideology: Marxism without guarantees. In D. Morley \& K. H. Chen (Ed.), Stuart Hall: critical dialogue in cultural studies (pp. 25-46). New York \& London: Routledge.

Hall, S. (1986). Gramsci's relevance for the study of race and ethnicity. In D. Morley \& K. H. Chen (Ed.), Stuart Hall: critical dialogue in cultural studies (pp. 411440). New York \& London: Routledge. 
Hall, S. (1992). Cultural studies and its theoretical legacies. In D. Morley \& K. H. Chen (Ed.), Stuart Hall: critical dialogue in cultural studies (pp. 262-275). New York \& London: Routledge.

Haraway, D. (2003). The companion species manifesto: dogs, people and significant others. Chicago: Princkly Paradigm Press.

Heston, A., \& Sicular, T. (2008). China and development of economics. In L. Brandt, \& T.G. Rawski (Eds.), China's great economic transformation (pp. 27-67). New York: Cambridge University Press.

Hofman, B. (2018). Reflections on 40 Years of China's reforms. In R. Garnaut, L. Song, \& C. Fang (Eds.), China's 40 Years of reform and development (pp. 53-66). Acton: Australian National University Press.

Hoggart, R. (1969). Contemporary cultural studies: an approach to the study of literature and society. Occasional Paper \#6 (pp. 3-23). Birmingham University: Centre for Contemporary Cultural Studies.

Hu, L., Flood, P., Li, Y., Tao, W., Zhao, P., Xia, Y...(2016). No pain labor \& delivery: a global health initiative's impact on clinical outcomes in China. Society for Obstetric Anesthesia and Perinatology, 122(6), 1931-1938.

Jiang, Q., Li, S., Feldman, M., \& Sánchez-Barricarte, J. (2012). Estimates of missing women in twentieth-century China. Continuity and Change, 27(3), 461-479.

Hershatter, G. (2007). Women in China's long twentieth century. Berkeley \& Los Angeles \& London: University of California Press.

hooks, b. (2015). Feminism is for everybody: passionate politics $\left(2^{\text {nd }}\right.$. ed.). New York \& 
London: Routledge.

Jacka, T. (2005). Finding a place. Critical Asian Studies, 37(1), 51-74.

Jin, Y. (2006). Rethinking the "iron girls": gender and labour during the Chinese Cultural Revolution (K.E. Manning \& L. Chu, Trans.). Gender \& History, 18(3), 613-634.

Khun-Pearce, K. E. (2008). Internet as social capital and social network: cyberactivity of Hong Kong and Shanghai women. In K. E. Khun-Pearce (ed.). Chinese women and the cyberspace. Amsterdam: Amsterdam University Press.

Kim, Y., S. (2010). Confucian scholars and specialized scientific and technical knowledge in traditional China, 1000-1700: A preliminary overview. East Asian Science, Technology and Society: an International Journal, 4, 207-228.

Kirby. W. C. (1989). Technocratic organization and technological development in China: the nationalist experience and Legacy, 1928-1953. In D. F. Simon \& M. Goldman (Eds.). Science and technology in Post-Mao China (pp. 23-43). Cambridge: Harvard University.

Lake, R. (2018). Leftover in China: the women shaping the world's next superpower. New York: W.W. Norton \& Company.

Lee, M. (2017). Confucianism: its roots and global significance. D. Jones (ed.). Honolulu: University of Hawaii Press.

Leggett, A. (2017). Online civic engagement and the anti-domestic violence movement in China: shifting norms and influencing law. Voluntas, 28, 2251-2277. 
Li, D., Qu, M., \& Tong, L. (2017). Prevention and nursing progress of postpartum depression in elderly primipara. Chinese Journal of Practical Nursing 33(34): 2713-2716.

Li, J., \& Li, X. (2017). Media as a core political resource: the young feminist movements in China. Chinese Journal of Communication, 10 (1), 54-71.

Li, L, M. (1982). Introduction: food, famine, and the Chinese state. The Journal of Asian Studies, 41(4), 687-707.

Lin, C. (2001). Whither feminist: a note on China. Sign: Journal of Women in Culture and Society, 26(4), 1281-1286.

Liu, J. (2014). The loosing family ethics: the marriage, family, parenthood and sex of temporary couples (Doctoral Dissertation). Retrieved from CNKI.

Liu, S., \& Ma, Y. (2009). The family and transitional China: focus on "housewives". Collection of Women's Studies, 93(3), 31-36.

Liu, W., Slack, J. D. (2015). I do not know who I am: The Chinese shidu mother. Women \& Language, 37 (2), 31-50

Lykke, N. (2002). Feminist cultural studies of technoscience and other cyborg studies: a cartography. In R. Braidotti, J. Nieboer, and S. Hirs (eds). The Making of European Women's Studies, IV (November), 133-143.

Ma, G., \& Yuan, L. (2015). Hybrid rice achievements, developments and prospect in China. Journal of Integrative Agriculture, 14(2), 197-205.

McNeil, M. (2007). Feminist cultural studies of science and technology. Abingdon \& New York: Routledge. 
McNeill, N., Li, S., \& Wang, J. (2010). Growing pains: Chinese engineering education during the late Qing Dynasty. School of Engineering Education Graduate Student Series. Paper 18. Retrieved from http://docs.lib.purdue.edu/enegs/18 McRobbie, A. (1980). Settling accounts with subcultures: a feminist critique. In T. Bennett, G. Martin, Colin Mercer, \& J.Woolacott (Ed.), Culture, ideology and social process (pp. 111-123). London: Batsford Academic and Educational Ltd.

Mencius. (n.d.). Mencius. Retrieved from www.indiana.edu/ p374/Mengzi.pdf

Minzner, C. (2015). China after the reform Era. Journal of Democracy, (3), 129-143.

Nelson, C., Treichler, P. A. , \& Grossberg, L. (1992). Cultural studies: an introduction. In Grossberg L., Nelson C., Treichler A. P. (eds.) Cultural studies (pp. 1-22). New York: Routledge.

Osburg, J. (2016). Pleasure, patronage, and responsibility: Sexuality and status among new rich men in contemporary China. In T. Zheng (Ed.), Cultural politics of gender and sexuality in contemporary Asia (pp. 108-123). Honolulu: University of Hawai'i Press.

Pan, J. (2018). The evolution and transformation of China's climate change response strategy: from preventing 'black swan' events to reducing 'grey rhino' risks. In R. Garnaut, L. Song, \& C. Fang (Eds.), China's 40 Years of reform and development (pp. 525-542). Acton: Australian National University Press.

Pei, Y., \& Ho, S. Y. (2008). Sex \& life politics formed through the internet: online \& offline dating experiences of young women in Shanghai. In K. E. Kuah-Pearce 
(Ed.), Chinese women and the cyberspace (pp. 203-221). Amsterdam: Amsterdam University Press.

Pekins, H. D. (2018) The complex task of evaluating China's economic reforms. In R. Garnaut, L. Song, \& C. Fang (Eds.), China's 40 Years of reform and development (pp. 135-154). Acton: Australian National University Press.

Pun, N., \& Chan, J. (2012). Global capital, the state, and Chinese workers: the Foxconn experience. Modern China, 38 (4), 383-410.

Rainey, L., D. (2010). Confucius \& Confucianism: the essential. West Sussex: WileyBlackwell.

Rodman, G.B. (1996). Elvis after Elvis: the posthumous career of a living legend. London \&New York: Routledge.

Roumasset, J., Burnett, K., \& Wang, H. (2008). Environmental resources and economic growth. In L. Brandt, \& T.G. Rawski (Eds.), China's great economic transformation (pp. 250-285). New York: Cambridge University Press.

Saich, T. (1989). Reform of China's science and technology organizational system. In D. F. Simon \& M. Goldman (Eds.). Science and technology in post-Mao China (pp. 69-88). Cambridge: Harvard University.

Shen, K., Crossley, J., N., \& Lun, A., W. (1999). The nine chapters on the mathematical arts. Beijing: Oxford University Press.

Slack, J.D., \& Whitt, L.A. (1993). Ethics and cultural studies. In Grossberg L., Nelson C., \& Treichler P. (Ed.), Cultural studies (pp. 571-592). New York: Routledge. 
Slack, J. D. (1996). The theory and method of articulation in cultural studies. In D. Morley \& K. H. Chen (Ed.), Stuart Hall: critical dialogue in cultural studies (pp. 112-127). New York \& London: Routledge.

Smil, V. (1990). China's great famine: 40 Years Later. BMJ, 319, 18-25.

Stockard, J. E. (2002). Marriage in Culture: practice and meaning across diverse societies. Belmont: Cangage Learning.

Sun, S. (2015). Thousand golden prescriptions in modern Chinese. Harbin: Heilong Jiang Science and Technology Press.

Swann, N.L. (1960). Pan Chao: foremost woman scholar of China. New York: Russell and Russell.

Tan, J. (2017). Digital masquerading: feminist media activism in China. Crime Media Culture, 13 (2), 171-186.

To, S. (2015). China's leftover women: late marriage among professional women and Its consequences. New York: Routledge.

To, S. M., \& Tam, H. L. (2014). Generational differences in work values, perceived job rewards, and job satisfaction of Chinese female migrant workers: implications for social policy and social services. Soc Indic Res, 118, 1315-1332.

Wajcman, J. (1991). Feminism confronts technology. University Park: The Pennsylvania State University.

Wang, J. (2011). Population and family planning: on family planning policies in Chinese history and a scientific outlook of population growth. Zheng Zhou: Zheng Zhou University Press. 
Wang, L. (2017, June). Reinterpret Mencius' the debate between human and animal from the two dimensions construction theory of information philosophy. Paper Presented at the IS4SI 2017 Summit Digitalisation for a Sustainable Society, Gothenburg, Sweden. Retrieved from www.mdpi.com/2504-3900/1/3/107/pdf Wang, M. (1997). Tai ping jing. Beijing: Zhonghua Shuju.

Wang, T. (2011). Towards a proper relation between men and women: beyond masculinism and feminism. In R. Fan (Ed.). The renaissance of Confucianism in contemporary China (pp. 91-107). New York: Springer.

Wei, Y. (2011). Illustrated annals of oversea countries. Changsha: Yuelu Press.

Werner, E.T.C. (1922). Myths and legends of China. New York: George G. Harrap \& Co. Ltd.

Williams, R. (1958). Culture is ordinary. Retrieved from artsites.ucsc.edu/faculty/gustafson/film\%20162.w10/readings/williams.ordinary.pdf Williams, R. (2011). The long revolution. Cardigan: Parthian.

Wu, X. (2010). Economic transition, school expansion and educational inequality in China, 1990-2000. Research in social stratification and mobility, 28, 91-108.

Xian, H., \& Woodhams, C. (2008). Managing careers: Experiences of successful women in the Chinese IT industry. Gender in Management, 23(6), 409-425.

Xu, Z. (2000). Shuo wen jie zi. Beijing: Bookstore Publisher.

Yang, L.; An, D.; \&Turner, J., A. (2005). Handbook of Chinese mythology. New York, NY: Oxford University Press.

Yeung, A., \& Fung, C, H. H. (2011). The soft power in the Confucian "kingly way". In 
R. Fan (Ed.). The renaissance of Confucianism in contemporary China (pp. 109134). New York: Springer.

Zhang, C. (2006). Reflection on the changes of the marital experiences of the Chinese women by the evolvement of the word "divorce" in Chinese. Journal of Fujian Commercial College, 3 (June), 79-82.

Zhang, J., \& Sun, P. (2014). When are you going to get married: parental matchmaking and middle-class women in contemporary urban China. In D. S. Davis, \& S. L. Friedman (Eds.), Wives, husbands, and lovers: marriage and sexuality in Hong Kong, Taiwan, and urban China (pp.118-144). Stanford: Stanford University Press.

Zhang, Y. (2018, August 7). Giving birth is a familial matter and a national issue too. Renming Ri Bao. Retrieved from http://society.people.com.cn/n1/2018/0806/c1008-30210020.html

Zeng, Y., \& Hesketh, T. (2018). The effects of China's universal two-child policy. Lancet, 388(10054), 1930-1938.

Zhou, M., \& Guo, H. (1995). The influences of new science and technology for women's job opportunities. Forum on Science and Technology in China 9: 31-32.

Zhuangzi (2013). The complete works of Zhuangzi (B. Watson Trans). New York: Columbia University Press.

Zuo, J. (2016). Work and family in urban China: women's changing experience since Mao. New York: Palgrave Macmillan. 


\section{Archives and Documents from Governments, IGOs, and NGOs}

Australian Government Department of the Environment and Energy. (n.d.) Particulate matter $\left(\mathrm{PM}_{10}\right.$ and $\left.\mathrm{PM}_{2.5}\right)$. Retrieved December 12, 2018, from http://www.npi.gov.au/resource/particulate-matter-pm10-and-pm25

Central People's Government of the People's Republic of China. (1980, September 25).

A letter to all the members of communist party and communist youth league concerning controlling Chinese population growth. Retrieved from: http://wenku.baidu.com/link?url=UNr0QNkeshGg5BcEfEqtxoNsCoB5wRvORXn nmvmhYn9QBxJXp_mH0iRVztMEGFZWeTM8piGTHstUscBmHEKtODt7m12D pi6BWnX0wHJNcZ7

Central People's Government of the People's Republic of China. (2015, December 27). Anti-domestic violence law of the People's Republic of China. Retrieved from https://www.66law.cn/laws/123038.aspx

Confucius Institute Headquarters (Hanban). Confucius institute/classroom. Retrieved January 5, 2018, from http://english.hanban.org/node_10971.htm

Commission on China. (2006). Marriage law of People's Republic of China. Retrieved from https:/www.cecc.gov/resources/legal-provisions/marriage-law-of-thepeoples-republic-of-china-amended

Dasgupta, S., Matsumoto, M, \& Xia, C. (2015). Women's in the labour market in China. International Labour Organization. Retrieved from http://www.oit.org/wcmsp5/groups/public/---asia/---robangkok/documents/publication/wcms_371375.pdf 
Deng Xiaoping (1979). Uphold the four cardinal principles. In Selected Works of Deng Xiaoping (1975-1982) (pp. 166-199). Translated by The Bureau for Translation of the Works of Marx, Engels, Lenin and Stalin. Foreign Languages Press, Beijing, 1984.

Hu, F. (2016, June 17). Yangtz flows: pollution \& Heavy metals. China Water Risk.

Retrieved from http://www.chinawaterrisk.org/resources/analysis-reviews/yangtzeflows-pollution-concerns/

Library of Congress. (2019). Regulation of air pollution: China. Retrieved from https://www.loc.gov/law/help/air-pollution/china.php

Mao, Z. (1945). On coalition government. Retrieved from https://www.marxists.org/reference/archive/mao/selected-works/volume3/mswv3_25.htm

National Bureau of Statistics of China. (2018). China statistical yearbook 2018. Retrieved from http://www.stats.gov.cn/tjsj/ndsj/2018/indexeh.htm National Bureau of Statistics of China. (2019, May). Distribution of migrant workers in China from 2011 to 2018, by gender [Graph]. In Statista. Retrieved May 22, 2019, from https://www.statista.com/statistics/259383/share-of-migrant-workers-inchina-by-gender/

National Bureau of Statistics of China. (2019, April). Number of migrant workers in China from 2008 to 2018 (in millions) [Graph]. In Statista. Retrieved June 15, 2019, from https://www.statista.com/statistics/234578/share-of-migrant-workersin-china-by-age/ 
National People's Congress Standing Committee (1992, April 3). Protection of women's rights and interests law of People's Republic of China. Retrieved from https://www.cecc.gov/resources/legal-provisions/protection-of-womens-rights-andinterests-law-of-the-peoples-republic-of

National People's Congress Standing Committee (1994, July 5). Labor Law of the People's Republic of China. Retrieved from https://www.cecc.gov/resources/legalprovisions/labor-law-of-the-peoples-republic-of-china

National People's Congress Standing Committee (2007, August 30). Employment Promotion Law of People's Republic of China. Retrieved from https://www.cecc.gov/resources/legal-provisions/employment-promotion-law-ofthe-peoples-republic-of-china

National Science Foundation (2018, January). Science \& Engineering indicators 2018. Retrieved from https://www.nsf.gov/statistics/2018/nsb20181/

New! The policies concerning buying apartment in 26 cities in China. (2018, May 30). Sohu.com. Retrieved from http://www.sohu.com/a/233452129_757183

Statistics Bureau of Wuhan. (2019, June 25). Statistics of salaries in Wuhan in 2018. Retrieved from http://tjj.wuhan.gov.cn/details.aspx?id=4403

The Fourth Session of the Sixth National People's Congress. (1986). Compulsory education law of the People's Republic of China. Retrieved from http://www.asianlii.org/cn/legis/cen/laws/celotproc520/

The Organization Department of the Central Committee of the CPC. (n.d.). Thousand talents plan. Retrieved May 23, 2018, from www.1000plan.org.cn 
The State Council, The People's Republic of China. (2006). The national outlines for medium and long-term planning for scientific and technological development (2006-2020). Retrieved from http://www.gov.cn/english/200602/09/content_183774.htm

The Sixth Plenary Session of the Eleventh Central Committee of the Communist Party of China (1981, June 27). Resolution on certain historical issues of the Party since the founding of the People's Republic. Retrieved from https://www.marxists.org/subject/china/documents/cpc/history/01.htm

The World Bank (a). (n.d.). Literacy rate, adult total (\% of people ages 15 or above). Retrieved November 8, 2017, from https://data.worldbank.org/indicator/SE.ADT.LITR.ZS?locations=CN

The World Bank (b). (n.d.). Arable land (hectares per person). Retrieved March 10, 2019, from https://data.worldbank.org/indicator/AG.LND.ARBL.HA.PC

The World Bank (c). (n.d.). Population growth rate (annual \%): China. Retrieved August 24, 2018, from https://data.worldbank.org/indicator/SP.POP.GROW?locations=CN The World Bank (d). (n.d.). Literacy rate, adult female: China. Retrieved February 5, 2019, from https://data.worldbank.org/indicator/SE.ADT.LITR.FE.ZS?locations $=\mathrm{CN} \& \mathrm{view}=\mathrm{c}$ hart

United Nations Conference on Trade and Development. (2019). General profile: China. Retrieved from https://unctadstat.unctad.org/CountryProfile/GeneralProfile/enGB/156/index.html 
U.S. Chamber Of Commerce. (2017). Made in China 2025: global ambitions built on local protections. Retrieved from https://www.uschamber.com > files > final_made_in_china_2025_report_full

U.S. Department of State Archive. (2006, December 30). U.S. China science and technology cooperation (S\&T Agreement): report to Congress. Retrieved from https://2001-2009.state.gov/g/oes/rls/or/2006/96328.htm

U.S. Department of Agriculture. (2019). China agricultural and economic data. Retrieved from https://data.ers.usda.gov/reports.aspx?ID=17884\&AspxAutoDetectCookieSupport $=1$

Wen, J. (2008, March 5). Report on the work of the government (2008). At the First Session of the Eleventh National People's Congress. Retrieved from http://www.gov.cn/english/official/2008-03/20/content_924600.htm

World Food Programme. (n.d.). China. Retrieved July 18, 2018, from https://www.wfp.org/countries/china

World Steel Association. (2019, April 29). March 2019 crude steel production. Retrieved from https://www.worldsteel.org/media-centre/press-releases/2019/March-2019crude-steel-production.html

Wuhan government. (2013, June). Population and family planning management in Wuhan. Retrieved from http://www.ldbj.com/renkouyujihuashengyutiaoli/wuhan_renkouyujihuashengyu_g uiding.htm 
Xi Jinping (2018). China will go forward with reforming and opening-up and will never stop. Collection of Reports on Xi Jinping. Retrieved January 7, 2019, from http://www.xinhuanet.com/politics/leaders/2018-10/25/c_1123611131.htm

Zhang, H. (2009). Labor migration, gender, and the rise of neo-local marriages in the economic boomtown of Dongguan, South China. Journal of Contemporary China, $18(61), 639-656$.

\section{Other Sources}

A 24-years-old online shop owner died in sudden: in order to manage her shop she slept less than 5 hours per day. (2012, July 20). Sohu.com Retrieved from http://it.sohu.com/20120720/n348670550.shtml

An investigation of lived experiences of bei nai ma mas: it is not easy. (2015, May 8).

Sohu.com. Retrieved from https://www.sohu.com/a/14196977_103613

An, S. (2016, June 7). Test-tube baby: how brave can a woman be? [Online forum].

Retrieved from http://bbs.tianya.cn/post-feeling-4122073-1.shtml

Anjuke.com (a). (2019, February). The trend of house price in Beijing. Retrieved from https://bj.fang.anjuke.com/fangjia/

Anjuke.com (b). (2019, February). The trend of house price in Shanghai. Retrieved from https://sh.fang.anjuke.com/fangjia/?from=hangqing_loupanlist

Backyard furnaces. (n.d.). Retrieved January 20, 2019, from Wikipedia: https://en.wikipedia.org/wiki/Backyard_furnace

BBC News. (2017, December 25). China: the world's biggest camera surveillance network. Retrieved from https://www.youtube.com/watch?v=pNf4-d6fDoY 
Beautiful Chinese families 2017 (2017, May 25). Chinanew.com. Retrieved from http://www.chinanews.com/gn/2017/05-25/8233478.shtml

Beautiful online shop owner was raped by five men on her way to delivery her products to them. (2017, July 19). Sina. com. Retrieved from http://sc.sina.com.cn/news/s/2015-07-19/detail-ifxfccux2781321.shtml

Because love won't wait. (2014). [Video file]. Baihe Wang. Retrieved October 14, 2017, from http://www.iqiyi.com/w_19rrbikxx9.html

Bergman, K. (2016, August 30). How Long Do Frozen Eggs Last? Growing Generations. Retrieved from https://www.growinggenerations.com/resources-for-eggdonors/how-long-do-frozen-eggs-last/

Birtles, B. (2018, January 19). China's birth rate drops despite end of one-child policy. ABC News. Retrieved from https://www.abc.net.au/news/2018-01-19/chinas-birthrate-drops-despite-end-of-one-child-policy/9344634

Branigan, T. (2013, January 1). China's great famine: the true story. The Guardian. Retrieved from https://www.theguardian.com/world/2013/jan/01/china-greatfamine-book-tombstone

Cai, C. (Director), \& Sun, S. (Writer). (1935). New Women. [Film]. China: Lianhua Film Company.

CEIC. (n.d.). China residential area per capita. Retrieved September 20, 2018, from https://www.ceicdata.com/en/china/residential-area-per-capita

Chang, G., G. (2015, March 1). Why China's consumers are flying to Japan to buy toilet seats. Forbes. Retrieved from 
https://www.forbes.com/sites/gordonchang/2015/03/01/why-chinas-consumers-areflying-to-japan-to-buy-toilet-seats/\#102636151a36

Chen, C, Qin, Y., \& Zhu, G. (2005). Three big mountains upon left-behind women. Semimonthly 11: 16-21.

Chen, D. (2017, August 28). The shift of maternal love: a leftover monkey becomes a mother of a chicken. Xinhua net. Retrieved from http://www.xinhuanet.com//world/2017-08/28/c_129690053.htm

Chen, H. (Director). (1991). Wai Lai Mei. [Television series]. China: China Film Group Corporation.

Chen, J. (2016, January 15). Having a boy and a girl means a perfect life. Sohu.com. Retrieved from http://mt.sohu.com/20160115/n434687372.shtml

Chongqing Wenming Wang. (2018, December 13). The brainwash of nü de ban must be stopped. Retrieved from http://cq.wenming.cn/wpsp/201812/t20181213_4936730.shtml

China has built the world's largest bullet-train network. (2017, January 13). The Economist. Retrieved from https://www.economist.com/china/2017/01/13/chinahas-built-the-worlds-largest-bullet-train-network

China has the world's largest test-tube baby population. (2018, October 6). China.org.cn. Retrieved from http://www.china.org.cn/china/2018-10/06/content_65030653.htm China's Alipay now has over 900m users worldwide. (2018, November 30). China Daily. Retrieved from http://www.chinadaily.com.cn/a/201811/30/WS5c00a1d3a310eff30328c073.html 
Dai, Q., \& Vingie. (n.d.). Stories of the eight thousands women from Hunan Province to move to Xin Jiang Province. Retrieved February 15, 2019, from https://news.qq.com/zt/2008/dialog/dqy.htm

Denyer, S. (2016, November 30). Researchers may have 'found' many of China's 30 million missing girls. The Washington Post. Retrieved from https://www.washingtonpost.com/news/worldviews/wp/2016/11/30/researchersmay-have-found-many-of-chinas-30-million-missing-girls/

Ding, H. (Designer). (1954, February). We are proud of participating in the founding of our country's industrialization [Poster]. Shanghai: Huadong Renmin MeishuChubanshe,. Retrieved from: https://chineseposters.net/posters/e16-17.php

Freezing. (n.d.). UCLA Obstetrics and Gynecology. Retrieved from http://obgyn.ucla.edu/egg-freezing

863 program. (n.d.). Retrieved March 25, 2018, from Baidu Baike: https://baike.baidu.com/item/国家高技术研究发展计划（863 计划） /9529335?fr=aladdin

Erzu, L. (2019, January 13). Good news! Shijijiayuan Wang is investigated by the government [Online forum]. Retrieved from https://www.douban.com/group/topic/131231190/?start=0

Every mother is a firefighter. (n.d.). [Commercial]. Johnson \& Johnson (China). Retrieved from http://sucai.redocn.com/psd/553017.html 
Feminist voice in Valentine's Day to against Baihe Wang. (2014, February 18). China Development Brief. Retrieved from http://www.chinadevelopmentbrief.org.cn/news-8657.html

Four modernizations. (n.d.). Retrieved October 23, 2017, from Baidu Baike: https://baike.baidu.com/item/\%E5\%9B\%9B\%E4\%B8\%AA\%E7\%8E\%B0\%E4\%BB $\%$ A3\%E5\%8C $\% 96$

Foxconn (n.d.). 2017 suicidal and environmental responsibility report. Retrieved January 10, 2019, from https://www.foxconn.com/Files/index/Foxconn_SER_en_2017.pdf

Fuller, P. (n.d.). North China famine, 1920-1921. DisasterHistory. org. Retrieved from http://www.disasterhistory.org/north-china-famine-1920-21

GREE. (April 26, 2018). Revenue of air conditioners of GREE Electric Appliances in China from 2009 to 2017 (in billion yuan) [Graph]. In Statista. Retrieved July 22, 2019, from https://static1.statista.com/statistics/409340/china-gree-electricappliances-air-conditioner-revenue/

Guanyin of nanshan. (n.d.). Retrieved December 22, 2018, from Wikipedia: https://en.wikipedia.org/wiki/Guanyin_of_Nanshan

Guo, H., \& Zhang, J. (2017, July 11). From career women to super mothers: the changes of the image of mothers. China Women's News. Retrieved from http://fj.people.com.cn/n2/2017/0711/c372371-30456004.html

Guo, J. (Director \& Producer). (2016). Mother's Life. [Television series]. China: Tianjing Jianxin Wenhua Chuanbo Youxian Gongsi. 
Guo, Y. (2019, January 13). Good news! Shijijiayuan Wang is investigated by the government [Online forum]. Retrieved from https://www.douban.com/group/topic/131231190/?start=100

He, W. (2017, July 10). Women are key to Alibaba's success: Jack Ma. China Daily. Retrieved from http://www.chinadaily.com.cn/business/201707/10/content_30061241.htm

How many leftover women deserve our sympathy? (2011, March 10). women of China.cn. Retrieved January 23, 2019, from http://m.kdnet.net/share-8839395.html

Huang, L. (Producer), \& Shen, Y. (Director). (2017). The first half of my life [Television series]. China: Xinli Dianshi Wenhua Touzi Youxian Gongsi

Hu, S. (1918). American Women. Retrieved from https://www.douban.com/note/352162218/

iResearch. (2018, February 27). The Analytical Report of the Industry of Online Dating Industry in China 2018. Retrieved from http://report.iresearch.cn/report/201802/3169.shtml

It is not easy to freeze eggs in China! The government prohibits single women from freezing their eggs. (2019, February 20). Icheruby.com. Retrieved from https://www.icheruby.com/news/2918.html

Jieji, T. (2015, August 5). Why the government prohibits single women from freezing their eggs? [Online forum]. Retrieved from http://bbs.tianya.cn/post-40-7607011.shtml 
Jin, Y. (2013). Heaven sword and dragon saber. Guangzhou: Guangzhou Publishing House.

Ke Jiao Xing Guo. (n.d.). Retrieved May 16, 2018, from Baidu Baike:

https://baike.baidu.com/item/\%E7\%A7\%91\%E6\%95\%99\%E5\%85\%B4\%E5\%9B $\% \mathrm{BD}$

Larmer, B. (2014, December 31). Insides a Chinese test-prep factory. The New York Times Magazine. Retrieved from https://www.nytimes.com/2015/01/04/magazine/inside-a-chinese-test-prepfactory.html

Lengyue, W. (2015, August 5). Why the government prohibits single women from freezing their eggs? [Online forum]. Retrieved from http://bbs.tianya.cn/post-40760701-1.shtml

Let love be right. (2018). Johnson \& Johnson (China). Retrieved from http://www.sohu.com/a/278916891_183589

Li, X. (2018, February 15). A blind date of a 25-year-old leftover woman: all the dozens of previous dating partners got married. Xinhua net. Retrieved from http://www.xinhuanet.com//2018-02/15/c_1122420196.htm

Liu, J. (2017, December 10). In your face: China's all-seeing state. BBC News. Retrieved from https://www.bbc.com/news/av/world-asia-china-42248056/in-your-facechina-s-all-seeing-state 
Liu, S. (2017, January 10). 1+15+50\%: "Hua Mulan" in STEM. CCTV.com. Retrieved from http://news.cctv.com/2017/01/09/ARTIVCuScv8tu3WPyHjfSerR170109.shtml

Lü, L. (Director), \& Qin, H. (Writer). (2018). Lost, Found. [Film]. China: Huayi Brothers Media Corp.

Ma, Y., Zhao, Y., Gong, X., Sun, L., \& Zheng, Y. (2018, May 2). Close the gender gap in Chinese science. Nature: International Journal of Science. Retrieved fromhttps://www.nature.com/articles/d41586-018-04996-3

Martin, E. (2018, May 9). Girl's education in China more accessible than ever. The Borgen Project. Retrieved from https://borgenproject.org/girls-education-in-china/

Meng, J. (2017, June 27). China revises laws on water pollution prevention and control. Xinhua Net. Retrieved from http://www.xinhuanet.com//english/201706/27/c_136399271.htm

Mocha, H (2014, February 7). Have you seen Weibo? Baihe Wang's commercial has enraged so many people [Online forum]. Retrieved from http://bbs.tianya.cn/postfuninfo-5019771-2.shtml

Mo, L. (2017, February 19). The word shengnv should disappear. China's Women's News. Retrieved from http://www.cssn.cn/shx/shx_gcz/201702/t20170219_3420753.shtml Mo, Y. (2016). Frog: a novel. New York: Penguin.

Mo Mo Wu Wen. (2018, November 23). Chinese people's attitude to science and technology. Retrieved from http://ieba.baidu.com/p/5958780368?traceid= 
More dink families appear in China. (2002, August 21). china. org. cn. Retrieved from http://www.china.org.cn/english/2002/Aug/40040.htm

More Chinese women seeking IVF treatment abroad. (2018, February 22). The Straits

Time. Retrieved from https://www.straitstimes.com/asia/east-asia/more-chinesewomen-seeking-ivf-treatments-abroad

Mosher, S., W. (2017, August 9). Forced abortions in China continue despite two child policy. Population Research Institute. Retrieved from https://www.pop.org/forced-abortions-in-china-continue-despite-two-child-policy/

Mozur, P. (2018, July 21). Wild about tech, China even loves robot waiters that can't serve. The New York Times. Retrieved from https://www.nytimes.com/2018/07/21/technology/china-future-robot-waiters.html

National Public Servant. (2018, November 5). The 10 most competitive positions in 2019 China's national public servant exam. Retrieved from http://www.chinagwy.org/html/xwsz/szzl/201811/22_270656.html nekoaisiteru (2014, February 7). Have you seen Weibo? Baihe Wang's commercial has enraged so many people [Online forum]. Retrieved from http://bbs.tianya.cn/postfuninfo-5019771-1.shtml

Nordqvist, J. (2018, February 5). IVF: What Does It Involves? Medical News Today. Retrieved from https://www.medicalnewstoday.com/articles/262798.php Pan, M. (1989). I want to have a home. It Is You [CD]. Taipei: SWCD. Perry, M., J. (2016, June 5). New US homes today are 1,000 square feet larger than in 
1973 and living space per person has nearly doubled. aei.org. Retrieved from http://www.aei.org/publication/new-us-homes-today-are-1000-square-feet-largerthan-in-1973-and-living-space-per-person-has-nearly-doubled/

Qing, T. (2016, August 19). Answer to "what is the experience of being a bei nai ma ma?”. Zhihu.com. Retrieved from https://www.zhihu.com/question/21325360

Rabinovitch, S. (2013, March 15). Data reveal scale of China abortions. Financial Times. Retrieved from https://www.ft.com/content/6724580a-8d64-11e2-82d200144feabdc0\#axzz2Nhxzw6d3

Reform and opening-up. (n.d.). Retrieved February 14, 2017, from Baidu Baike: https://baike.baidu.com/item/\%E6\%94\%B9\%E9\%9D\%A9\%E5\%BC\%80\%E6\%94 $\% \mathrm{BE} / 886098 ? \mathrm{fr}=$ aladdin

Report of the outcome of the implementation of opinion of state on women's development (2018, November 12). China's Women's News. Retrieved January 6, 2019, from http://paper.cnwomen.com.cn/content/201811/12/edition10440_A4.html

Samson (2019, August 23). Answer to "how much does it cost to receive IVF treatment?". Zhihu.com. Retrieved from https://www.zhihu.com/question/26900811

San, J. (2019, January 1). Answer to "what is the experience of being a bei nai ma ma?". Zhihu.com. Retrieved from https://www.zhihu.com/question/21325360

Shan, J. (2014, October 30). Fewer couples want second child. China Daily. Retrieved from http://www.chinadaily.com.cn/chinawatch/201410/30/content_18828953.htm 
Shanghai has the lowest marriage rate in China: young people, do you still want to get married? (2019, August 9). Xin Min Wan Bao. Retrieved from https://baijiahao.baidu.com/s?id=1641391479062469558\&wfr=spider\&for=pc

Shen, Y. (Director) \& Qin, W. (Writer). (2013). Hot Mom! [Television series]. China: Xinli Chuanmei Gufen Youxian Gongsi.

Shen, Z. (2016, August 11). Cai Yuanpei's statement of choosing a wife. people.com. Retrieved from http://dangshi.people.com.cn/n1/2016/0811/c85037-28628801.html Shuwa, D. (2014, February 7). Have you seen Weibo? Baihe Wang's commercial has enraged so many people [Online forum]. Retrieved from http://bbs.tianya.cn/postfuninfo-5019771-1.shtml

Smith, C. (2019, June 26). 15 interesting Mobike statistics and facts (2019). DMR. Retrieved from https://expandedramblings.com/index.php/mobike-statistics-facts/ Spark program. (n.d.). Retrieved April 10, 2018, from Baidu Biake: https://baike.baidu.com/item/\%E6\%98\%9F\%E7\%81\%AB\%E8\%AE\%A1\%E5\%88 $\% 92 / 1041309 ? \mathrm{fr}=$ aladdin

Special fund for marriage consumption subsidies. (n.d.). Retrieved March 10, 2018, from Baidu Baike: https://baike.baidu.com/item/\%E4\%B8\%AD\%E5\%9B\%BD\%E7\%A4\%BE\%E4\% ВC\%9A\%Е5\%B7\%A5\%E4\%BD\%9C\%E8\%81\%94\%E5\%90\%88\%Е4\%BC\%9A \%Е5\%A9\%9A\%Е5\%A7\%BB\%E6\%B6\%88\%Е8\%B4\%B9\%E8\%A1\%A5\%Е8\%B 4\%B4\%E4\%B8\%93\%E9\%A1\%B9\%E5\%9F\%BA\%E9\%87\%91/22114061?fr=ala ddin 
Statista. (2019). Gini coefficient in China: inequality of income distribution in China from 2005 to 2016. Retrieved February 10, 2019 from: https://www.statista.com/statistics/250400/inequality-of-income-distribution-inchina-based-on-the-gini-index/

Striking slogans in China. (2017, June 6). ifeng.com. Retrieved from http://news.ifeng.com/a/20170606/51203046_0.shtml

Sudworth, J. (2016, October 28). China's forbidden babies still an issue. BBC News. Retrieved from https://www.bbc.com/news/world-asia-china-37788712

Suiyu, E. (2018, December 17). Answer to "how much does it cost to receive IVF treatment?". Zhihu. com. Retrieved from https://www.zhihu.com/question/26900811

Sun Jie - CEO of Ctrip: science and technology enable women to do what men can do. (2019, March 8). sina.com. Retrieved from https://tech.sina.com.cn/mobile/n/n/2019-03-08/doc-ihsxncvh0876589.shtml

Tao, N. (2017, April 14). Ctrip provides the travel plan to the U.S. for the specialized purpose of egg freezing: a trip costs 218,000 Yuan. Sina.com. Retrieved from https://tech.sina.com.cn/i/2017-04-14/doc-ifyeimqy1587248.shtml

The complete process of receiving IVF treatment, brave women. (2017, September 12). Sohu.com. Retrieved from https://www.sohu.com/a/191574140_664286

The first female chief editor of Nature: the status of female researchers and scholars in STEM. (2018, August 4). Sohu.com. Retrieved from http://www.sohu.com/a/245138026_744387 
The population of single adults in China reaches 200,000,000: A population that equates to the entire populations of Russia and the U.K. Combined. (2017, August 16). Retrieved from http://lady.people.com.cn/n1/2017/0816/c1014-29473001.html The ridicule of people in Shan Dong Province during the Spring Festival is a reflection of the corruption of Chinese culture. (2019, February 10). 163.com. Retrieved from http://news.163.com/19/0210/16/E7LS5D5K000187UE.html

The rise of a superpower: The number of Chinese articles in science and engineer surpasses the number of American article in S\&E and ranks the first worldwide. (2018, February 3). Sina.com. Retrieved from http://k.sina.com.cn/article_6439779095_17fd73b170010032zl.html

The universal two-child policy. (n.d.). Retrieved April 10, 2018, from Baidu Baike: https://baike.baidu.com/item/\%E5\%85\%A8\%E9\%9D\%A2\%E4\%B8\%A4\%E5\%A D\%A9/18762105

The World Food Prize. (2008, September 5). A world-brand name: Yuan Longping, the father of hybrid rice. Retrieved from https://www.worldfoodprize.org/index.cfm/87428/40007/a_worldbrand_name_yua n_longping_the_father_of_hybrid_rice

Tu, Y. (Producer), \& Hu, B. (Writer). (2018). China scumbag illustration [Video file]. Retrieved from https://www.youtube.com/watch?v=vV572T88hp8

Tu Youyou Facts. (n.d.). The Nobel Prize. Retrieved September 20, 2018, from https://www.nobelprize.org/prizes/medicine/2015/tu/facts/ 
Wei, N. (2016, February 24). Answer to "Which online date website is the best? Baihe Wang, Shijijiayuan Wang, or Zhenai Wang?". Zhihu. com. Retrieved from https://www.zhihu.com/question/19950327

Will Zhang Dayi's company list on the U.S. Stock Exchange? A daily revenue is more than 170,000,000Yuan. (2018, November 17). Wall Street China. Retrieved from https://wallstreetcn.com/articles/3434294

Why? An increasing number of single women in big cities want to buy apartments. (2019, March 27). sohu.com. Retrieved from http://www.sohu.com/a/304148712_120115883

Wu, W. (2017, December 10). Heilongjiang Province has more than 20 billion Yuan deficit in pension, and 13 more provinces will face fiscal deficit in pension in 2018. Chinanews.com. Retrieved from http://www.chinanews.com/cj/2017/1210/8396662.shtml

Xiao, M. (2014, February 7). Have you seen Weibo? Baihe Wang's commercial has enraged so many people [Online forum]. Retrieved from http://bbs.tianya.cn/postfuninfo-5019771-1.shtml

Xie, W. (2018, December 29). Matchmaking changes in China over past 40 years. Women of China. cn. Retrieved from http://www.womenofchina.cn/womenofchina/html1/special/40/1901/725-1.htm Xinhua. (2018, May 29). China focus: Xi calls for developing China into world science and technology leader. Retrieved from http://www.xinhuanet.com/english/201805/29/c_137213175.htm 
Xu, Z. (2016). The investiture of the Gods. Changsha: Yuelu Publishing House.

Ye, W. (2017, August 23). More Than 3800 Freshmen Registered in Tsinghua University. Tsinghua University.edu. Retrieved from http://www.tsinghua.edu.cn/publish/thunews/9650/2017/201708231629544893010 86/20170823162954489301086_html

Ying, Y. (2017, March 18). Answer to "have you ever used Shijijiayuan Wang or Baihe Wang?”. Zhihu.com. Retrieved from https://www.zhihu.com/question/20246674

Yitiao. (Producer). (2019, January 21). Celebrity couple move to a rented house in a small city and pay 700 Yuan monthly. [Video file]. Retrieved https://www.youtube.com/watch?v=g0O83a2ffVI

Yu, A. (2014, February 7). Have you seen Weibo? Baihe Wang's commercial has enraged so many people [Online forum]. Retrieved from http://www.easybib.com/guides/how-to-cite-a-reddit-ask-me-anything-thread/

Yuan, B. (Director \& Producer). (2016-2018). Super Mom. [Reality Show]. China: Hunan Television Station.

Zhang, J., \& and Zhang, Q. (2006). Survey on the abnormal life of around 50 million rural left-behind women. China Economic Weekly10: 14-19.

Zhou, X. (2019, February 12). A 40-year-old leftover woman: I am still expecting love, but I am prepared to spend the rest of my life lonely. Xinhua net. Retrieved from http://www.xinhuanet.com/2019-02/12/c_1124101755.htm

Zillow.com (a) (n.d.).Chicago home prices \& values. Retrieved January 15, 2019, from https://www.zillow.com/chicago-il/home-values/ 
Zillow. com (b) (n.d.). Manhattan home prices \& values. Retrieved January 15, 2019, from https://www.zillow.com/manhattan-new-york-ny/home-values/ 


\section{Appendix A}

\section{Fair Use Evaluation Documentation}

Compiled using the Fair Use Evaluator [cc] 2008 Michael Brewer \& the Office for Information Technology Policy http:/librarycopyright.net/fairuse/

\begin{tabular}{ll}
\hline Name: & Wenjing Liu \\
\hline Job Title: & Graduate Student \\
\hline Institution: & Michigan Technological University \\
\hline Title of Work Used: & We are proud of participating in the founding of our country's industrialization \\
\hline Copyright Holder: & unknown \\
\hline Publication Status: & Published \\
\hline Publisher: & Huadong Renmin Meishu Chubanshe, Shanghai \\
\hline Place of Publication: & China \\
\hline Publication Year: & 1954 \\
\hline Description of Work: & The Chinese government released this post to promote the image of "iron women." \\
\hline Date of Evaluation: & August 16, 2019 \\
\hline Date of Intended Use: & August 16, 2019 \\
& \\
\hline
\end{tabular}

Describe the PUPOSE and Character of Your Intended Use:

[+] Use is for "criticism, comment, news reporting, teaching, (including multiple print copies for classroom use) scholarship or research"

$[+]$ Use is transformative, i.e. it uses the existing work in a new way (creates an index to the work) or for a new

purpose (parody, pastiche, instructional materials, etc.) Transformative works are favored because the purpose of U.S.

Copyright Law is to encourage the development and dissemination of new knowledge to benefit the public and thereby

advance learning.

$[+]$ Use is socially beneficial (promotes the creation of new knowledge, learning, etc.) [define how]

$[+]$ Use is not-for-profit

[+] Use is clearly defined and is restricted in scope (limited duration, not iterative, restricted access, etc.)

$[+]$ Use is one-time, or is only occasional or spontaneous

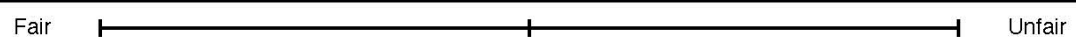

Page 1 
Describe the Neflure of Yourtended Use of the Copyrighted Work:

$[+]$ Work to be used has been previously PUBLISHED

[+] Work to be used contains limited new knowledge, content, or creative expression (in relation to previously copyrighted works)

$[+]$ Work to be used is primarily of a factual nature (non-fiction, collection of facts, etc.)

Fair

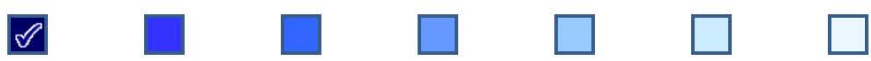

Describe the A

[[+] If the entire work is to be used (Which would NOT favor the use being fair), it is clear that no less than the entire work will achieve the stated purpose of the use (e.g. use of a photograph, a short poem, an article, etc.)

Fair

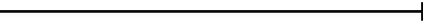

$+$

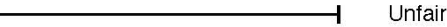

$\mathscr{4}$ Describe the
Work:

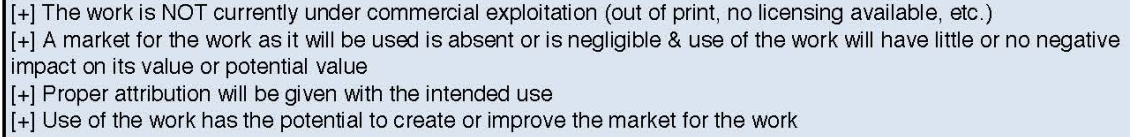

[+] The work is NOT currently under commercial exploitation (out of print, no licensing available, etc.)

[+] A market for the work as it will be used is absent or is negligible \& use of the work will have little or no negative

impact on its value or potential value

[+] Proper attribution will be given with the intended use

[+] Use of the work has the potential to create or improve the market for the work

Fair

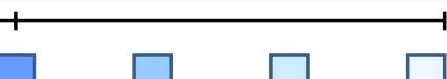

Unfair

Page 2 
The Average "FairnesS LeVel," Based on Your Rating of Each of the 4

Factors, Is:

[see tool disclaimer for important clarifying information]:

Fair

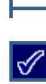

Unfair

Based on the information and justification I have provided above, I, Wenjing Liu, am asserting this use is FAIR under Section 107 of the U.S. Copyright Code.

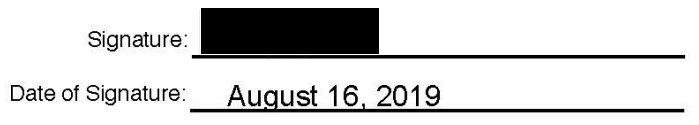

"Disclaimer: This document is intended to help you collect, organize \& archive the information you might need to support your fair use evaluation. It is not a source of legal advice or assistance. The results are only as good as the input you have provided by are intended to suggest next steps, and not to provide a final judgment. It is recommended

that you share this evaluation with a copyright specialist before proceeding with your intended use. 


\section{Appendix B}

\section{Fair Use Evaluation Documentation}

Compiled using the Fair Use Evaluator [cc] 2008 Michael Brewer \& the Office for Information Technology Policy, http://ibrarycopyright.net/fairuse/

\begin{tabular}{ll}
\hline Name: & Wenjing Liu \\
\hline Job Title: & Graduate Student \\
\hline Institution: & Michigan Technological University \\
\hline Title of Work Used: & Because Love Won't Wait \\
\hline Copyright Holder: & unknown \\
\hline Publication Status: & Published \\
\hline Publisher: & Baihe Wang \\
\hline Place of Publication: & China \\
\hline Publication Year: & 2014 \\
\hline Description of Work: & $\begin{array}{l}\text { Baine Wang released this commercial, which can be openly accessed online and } \\
\text { from television. }\end{array}$ \\
\hline Date of Evaluation: & August 16, 2019 \\
\hline Date of Intended Use: & August 16, 2019 \\
& \\
\hline
\end{tabular}

Describe the 19096 and Character of Your Intended Use:

[+] Use is for "criticism, comment, news reporting, teaching, (including multiple print copies for classroom use) scholarship or research"

[+] Use is transformative, i.e. it uses the existing work in a new way (creates an index to the work) or for a new

purpose (parody, pastiche, instructional materials, etc.) Transformative works are favored because the purpose of U.S.

Copyright Law is to encourage the development and dissemination of new knowledge to benefit the public and thereby

advance learning.

$[+]$ Use is socially beneficial (promotes the creation of new knowledge, learning, etc.) [define how]

$[+]$ Use is not-for-profit

[+] Use is clearly defined and is restricted in scope (limited duration, not iterative, restricted access, etc.)

$[+]$ Use is one-time, or is only occasional or spontaneous

Fair


Describe the Neflure of Yourtended Use of the Copyrighted Work:

$[+]$ Work to be used has been previously PUBLISHED

[+] Work to be used contains limited new knowledge, content, or creative expression (in relation to previously copyrighted works)

$[+]$ Work to be used is primarily of a factual nature (non-fiction, collection of facts, etc.)

Fair

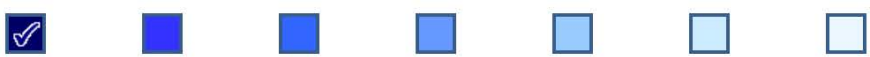

Describe the A

$[+]$ Only limited and reasonable portions will be used

$[+]$ Only the amount required to achieve the stated, socially-beneficial purpose or objective will be used (be that educational, artistic, scholarly, joumalistic, etc.)

Fair

\begin{tabular}{lllll}
\hline & $\square$
\end{tabular}$\quad \square \quad \square \quad \square \quad$ Unfair
Describe the Effet of Your Intended Use on the Potential Market or Value of the Copyrighted
Work:

[+] The work is NOT currently under commercial exploitation (out of print, no licensing available, etc.)

$[+]$ A market for the work as it will be used is absent or is negligible \& use of the work will have little or no negative impact on its value or potential value

[+] Proper attribution will be given with the intended use

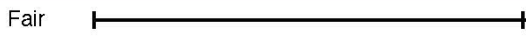

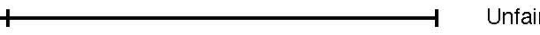

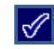

Page 2 
The Average "Fairness LeVel," Based on Your Rating of Each of the 4

Factors, Is:

[see tool disclaimer for important clarifying information]:

Fair

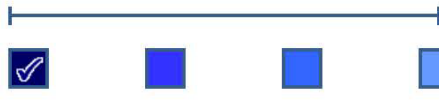

Based on the information and justification I have provided above, I, Wenjing Liu, am asserting this use is FAIR under Section 107 of the U.S. Copyright Code.

\author{
Signature: \\ Date of Signature
}

"Disclaimer: This document is intended to help you collect, organize \& archive the information you might need to support your fair use evaluation. It is not a source of legal advice or assistance. The results are only as good as the input you have provided by are intended to suggest next steps, and not to provide a final judgment. It is recommended

that you share this evaluation with a copyright specialist before proceeding with your intended use. 


\section{Appendix C}

WPATERTER

Michigan Technological University
Office of Compliance, Integrity, and Safety 302 Lakeshore Center 1400 Townsend Drive Houghton, Ml 49931 906.487 .2902

\section{MEMO}

DATE: June 9,2014

TO:

FROM:

RE:

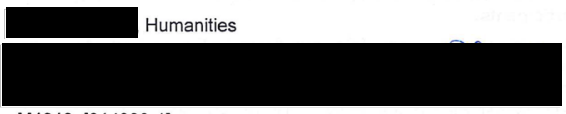

M1212, [614903-1]

TITLE:

A Study of Chinese "Shidu" Mothers

SUBMISSION TYPE:

New Project

STATUS:

New Project, APPROVED

The Institutional Review Board (IRB) has reviewed and approved your research application as compliant with all applicable sections of the federal regulations, Michigan law, and Michigan Tech IRB policies and procedures. All research must be conducted in accordance with this approved submission. APPROVAL DATE: June 9, 2014 EXPIRATION DATE: June 8, 2015

A pdf of this signed memo and any stamped approved documents, if applicable, have been placed in the review details under "board documents" for this project.

This approval applies only for this project, and only under the conditions and procedures described in the application. If/when changes become necessary but are not limited to: changes in protocol, personnel, study location, participant recruitment, etc., as set forth in this approval, you must IRBNet libry $Y$.

Approvals are granted for up to a one year period. You are responsible for submitting requests for continuation in advance of the expiration date for each year of the project. You will need to request a is not missed. Failure to ro to the end dale initiow materials on time will result in the termination of this protocol on the expiration date listed above.

Please note the following in order to comply with federal regulations and IRB policy:

1. Please remember that informed consent is a process beginning with a description of the study and assurance of participant understanding followed by a signed consent form. Informed consent mus continue throughout the study via a dialogue between the researcher and research participant.
Federal regulations require each participant receive a copy of the signed consent document. 
2. Individual identification of human subjects in any publication is an invasion of privacy. Before beginning a project involving human subjects, and only if required, the principal investigator must obtain a properly executed informed consent from each subject and/or the person legally attached with an official date stamp on it. Only copies of the official date stamped informe consent are to be distributed to participants relating to this project. If any changes or modifications are needed regarding this form, you must first submit the revised document for review and approval prior to use. The PI must retain informed consent forms on file for at least three years after the end of the project.

3. The approved project will be subject to periodic review. This review will consist of consulting with the $\mathrm{Pl}$ and examining the appropriate project records. All required research records must be securely retained in either paper or electronic format for a minimum of three years following the closure of the approved study. This includes signed con of all participants.

4. All Unanticipated Problems / Serious Adverse Events to participants or other parties affected by the research must be reported to this office within two days of the event occurrence. All instances of non-compliance or complaints regarding this study must be reported to this office in a timely manner. Please use the INSTRUCTIONS and FORM: Unanticipated Problem / Serious Adverse Event Form found both on our web site and the IRBNet Library.

If you have any questions, please contact the Compliance, Integrity, and Safety Office at 906.487 .2902 or send your message via email through IRBNet using the Send Project Mail feature. 


\title{
Consent to Participate in Interview Research
}

\author{
A Study of Chinese "Shidu" Mothers
}

You are asked to participate in an interview conducted by Wenjing Liu, from the Department of Humanities at Michigan Technological University. This interview is being conducted as part of a graduate student project. Your participation in this study is entirely voluntary. Please read the information below and ask questions about anything you do not understand, before deciding whether or not to participate.

PURPOSE OF THE STUDY

The purpose of the interview is to encourage you to talk about your personal experience as a "Shidu" mother. I will ask you several questions such as what your current situation as a "Shidu" mother is, and what your future plans are.I will especially focus on your understanding of the significance of your experience and motherhood.

PROCEDURES

If you volunteer to participate in this study, you will be asked to do the following:

-Participate in a 60 minute face-to-face or online interview. The interview will be conducted in Chinese and I will translate and transcribe it as part of my research.

-Participate in a 30-50 minute follow-up interview in order to review my analyses and ask about particular excerpts from the interviews.

You may request a copy of the full interview transcript.

POTENTIAL RISKS AND DISCOMFORTS

There is minimal risk involved. In the event of physical and/or mental injury resulting from participation in this research project, Michigan Technological University does not provide any medical, hospitalization or other insurance for you in this research study, nor will Michigan Technological University provide any medical treatment or compensation for any injury sustained as a result of participation in this research study, except as required by law. However if you feel psychologically uncomfortable because of the interviews, I urge you to seek professional help at the Wuhan Hospital for Psychotherapy or Psychotherapy Centre in Tongji Medical College for professional help

POTENTIAL BENEFITS TO SUBJECTS AND TO SOCIETY

You will not benefit directly from participation. However, this research will provide new perspectives to help others understand the tough situation Chinese "Shidu" mothers face. This information may aid Chinese officials in formulating a policy of relief.

CONFIDENTIALITY

Any information that is obtained in connection with this study and that can be identified with you will remain confidential and will be disclosed only with your permission or as required by law. Confidentiality will be maintained by keeping all interview notes, transcripts, and

Michigan Tech Apprived on: 06-09-14 Expres on: 06-08-15 IRB APPROVAL Study number. 614903-1, M1212 Page 1 
recordings securely stored on a password-protected computer that only I can access. The audio-recorded interviews will be transferred from the audio-recorder to a password-protected computer account that is accessible only to me. Audio on the digital recorder will be erased once the transfer is made. I will write a full transcription of the audio data. In addition, I will translate the Chinese transcription into English. The transcription and the corresponding English translation will be stored on a password-protected computer account that is accessible only to me.Federal IRB regulations require the retention of records for three years after the completion of the final report, however I plan to maintain the coded information for six years in the event that I use it for my dissertation.

I may discuss my interview and analyses with my instructors in Humanities Department Michigan Technological University. The information maybe used in any way that I think is best for publication or education. Any information used for publication will not identify you.

PARTICIPATION AND WITHDRAWAL

You can choose whether or not to do this interview. You may withdraw at any time without consequences of any kind or loss of benefits to which you are otherwise entitled. You may also refuse to answer any questions you do not want to answer. There is no penalty if you withdraw from the study and you will not lose any benefits to which you are otherwise entitled.

IDENTIFICATION OF INVESTIGATORS

If you have any questions or concerns about this research, please contact:

University

Michigan Technological

Michigan Technological University

RIGHTS OF RESEARCH SUBJECTS

The Michigan Tech Institutional Review Board has reviewed my request to conduct this project. If you have any concerns about your rights in this study, please contact the Institutional Review Board, Michigan Tech-IRB at 906-487-2902 or email IRB@mtu.edu. 
I understand the procedures described above. My questions have been answered to my satisfaction, and I agree to participate in this study. I have been given a copy of this form.

Interview.

I decline permission to the researcher to audio-record me during my interview

Printed Name of Subject

Signature of Subject

Date:

Michigan Tech Approved on 06-09-14 Expires on: 06-08-15 IRB APPROVAL Study number: 614903-1, M1212

Page 


\section{Appendix D}

\section{Fair Use Evaluation Documentation}

Compiled using the Fair Use Evaluator [cc] 2008 Michael Brewer \& the Office for Information Technology Policy, http://ibrarycopyright.net/fairuse/

\begin{tabular}{ll}
\hline Name: & Wening Liu \\
\hline Job Title: & Graduate Student \\
\hline Institution: & Michigan Technological University \\
\hline Title of Work Used: & An advertisement to promote the childrenâ€t' s fever reducer Mei Lin \\
\hline Copyright Holder: & unknown \\
\hline Publication Status: & Published \\
\hline Publisher: & Johnson \& Johnson (Shanghai, China) \\
\hline Place of Publication: & China \\
\hline Publication Year: & unknown \\
\hline Description of Work: & The Chinese government released this post to promote the image of "iron women." \\
\hline Date of Evaluation: & August 16, 2019 \\
\hline Date of Intended Use: & August 16, 2019 \\
& \\
\hline
\end{tabular}

Describe the PUPOSE and Character of Your Intended Use:

[+] Use is for "criticism, comment, news reporting, teaching, (including multiple print copies for classroom use) scholarship or research"

$[+]$ Use is transformative, i.e. it uses the existing work in a new way (creates an index to the work) or for a new

purpose (parody, pastiche, instructional materials, etc.) Transformative works are favored because the purpose of U.S.

Copyright Law is to encourage the development and dissemination of new knowledge to benefit the public and thereby

advance learning.

$[+]$ Use is socially beneficial (promotes the creation of new knowledge, learning, etc.) [define how]

$[+]$ Use is not-for-profit

[+] Use is clearly defined and is restricted in scope (limited duration, not iterative, restricted access, etc.)

$[+]$ Use is one-time, or is only occasional or spontaneous

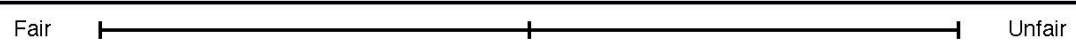

Page 1 
Describe the Neflure of Yourtended Use of the Copyrighted Work:

$[+]$ Work to be used has been previously PUBLISHED

[+] Work to be used contains limited new knowledge, content, or creative expression (in relation to previously copyrighted works)

$[+]$ Work to be used is primarily of a factual nature (non-fiction, collection of facts, etc.)

Fair

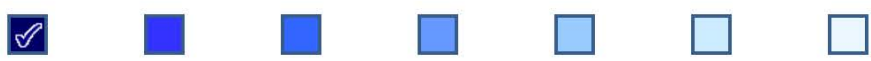

Describe the A

[[+] If the entire work is to be used (Which would NOT favor the use being fair), it is clear that no less than the entire work will achieve the stated purpose of the use (e.g. use of a photograph, a short poem, an article, etc.)

Fair

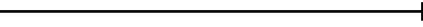

$+$

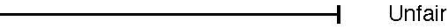

$\mathscr{4}$ Describe the
Work:

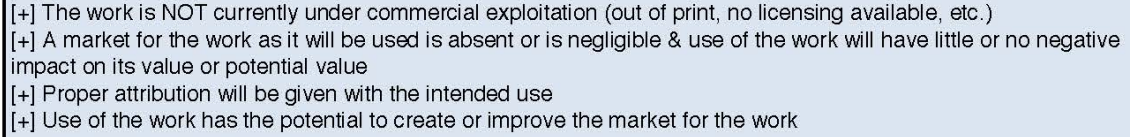

[+] The work is NOT currently under commercial exploitation (out of print, no licensing available, etc.)

[+] A market for the work as it will be used is absent or is negligible \& use of the work will have little or no negative

impact on its value or potential value

[+] Proper attribution will be given with the intended use

[+] Use of the work has the potential to create or improve the market for the work

Fair

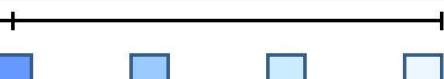

Unfair

Page 2 
The Average "FairnesS LeVel," Based on Your Rating of Each of the 4

Factors, Is:

[see tool disclaimer for important clarifying information]:

Fair

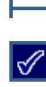

Unfair

Based on the information and justification I have provided above, I, Wenjing Liu, am asserting this use is FAIR under Section 107 of the U.S. Copyright Code.

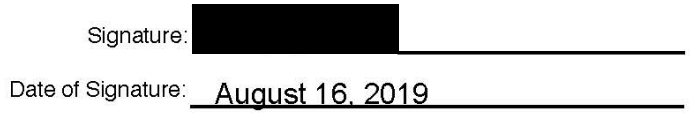

"Disclaimer: This document is intended to help you collect, organize \& archive the information you might need to support your fair use evaluation. It is not a source of legal advice or assistance. The results are only as good as the input you have provided by are intended to suggest next steps, and not to provide a final judgment. It is recommended

that you share this evaluation with a copyright specialist before proceeding with your intended use. 


\section{Appendix E Copyright documentation}

Figure 2.1 Bagua In A Coin. This photo was taken by the author. The author owns the copyright of this image.

Figure 2.2 A Collarbone Holds Coins. This photo was taken by the author. The author owns the copyright of this image.

Figure 2.3. Rice Stamp.This photo was taken by the author. The author owns the copyright of this image.

Figure 2.4 Pork Stamp. This photo was taken by the author. The author owns the copyright of this image.

Figure 3.1 The Image Of Taiji. This image was drawn by the author. The author owns the copyright of this image.

Figure 3.2 Screen Capture Of Online Articles On Leftover Women On Xin Hua Net. These articles are from a publiclyavailable online source. The author took the screen capture. Citation and attribution information is available in its caption.

Figure 3.3 Stamp Of The Year Monkey (2016). This photo was taken by the author. The author owns the copyright of this image.

Figure 3.4 Stamp Of The Year Pig (2019). This photo was taken by the author. The author owns the copyright of this image.

Figure 3.5 A Poster Of An Iron Girl. This poster is from a publiclyavailable online source. Appendix I contains the fair use evaluation document to demonstrate the author's fair use of this image. Citation and attribution information is available in its caption.

Figure 4.1, Figure 4.2, Figure 4.3, Figure 4.4, and Figure 4.5 Screen Captures Of The Commercial "Because Love Won't Wait." This commercial is from a publiclyavailable online source. Appendix II containsthe fair use evaluation document to demonstrate the author's fair use of this image. Citation and attribution information is available in its caption.

Figure 4.6 A Screen Capture Of The Message From Zhenai Wang. This message was retrieved from the author's personal communication and the screen capture was taken by the author. Citation and attribution information is available in its caption.

Figure 4.7 An Advertisement To Promote The Children's Fever Reducer Mei Lin. This image is from a publiclyavailable online source. Appendix IV containsthe fair use 
evaluation document to demonstrate the author's fair use of this image. Citation and attribution information is available in its caption. 